Prepared for the U.S. Department of Energy under Contract DE-AC05-76RL01830

\title{
Treatability Test Report: Characterization of Vadose Zone Carbon Tetrachloride Source Strength Using Tomographic Methods at the 216-Z-9 Site
}
MJ Truex
KC Carroll
VJ Rohay
RD Mackley
KR Parker

September 2012

Pacific Northwest

NATIONAL LABORATORY

Proudly Operated by Battelle Since 1965 


\title{
DISCLAIMER
}

This report was prepared as an account of work sponsored by an agency of the United States Government. Neither the United States Government nor any agency thereof, nor Battelle Memorial Institute, nor any of their employees, makes any warranty, express or implied, or assumes any legal liability or responsibility for the accuracy, completeness, or usefulness of any information, apparatus, product, or process disclosed, or represents that its use would not inf ringe privately owned rights. Reference herein to any specific commercial product, process, or service by trade name, trademark, manufacturer, or otherwise does not necessarily constitute or imply its endorsement, recommendation, or favoring by the United States Government or any agency thereof, or Battelle Memorial Institute. The views and opinions of authors expressed herein do not necessarily state or reflect those of the United States Government or any agency thereof.

\author{
PACIFIC NORTHWEST NATIONAL LABORATORY \\ operated by \\ BATTELLE \\ for the \\ UNITED STATES DEPARTMENT OF ENERGY \\ under Contract DE-AC05-76RL01830
}

Printed in the United States of America
Available to DOE and DOE contractors from the
Office of Scientific and Technical Information
P.O. Box 62, Oak Ridge, TN 37831-0062;
ph: (865) 576-8401
fax: $(865) 576-5728$
email: reports@adonis.osti.gov

Available to the public from the National Technical Information Service

5301 Shawnee Rd., Alexandria, VA 22312

ph: (800) 553-NTIS (6847)

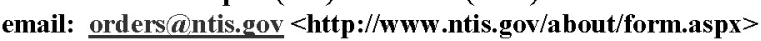

Online ordering: http://www.ntis.gov

This document was printed on recycled paper. 


\title{
Treatability Test Report:
}

Characterization of Vadose Zone

Carbon Tetrachloride Source Strength Using Tomographic Methods at the 216-Z-9 Site

\author{
MJ Truex \\ KC Carroll \\ VJ Rohay $^{1}$ \\ RD Mackley \\ KR Parker
}

September 2012

Prepared for

the U.S. Department of Energy

under Contract DE-AC05-76RL01830

Pacific Northwest National Laboratory

Richland, Washington 99352

\footnotetext{
${ }^{1}$ CH2M HILL Plateau Remediation Company, Richland, Washington
} 


\section{Acknowledgments}

This work was funded by the U.S. Department of Energy - Office of Environmental Management, Office of Groundwater and Soil Remediation. The Pacific Northwest National Laboratory is operated by Battelle Memorial Institute for the U.S. Department of Energy (DOE) under Contract DE-AC05-

76RL01830. We also thank Mark Brusseau (University of Arizona) and Dave Becker (U.S. Army Corps of Engineers) for their review of this report. 


\section{Acronyms and Abbreviations}

$\begin{array}{ll}\text { ACFM } & \text { actual cubic feet per minute } \\ \text { CCU } & \text { Cold Creek Unit } \\ \text { CERCLA } & \begin{array}{l}\text { Comprehensive Environmental Response, Compensation, and Liability Act } \\ \text { of } 1980 \\ \text { carbon tetrachloride } \\ \text { CT }\end{array} \\ \text { DNAPL } & \text { U.S. Department of Energy } \\ \text { DOE } & \text { U.S. Department of Energy Richland Operations Office } \\ \text { DOE-RL } & \text { U.S. Department of Energy Office of Groundwater and Soil Remediation } \\ \text { EM-32 } & \text { U.S. Environmental Protection Agency } \\ \text { EPA } & \text { full-scale output } \\ \text { FSO } & \text { gas chromatograph } \\ \text { GC } & \text { horizontal permeability } \\ \text { Kh } & \text { vertical permeability } \\ \text { Kz } & \text { laboratory control samples } \\ \text { LCS } & \text { source mass discharge } \\ \text { MFr } & \text { operable unit } \\ \text { OU } & \text { part(s) per billion } \\ \text { ppb } & \text { gravimetric moisture content used in the analysis } \\ \theta_{g} & \text { part(s) per million volume } \\ \text { ppmv } & \text { Record of Decision } \\ \text { ROD } & \text { residual sum of square error } \\ \text { RSS } & \text { standard cubic feet per minute } \\ \text { scfm } & \text { soil vapor extraction } \\ \text { SVE } & \text { U.S. Army Corps of Engineers } \\ \text { USACE } & \text { volatile organic compound } \\ \text { VOC } & \end{array}$




\section{Contents}

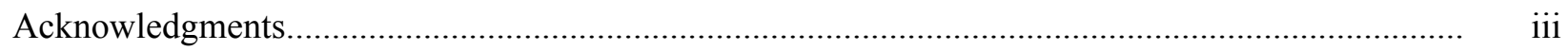

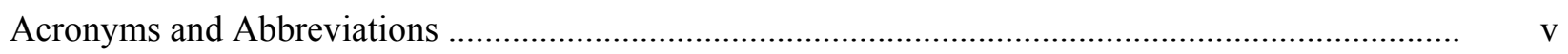

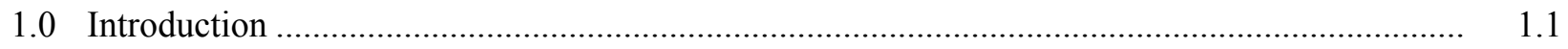

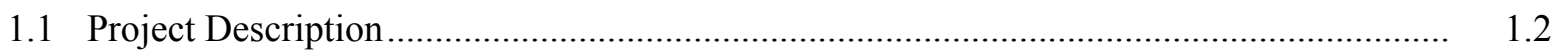

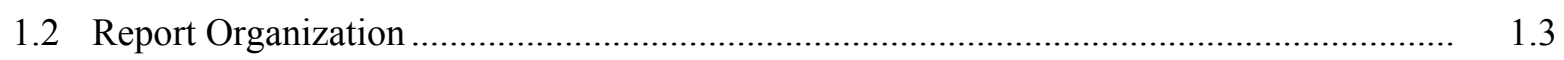

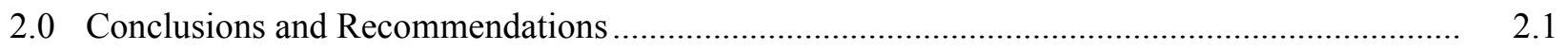

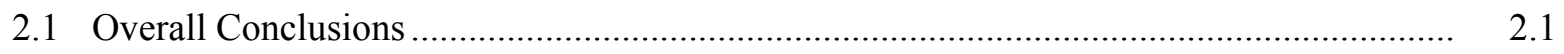

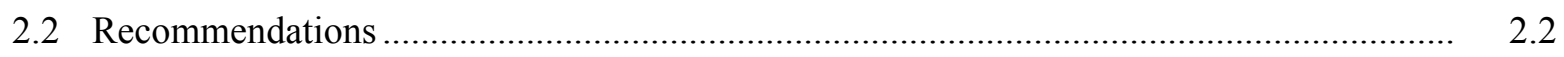

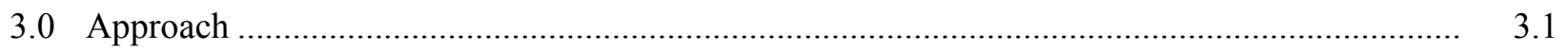

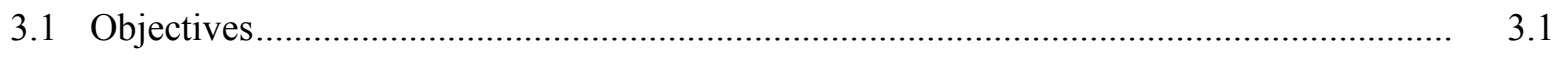

3.2 Experimental Design and Procedures..................................................................... 3.1

3.2.1 Test Site Location and Description ............................................................. 3.1

3.2.2 Test Layout and Operations ….................................................................. 3.2

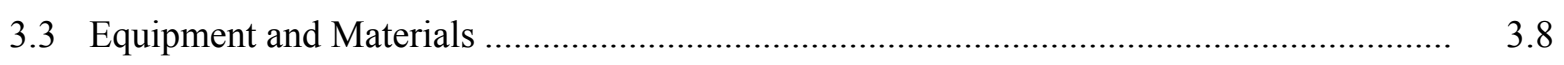

3.3.1 Flow and Pressure Monitoring and Data Acquisition Equipment .......................... 3.8

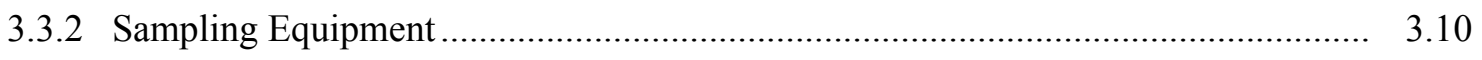

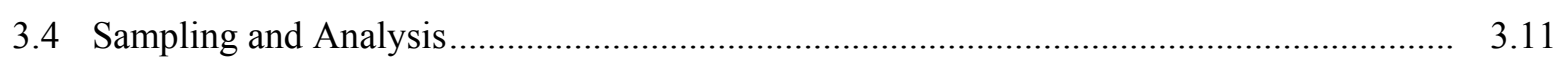

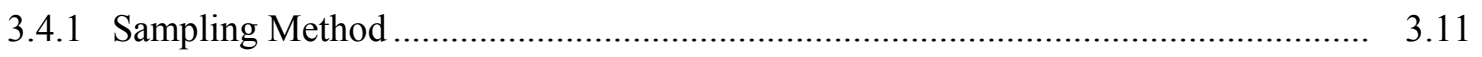

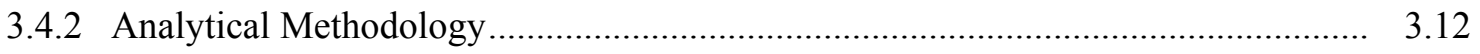

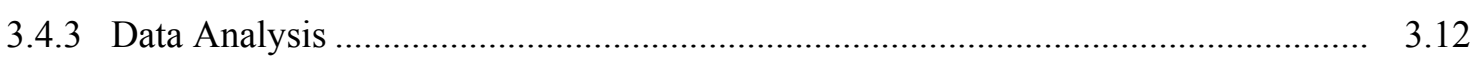

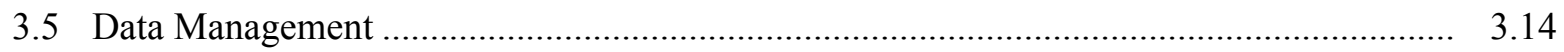

3.6 Deviations from Work Plan.................................................................................... 3.14

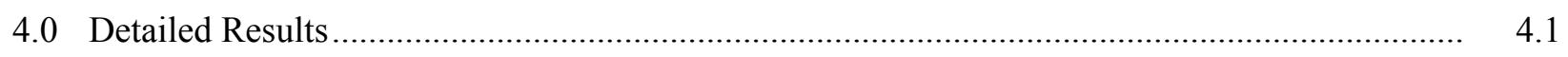

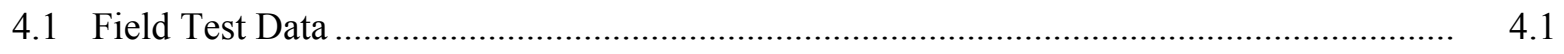

4.1.1 Source Mass Discharge ............................................................................. 4.1

4.1.2 Source Size and Location: Single-Well Test..................................................... 4.6

4.2 Data Assessment with Respect to Field Test Objectives................................................. 4.29

4.2.1 Source Mass Discharge ................................................................................ 4.29

4.2.2 Source Size and Location ......................................................................... 4.30

4.2.3 Implications for Impact to Groundwater ...................................................... 4.38

5.0 Quality Assurance Results ....................................................................................... 5.1

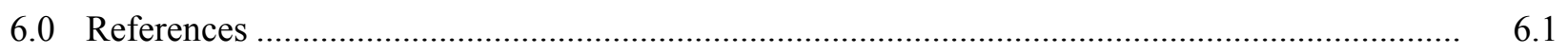




\section{Figures}

2.1 Simulated Groundwater CT Concentration for a 10-m Well Screen Resulting from the

Specified Vadose Zone Source

3.1 Location Map of Soil Vapor Extraction Wells Selected for Testing at the Z-9 Trench............. 3.3

3.2 Vapor Concentrations as a Function of Time Measured at Wells Screened Above the CCU during SVE Operations at the Z-9 Trench from 1995 through 2008

3.3 Vapor Concentrations as a Function of Time Measured at Wells Screened Below the CCU during SVE Operations at the Z-9 Trench from 1995 through 2008

3.4 Cross-Section A-A' for the Z-9 Trench Indicating Well-Screen Locations, the Trench Location, Groundwater Table Elevation, and Generalized Subsurface Lithologic Units

3.5 Schematic of the Z-9 Trench SVE System

3.6 Extraction Well Monitoring System

3.7 Well Head Pressure Monitoring Equipment

3.8 Summa Canister Sample Collection for a Single-Well Test at a Port on the Extraction Well Monitoring Apparatus

3.9 Correlation of Flow Rate and Vacuum between the SVE System and Extraction Well Monitoring System for Evaluation of Actual Flow Rate and Concentration Dilution Factors

4.1 Maximum and Asymptotic Carbon Tetrachloride Vapor Concentrations in the SVE Extraction System from 1998 through 2011

4.2 Above the CCU, Individual Well Characterization Data, 1998-2010

4.3 Below the CCU, Individual Well Characterization Data, 1998-2010

4.4 SVE System Extracted CT Concentrations, 1998-2011.

4.5 Time Series of Computed Source Mass Discharge, 1997-2010

4.6 Comparison of Flow Rates and CT Concentrations from the SVE System Before and After the Single-Well Testing Period....

4.7 Well 299-W15-8U Single-Well Extraction SVE System CT Concentration and FlowRate and Extraction Well Monitoring System Flow-Rate Transient Data

4.8 Well 299-W15-9U Single-Well Extraction SVE System CT Concentration and FlowRate and Extraction Well Monitoring System Flow-Rate Transient Data.

4.9 Well 299-W15-48 Single-Well Extraction SVE System CT Concentration and FlowRate and Extraction Well Monitoring System Flow-Rate Transient Data.....

4.10 Well 299-W15-84U Single-Well Extraction SVE System CT Concentration and Flow-

Rate and Extraction Well Monitoring System Flow-Rate Transient Data

4.11 Well 299-W15-85 Single-Well Extraction SVE System CT Concentration and FlowRate and Extraction Well Monitoring System Flow-Rate Transient Data....

4.12 Well 299-W15-95U Single-Well Extraction SVE System CT Concentration and FlowRate and Extraction Well Monitoring System Flow-Rate Transient Data.

4.13 Well 299-W15-216U Single-Well Extraction SVE System CT Concentration and FlowRate and Extraction Well Monitoring System Flow-Rate Transient Data. 
4.14 Well 299-W15-217 Single-Well Extraction SVE System CT Concentration and Flow-

Rate and Extraction Well Monitoring System Flow-Rate Transient Data.....

4.15 Well 299-W15-218U Single-Well Extraction SVE System CT Concentration and FlowRate and Extraction Well Monitoring System Flow-Rate Transient Data.

4.16 Well 299-W15-219U Single-Well Extraction SVE System CT Concentration and FlowRate and Extraction Well Monitoring System Flow-Rate Transient Data.....

4.17 Well 299-W15-220U Single-Well Extraction SVE System CT Concentration and FlowRate and Extraction Well Monitoring System Flow-Rate Transient Data.

4.18 Well 299-W15-223 Single-Well Extraction SVE System CT Concentration and FlowRate and Extraction Well Monitoring System Flow-Rate Transient Data....

4.19 Well 299-W15-8L Single-Well Extraction SVE System CT Concentration and FlowRate and Extraction Well Monitoring System Flow-Rate Transient Data.....

4.20 Well 299-W15-32 Single-Well Extraction SVE System CT Concentration and Flow-

Rate and Extraction Well Monitoring System Flow-Rate Transient Data....

4.21 Well 299-W15-84L Single-Well Extraction SVE System CT Concentration and FlowRate and Extraction Well Monitoring System Flow-Rate Transient Data.....

4.22 Well 299-W15-86 Single-Well Extraction SVE System CT Concentration and FlowRate and Extraction Well Monitoring System Flow-Rate Transient Data.

4.23 Well 299-W15-95L Single-Well Extraction SVE System CT Concentration and FlowRate and Extraction Well Monitoring System Flow-Rate Transient Data.

4.24 Well 299-W15-216L Single-Well Extraction SVE System CT Concentration and FlowRate and Extraction Well Monitoring System Flow-Rate Transient Data.

4.25 Well 299-W15-218L Single-Well Extraction SVE System CT Concentration and FlowRate and Extraction Well Monitoring System Flow-Rate Transient Data....

4.26 Well 299-W15-219L Single-Well Extraction SVE System CT Concentration and FlowRate and Extraction Well Monitoring System Flow-Rate Transient Data.

4.27 Well 299-W15-220L Single-Well Extraction SVE System CT Concentration and FlowRate and Extraction Well Monitoring System Flow-Rate Transient Data.

4.28 Hanford Meteorological Station Barometric Pressure Data

4.29 Barometric Correction.

4.30 Comparison of Type-Curve Fits With and Without Anisotropy...

4.31 Measured Water Content as a Function of Elevation.

4.32 Summary of Single-Well Test Data for Above the CCU and at Well 86.

4.33 Summary of Single-Well Test Data for Below the CCU and at Well $86 .$.

4.34 Summary of Single-Well Test Data on a North-South Cross Sectional View of Test Wells

4.35 Simulated Soil Gas Concentration Contours after 6 Months of Rebound for a Small and Large Source.....

4.36 Concentration and Vapor Mass Discharge as a Function of Distance from the CCU .....

4.37 Framework for Relating Source Mass Discharge to Resultant Groundwater Contaminant Concentration Showing Variability Associated with Commonly Uncertain Input Parameters Including Source Size. 


\section{Tables}

3.1 SVE Wells During Annual Cyclic Operations..................................................................... 3.6

3.2 Individual Well and Pneumatic Tomography Testing Wells and Schedule .............................. 3.7

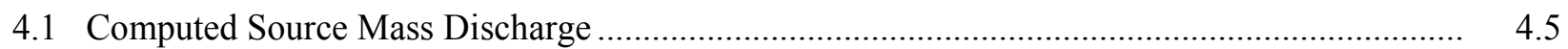

4.2 Summary of Average Values Monitored during Individual Testing After Concentration

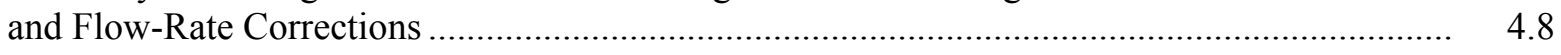

4.3 Summary of the Summa Canister Sample Analysis Results................................................ 4.9

4.4 Summary of the Summa Canister Duplicate or Replicate Sample Analysis Results.................. 4.11

4.5 Summary of Individual Test Results Averaged over the Test Period ........................................ 4.23

4.6 Summary Results of Steady-State Pneumatic Testing Permeability Estimates .......................... 4.26

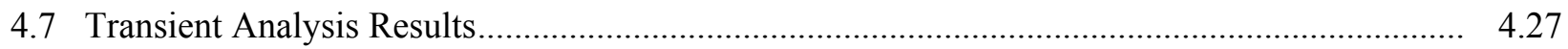

4.8 Comparison of Maximum CT Concentrations Measured during the 2011 Single-Well Testing and the 2010 SVE Operations Individual Well Characterization Sampling .................. 4.38 


\subsection{Introduction}

At the U.S. Department of Energy (DOE) Hanford Site, carbon tetrachloride (CT) was discharged to the subsurface through three engineered waste sites from 1955 through 1973 . These three waste sitesthe 216-Z-9 Trench, the 216-Z-1A Tile Field, and the 216-Z-18 Crib-are part of the 200-PW-1 Operable Unit (OU). The disposed CT contaminated the vadose zone and groundwater underlying these waste sites. Soil vapor extraction (SVE) has been in use as an interim remedial action in the vadose zone since 1992 and has significantly reduced vadose zone contamination. SVE operational data suggests that SVE has been effective in the highly permeable sand and gravel portions of the vadose zone and that remaining contamination is present in low-permeability silt zones. The Record of Decision (ROD) for the 200-PW-1 OU, approved in 2011, selected SVE as the remedy for the vadose zone CT contamination (EPA et al. 2011). The ROD provides a final cleanup level for CT of 100 parts per million by volume (ppmv) based on groundwater protection, with further refinement and assessment of soil vapor concentrations to ensure they are protective of groundwater (EPA et al. 2011, Table 35).

A treatability test was conducted in 2011 at the 216-Z-9 Trench to evaluate methods for collecting characterization information that supports refined assessment of SVE performance goals based on impact to groundwater. The characterization information can also provide input to operational strategies for continued SVE operation and decisions regarding closure of the SVE system or transition to other remedies if necessary. The treatability test was conducted in accordance with the treatability test plan (DOE-RL 2010).

The DOE Office of Groundwater and Soil Remediation (EM-32) program has developed approaches for characterizing volatile contaminants, such as $\mathrm{CT}$, in the vadose zone and evaluating their impact on groundwater (Truex et al. 2009; Oostrom et al. 2010; Brusseau et al. 2010; Carroll et al. 2012). These approaches and related ongoing EM-32 development efforts are the technical basis for evaluation of treatability test results. Existing guidance from the U.S. Army Corps of Engineers (USACE 2002) and the U.S. Environmental Protection Agency (EPA 2001) provided the context for the test. These USACE and EPA approaches for closure and transition decisions related to protecting groundwater can be summarized using an organization based on the four elements outlined by the EPA.

1. Define a conceptual model of the site appropriate for use as a context to support SVE data analysis relative to closure and transition decisions.

2. Provide design information that shows how SVE was configured and operated to appropriately address the contamination.

3. Provide SVE performance monitoring to demonstrate mass extraction and decreases in the subsurface contamination.

4. Quantify the contaminant mass flux to groundwater to define the impact of remaining vadose zone contamination on groundwater remediation goals and thereby set a quantitatively determined remediation endpoint for the vadose zone contamination.

The treatability test provides data to refine the conceptual model of the site (i.e., element 1 from above) that is relevant to CT distribution within the vadose zone at the time of the decision for SVE closure and transition, and supports quantifying the contaminant mass flux to groundwater (element 4 from above). As described by Truex et al. (2009), CT contaminant transport in the vadose zone is 
predominantly in the vapor phase. As such, the test focused on characterizing the CT vadose zone source strength and distribution in terms of vapor-phase transport. Characterizing the transport and fate of CT vapor in the vadose zone requires knowledge of the spatial distribution of sources and mass-transport processes. The techniques applied in the treatability test were intended to provide this type of information using the existing well infrastructure and in a manner that provides data useful for supporting SVE system closure and transition decisions.

Specifically, the area of focus for this investigation was the vadose zone underlying the 216-Z-9 waste disposal area (hereafter, "Z-9 Trench"), which has undergone active SVE remediation since 1993. Dense nonaqueous phase liquid (DNAPL) and aqueous phases containing CT were disposed to the subsurface through an engineered infiltration facility, which resulted in contamination within the underlying soil gas and groundwater (Rohay 2007). Significant amounts of CT mass have been removed from the vadose zone through the SVE operations over the past two decades. However, SVE operations data, subsurface monitoring, and concentration-rebound data suggest that a long-term source of CT remains within the low-permeability Cold Creek Unit (CCU). Significant declines in the rate of mass removal are common for SVE systems. SVE is highly effective at removing subsurface contaminant mass from permeable portions of the vadose zone. However, diffusive-mass transfer typically limits the effectiveness of SVE when the remaining mass is located within lower permeability zones. For example, the Z-9 Trench SVE operation from 1993 to 1996 was highly effective, and removed several thousand kilograms of CT before the concentrations and mass removal rate substantially decreased. From 1997 through the present, cyclic operation has been applied to allow vapor concentration rebounding due to diffusive-mass transfer from low-permeability source zones (Rohay 2007; Brusseau et al. 2010).

\subsection{Project Description}

Two elements of the treatability test were conducted at the Z-9 Trench. The first element involved collecting data during the period of standard SVE system operation from March through August 2011 to quantify the SVE performance parameters as described by Brusseau et al. (2010). These data were used to append the data set quantifying SVE system performance over the previous 15 years where the SVE system has been operated in a cyclic mode. A key result of the treatability test effort is to provide data that are used to calculate the overall source strength as defined by the "MFr" calculation of Brusseau et al. (2010). This value is the vapor-phase contaminant mass discharge from the vadose zone source in the absence of SVE operations (i.e., the contaminant mass discharge from the source that would exist if the SVE system were terminated; hereafter, "source mass discharge").

The second element involved conducting a series of tests at individual SVE system extraction wells to provide data that were used to calculate location-specific CT mass discharge from each well. Data collected included gas flow rate and vapor-phase CT concentrations to compute CT mass discharge from

the well. Pressure data were also collected at the individual extraction well and at surrounding unstressed wells before, during, and after pumping was induced at the extraction well. These pneumatic data were used to evaluate subsurface hydraulic properties and gas flow paths. These individual well test procedures were applied at multiple locations to generate a three-dimensional data set. Together, the CT concentration, CT mass discharge, and pneumatic data, along with existing conceptual site model information, can be analyzed to estimate the vadose zone source size and location. 


\subsection{Report Organization}

This report is organized following the guidelines for reporting of Comprehensive Environmental Response, Compensation, and Liability Act of 1980 (CERCLA) treatability tests (EPA 1992). Section 2.0 provides the conclusions and recommendations for the study. The test approach is described in Section 3.0 followed by a presentation of the detailed results in Section 4.0. Quality assurance for the project is presented in Section 5.0. 


\subsection{Conclusions and Recommendations}

\subsection{Overall Conclusions}

Initial SVE operations at the Z-9 Trench from 1993 through 1996 removed 50,744 $\mathrm{kg}$ of CT from the vadose zone. Since then, the rate of CT removal during SVE operations has declined significantly. The treatability test was conducted to apply and evaluate two types of characterization methods targeted at 1) quantifying the overall source mass discharge in the vadose zone, and 2) estimating the size and location of CT sources. In summary, historical data and data collected as part of this test were analyzed and show that the source mass discharge has declined over time to a value of about $70 \mathrm{~g} / \mathrm{d}$ in 2010 . Additional data collected during this test were used to verify that the remaining contaminant source material primarily resides in the $\mathrm{CCU}$ and to estimate the current lateral dimensions of the source zone as 90 by $90 \mathrm{~m}$. Conclusions related to these results are discussed below. This characterization information can be used to evaluate 1) expected future decline in the contaminant source over time and 2) how the remaining source can impact the groundwater if SVE is terminated. Recommendations for this type of assessment are provided in Section 2.2. The results can be used as input for setting an appropriate endpoint for SVE operations.

The source mass discharge was quantified using cyclic operational data from the SVE system operations and evaluation method of Brusseau et al. (2010). Cyclic operation of the SVE system has been applied since 1997 where the SVE system is operated for a period of time (nominally 6 months) and then shut down to allow vapor CT concentrations to rebound over a period of time (nominally 6 months). The nature of the CT contamination at the Z-9 Trench has changed over time due to mass removal through SVE operation. Between 1997 and 2005, the CT vapor concentration upon restart of SVE after a shutdown period was significantly higher than the CT concentration at the end of the previous operational period. This response indicates that vapor concentrations increased (rebounded) significantly during shutdown periods. After 2005, there have been only small differences in initial and final vapor concentrations during SVE operations. This response indicates a much smaller rebound during the shutdown period. The temporal profile of the vapor concentrations extracted by the SVE system has become less dynamic over time, and in 2009 and 2011 did not show the characteristic progression from high initial concentrations to lower asymptotic concentrations during an operational cycle. In addition to these changes, SVE system data also show that the vapor concentrations at the end of each SVE operational cycle are not near zero, and especially in recent years, are relatively high compared to the initial vapor concentrations. In Brusseau et al. (2010), data from the Hanford Site were used as an example for the evaluation method, and based on observations from the early and mid-years of SVE operation, the background concentrations in the advective domain were assumed to be negligible compared to the initial rebound concentrations. Information from the current treatability test suggests that background concentrations in the most recent years are non-negligible. The approach to estimating source mass discharge is based on measuring the contaminant that was released from the source zone during the rebound period. The background concentrations are not part of the mass discharge during the rebound period and must either be negligible or accounted for in the calculation. Site-specific information was applied to refine the calculation of overall source mass discharge based on an assessment of the background CT vapor concentrations collected during the treatability test and previous operational data. This information was used to establish the nonzero background CT vapor concentrations to use in the CT mass integration portion of the calculation. 
The source mass discharge estimate for the 2010 operational data is $70 \mathrm{~g} / \mathrm{d}$. This value, along with information on the source size and locations discussed below, can be used as input to estimate the groundwater CT concentration that will result from this remaining vadose zone source. However, the current source mass discharge estimate is based on data from a time when the rebound response used in the estimate is relatively low. Use of a revised SVE operational approach to improve the estimate of the source mass discharge, as described in Section 2.2, "Recommendations," is expected to improve this estimate by providing for a longer period of rebound and minimizing the vapor concentrations remaining at the end of the operational cycle.

The Brusseau et al. (2010) method provides important information on the vadose zone source strength in terms of the source mass discharge. However, to estimate the impact of the vadose zone contamination on groundwater CT concentrations, the location and size of the source are also needed (Carroll et al. 2012). A series of single-well tests to measure pneumatic responses and location-specific CT mass discharge were conducted as part of the treatability test to assess source size and location.

Pneumatic data were collected to determine whether non-uniform gas flow patterns need to be incorporated into the analyses. Tomographic analysis methods have been applied in other cases where non-uniform flow patterns are present. However, pneumatic data from the Hanford Site test showed that relatively uniform hydraulic conditions are present in the Hanford and Ringold Formations and tomographic methods with respect to data interpretation are not needed.

In the single-well tests, $\mathrm{CT}$ concentration and flow-rate data were collected during extraction from the stressed well. The CT concentration and related mass discharge profile over time during these single-well tests are indicative of the variations in vapor concentrations within the swept volume of the extraction well. If mass discharge rates vary over time, tomographic methods could be applied to jointly interpret data from multiple single-well tests and identify the location and size of contaminant source "hot spots." Significant vapor concentration variations were not observed for most of the single-well tests and therefore only limited tomographic analyses were applied to the test data. However, there was a distinct pattern in the CT concentration and mass discharge data that show higher values near the CCU within a distinct lateral extent. These patterns and historical SVE operational data were used to conclude that the $\mathrm{CCU}$ is the primary remaining source of CT in the vadose zone and that the areal extent of the source zone within the CCU is approximately 90 by $90 \mathrm{~m}$.

\subsection{Recommendations}

The treatability test applied characterization methods and analysis of SVE operational periods and produced an estimated source mass discharge of approximately $70 \mathrm{~g} / \mathrm{d}$. It was determined that this discharge is from a source in the CCU over a lateral extent of about 90 by $90 \mathrm{~m}$. Data from SVE operations were used to quantify the decline in the vadose zone contaminant source discharge over time and an extension of this approach can be used to estimate the decline in the contaminant source discharge over time after the SVE system is terminated. Using the method of Carroll et al. (2012), these vadose zone source characteristics can be used to estimate the groundwater CT concentration that will result from the presence of this vadose zone source if SVE operations were terminated. This type of analysis, using the data collected during the treatability test, can be applied to evaluate the post-SVE impact to groundwater and how this impact to groundwater is expected to change over time, especially in the 
context of the existing groundwater remediation approach. The material below describes these analyses and is intended to support SVE operational decisions and a refined definition of the SVE remediation endpoint.

The predictive modeling analysis of Carroll et al. (2012) estimates the post-SVE impact of the vadose zone contaminant source to groundwater assuming that this source remains constant and is the only contaminant source to groundwater. This scenario is conservative in that it computes the maximum contribution of the vadose zone source to a groundwater contaminant plume. While the source mass discharge from the vadose zone source was measured in this test, through the modeling analysis the source mass discharge can also be related to a corresponding CT source vapor concentration (e.g., at the interface between the Ringold Formation and the CCU). Figure 2.1 shows simulated CT concentrations through the centerline of the vadose zone source along the axis of groundwater flow direction as a function of the vadose zone source strength expressed as a source mass discharge and as a corresponding CT source vapor concentration.

The information in Figure 2.1 can be interpreted to refine the definition of the SVE remediation endpoint in the context of the existing groundwater remediation approach. For instance, Figure 2.1 shows the estimated CT concentrations in groundwater if the vadose zone source is assumed to be the only source of contamination and the groundwater is otherwise uncontaminated. Under the current conditions in the 200-ZP-1 operable unit, the groundwater is contaminated and would inhibit migration of vapors from the vadose zone to the groundwater (i.e., the concentration gradient from the vadose zone to the groundwater is decreased and may even be upward if the groundwater is currently contaminated). In the future, as groundwater contamination is decreased through the groundwater remedy, the impact of the vadose zone source needs to be estimated. If the vadose zone source were to remain constant over time at $70 \mathrm{~g} / \mathrm{d}$, the related estimated groundwater CT concentration profile in Figure 2.1 shows a maximum $\mathrm{CT}$ concentration of $24 \mu \mathrm{g} / \mathrm{L}$.

SVE operational data since 1997, when the system began cycled operations (discrete periods of operation with shut down periods in between), have shown a progression toward a smaller contaminant mass discharge from the vadose zone source. During each rebound period (quiescent time), contaminants have diffused out of the source zone and are then removed by the SVE system. The mass discharge of contaminants diffusing from the source zone, as quantified through the method of Brusseau et al. (2010) that was applied in this treatability test, has declined by a factor of 10 in about 10 years (Figure 4.5). These data can be used to project the rate of decline if the SVE system is terminated. After SVE is terminated, the driving force for mass diffusing from the source will be smaller because the SVE system will no longer periodically "clean out" the high permeability Hanford and Ringold formations. However, diffusion will still occur with the majority of contaminant mass moving out of the vadose zone at the ground surface (Oostrom et al. 2010). The method of Carroll et al. (2012) estimated the relative source mass discharge under conditions representative of periodic SVE operation and demonstrated that the source mass discharge declines over time under post-SVE conditions. Using the information in Carroll et al. (2012), the rate of decline in source mass discharge after SVE is terminated is estimated to be a factor of about 5 slower than the rate of decline in source mass discharge during SVE operations. From this estimate, a source mass discharge starting at a value of $70 \mathrm{~g} / \mathrm{d}$ would be expected to drop below $10 \mathrm{~g} / \mathrm{d}$ in about 40 years after SVE shut down. As shown in Figure 2.1, a source mass discharge of $10 \mathrm{~g} / \mathrm{d}$ results in groundwater concentrations at or less than $3.4 \mu \mathrm{g} / \mathrm{L}$. In 125 years (representing 25 years of Pump-and-Treat operations and 100 years of Monitored Natural Attenuation in the groundwater) the source mass discharge is expected to be negligible. 


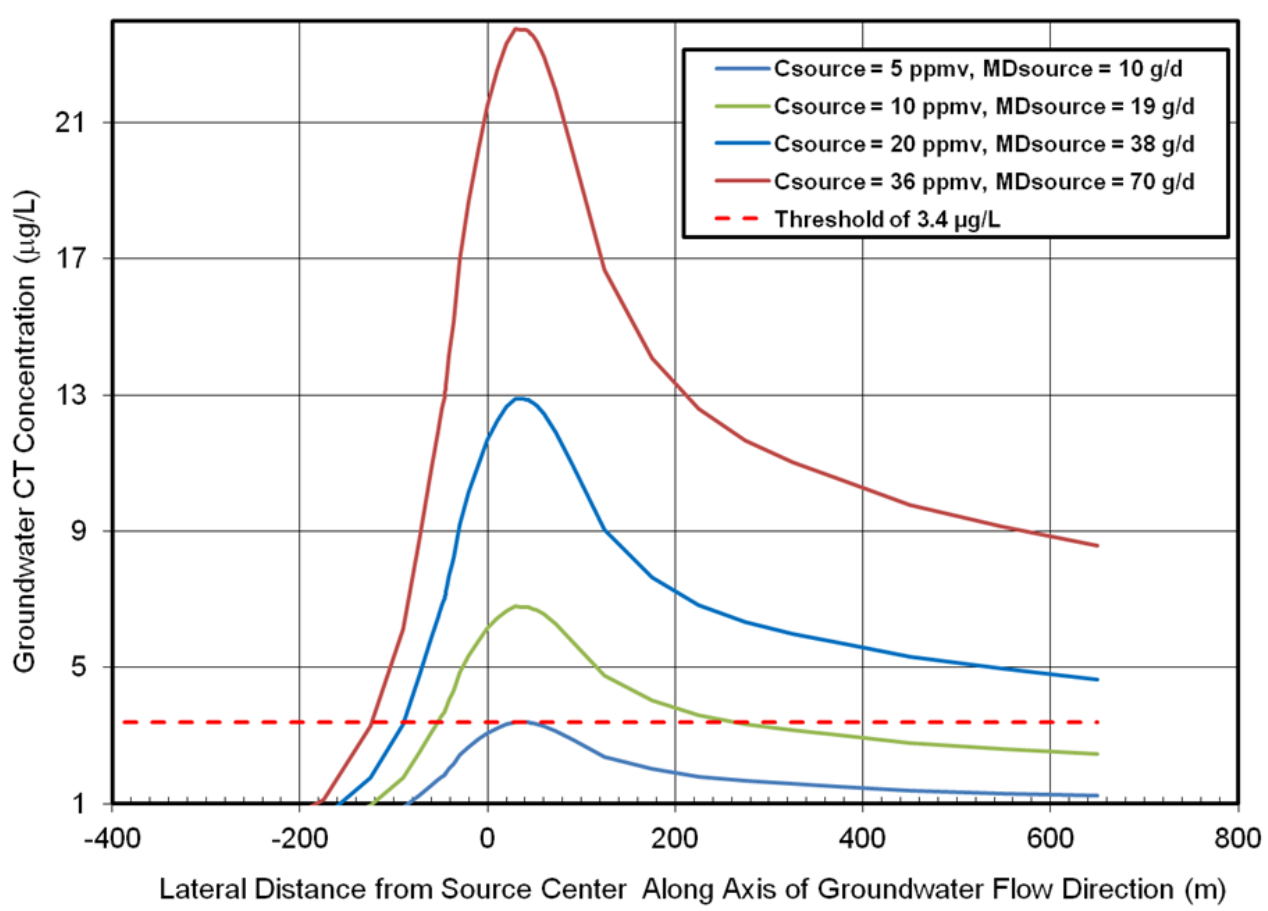

Figure 2.1. Simulated Groundwater CT Concentration for a 10-m Well Screen Resulting from the Specified Vadose Zone Source. The vadose zone source strength is shown as Csource, the CT source vapor concentration at the interface between the Ringold Formation and the CCU; and the MDsource, the source mass discharge as determined using the methods described in this treatability test.

Application of the information and analyses from this treatability test should include the following considerations. The Carroll et al. (2012) analysis method relates the source mass discharge measured using cyclic SVE operations to the resultant groundwater CT concentration. As noted in Section 2.1, the source mass discharge estimate of $70 \mathrm{~g} / \mathrm{d}$ is based on data from a time when the rebound response used in the estimate is relatively low. Use of a revised SVE operational approach to improve the estimate of the source mass discharge is recommended. There are three operational conditions that can be adjusted to improve the source mass discharge estimate. First, SVE operations can be continued for a longer period of time to minimize the CT vapor concentrations when the system is shut off. Second, the period of shut down can be lengthened to provide additional time for rebound in the vapor concentrations. Third, when SVE operations are restarted after the long rebound period, extraction wells can be selected to target the zone of diffusive mass discharge based on the CCU source distribution identified in the treatability test effort.

The Carroll et al. (2012) estimate is based on an assumption that the source mass discharge remains constant over time. However, continued mass discharge from the source will, over time, reduce the source mass discharge as discussed above. Potentially, this process can be evaluated over time based on the observed vapor-phase concentrations and comparison to the maximum estimated in the Carroll et al. (2012) analysis as shown in Figure 2.1. Wells 299-W15-95L, 299-W15-9L, and 299-W15-84L may be appropriate for this type of monitoring. Well 95L is screened closest to the CCU; however, because concentration profiles in the absence of SVE will become fairly uniform with depth directly beneath the source area, all three wells may be suitable for monitoring in the long term. 
The estimate of CT concentration in groundwater is a function of the input parameters and subject to uncertainty in these parameters. For instance, a moderately higher groundwater velocity will result in lower groundwater contaminant concentrations from the same vadose zone source (Truex et al. 2009; Carroll et al. 2012). Source size also impacts the resultant groundwater contaminant concentration and is a part of the Carroll et al. (2012) analysis that is not accounted for in the analytical solution used by Truex et al. (2009). Quantification of the source size from this treatability test provides the necessary information to estimate the current and future impact of the vadose zone source on the groundwater. Recharge rates can also be an important factor at some sites, but at the Hanford Site, recharge rates are expected to remain low enough that the vapor-phase component of the impact to groundwater dominates and small variations in recharge will not have a significant impact. The Carroll et al. (2012) analysis demonstrates that in the long term, sorption has negligible effects on the groundwater impact. However, in the short term, sorption can mitigate impact in conjunction with decay in the source mass discharge. The impact of abiotic CT degradation is also not included and would also act to reduce source concentrations over time. Interpretation of results should also consider that the Carroll et al. (2012) analysis applies an approach that maximizes mass transfer across the water table to provide a conservative estimate of groundwater contaminant concentration.

The estimated CT source vapor concentration at the interface between the Ringold Formation and the CCU is lower than the estimate based on the one-dimensional analytical technique presented in Truex et al. (2009) for the same resultant groundwater CT concentration. Limitations of the analytical technique are discussed in Truex et al. (2009). Most notably for the Hanford Site application, vapor transport in the vadose zone and the coupled processes for contaminant mass transfer into the groundwater are by nature multidimensional. The analytical technique cannot account for the impact of combined lateral and vertical vapor transport. In addition, the impact of large source size in terms of cumulative mass transfer to the groundwater along the flow path and for a spatially large vapor plume is not included in the analytical technique. Oostrom et al. (2010) provides additional analysis of the difference between one-dimensional analyses and three-dimensional analysis for vapor-transport and resultant impacts to groundwater. 


\subsection{Approach}

This section presents the test objectives, experimental design, and equipment, sampling and analysis, data management, and deviations from the work plan.

\subsection{Objectives}

The primary objective for this treatability test was to evaluate methods for collecting characterization information suitable to support decisions for SVE system closure or transition to other remedies at the 200 West Area of the Hanford Site. The methodology is targeted at collecting data to verify or refine the conceptual model of contaminant nature and distribution in the vadose zone beneath a waste disposal site. A key element of the method development is to test approaches for characterizing the magnitude and spatial distribution of source mass discharge.

The approximately two decades of site characterization and remediation operations have generated a substantial amount of site-specific knowledge and data related to vapor transport. However, uncertainty remains - specifically related to the location and distribution of source zones within localized lowpermeability units such as the CCU (Oostrom et al. 2007). The mass flux and vapor transport associated with these zones controls the long-term contamination of the vadose zone and the groundwater. The treatability test investigation was designed to characterize the distribution of source zones, diffusive mass transfer behavior, and the vapor transport behavior within the subsurface. The investigation was specific to the zone of influence of the SVE system beneath the former waste disposal sites (the location most likely to contain persistent contamination); specifically, the Z-9 Trench SVE system for this test.

\subsection{Experimental Design and Procedures}

The treatability test was conducted at the Z-9 Trench using the existing wells and SVE system. The following sections describe the test site, location, layout, and operations.

\subsubsection{Test Site Location and Description}

Plutonium recovery operations within the Z-Plant aggregate area (Plutonium Finishing Plant or PFP) at the Hanford Site resulted in organic and aqueous wastes that were disposed of at several cribs, tile fields, and French drains. The organic wastes consisted of CT mixed with lard oil, tributyl phosphate, and dibutyl butyl phosphonate. The main disposal areas were the Z-9 Trench, the 216-Z-1A tile field, and the 216-Z-18 Crib (Oostrom et al. 2007). Active SVE has been removing CT and other contaminants from the vadose zone since 1992. The Z-9 Trench was selected as an appropriate test site for this investigation because of its subsurface heterogeneity, persistent contaminant source despite decades of remediation, and the potential applicability of the test methods for evaluating remediation effectiveness for closure evaluation and planning.

In general, the $\mathrm{CCU}$ in the vadose zone underlying the Z-9 Trench has been characterized as containing the majority of the remaining CT mass (Rohay 2007). The low-permeability CCU is a mixture of caliche (or calcrete), a fine- to coarse-grained, calcium-carbonate cemented paleosol, and a cohesive, compact, massive to laminated, and stratified fine-grained sand and silt (e.g., sandy mud). Above and 
below this unit are the higher-permeability units called the Hanford and Ringold Formations, respectively. The Ringold Formation is a sedimentary sequence of fluvial-lacustrine clay, silt, sand, and granule to cobble gravel deposited by the ancestral Columbia River. The Hanford formation contains a sequence of interbedded sand and mud, coarse to medium sand, and sandy gravel (Oostrom et al. 2007). The majority of the vapor extraction wells are screened either above or below the CCU. A few wells are screened across the CCU (e.g., 299-W15-86) or across the water table (e.g., 299-W15-32).

\subsubsection{Test Layout and Operations}

There were two operational phases of the test. The first phase consisted of the standard annual operation of the SVE system at the Z-9 Trench (March through August 2011) where the system was operated at a nominal extraction rate of $500 \mathrm{cfm}$ with extraction from multiple wells at the site. This element of the test is a continuation of cyclic operation of the SVE system that has occurred since 1997 where annually the SVE system is off for part of the year and is operated for part of the year. During periods when the system is off, the vapor-phase CT concentrations in the subsurface rebound as CT diffuses out of remaining sources within low permeability zones. When the SVE system is cycled back on, it removes CT that has diffused into the permeable portion of the SVE swept zone. The SVE operations are terminated when the CT mass removal rate diminishes and nominally approaches an asymptote. At this point, measurement of source mass discharge would represent CT mass diffusing out of low-permeability regions from remaining sources (i.e., the rebound period).

Under the rebound conditions after the standard annual SVE operation, the second element of the test was conducted to measure CT concentrations, CT mass discharge, and pneumatic responses during extraction from individual wells as a means to characterize the size and location of the remaining CT sources. This procedure was repeated for multiple wells at the Z-9 Trench to provide data for interpreting the location of the sources in three dimensions. The layout and operations for both test elements are described below.

The two elements of the test used the existing SVE wells shown on Figure 3.1. The previous site characterization and monitoring evidence indicates that the primary remaining source of CT within the vadose zone is located within the $\mathrm{CCU}$, although some secondary sources may exist in localized regions outside the CCU. The CT concentrations measured within vapor samples collected at selected wells during historical SVE operations are shown for wells screened above and below the CCU in Figures 3.2 and 3.3, respectively. A cross-section for the Z-9 Trench area showing well screen intervals is provided as Figure 3.4. 


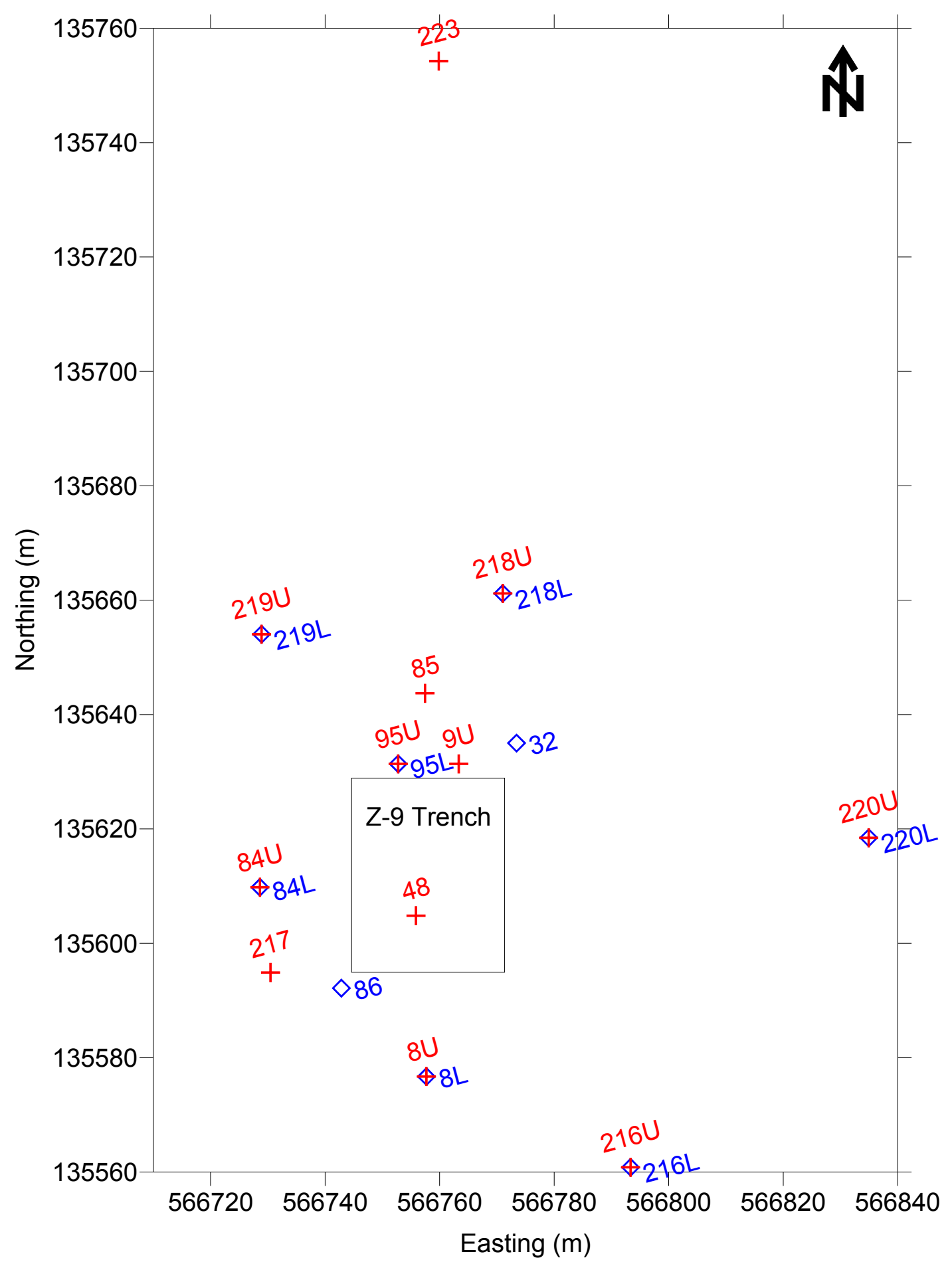

Figure 3.1. Location Map of Soil Vapor Extraction Wells Selected for Testing at the Z-9 Trench. The 299-W15 prefix has been omitted from all well names. Red and blue labels indicate wells screened above or below the CCU, respectively (except for 86 which is screened across the $\mathrm{CCU})$. 


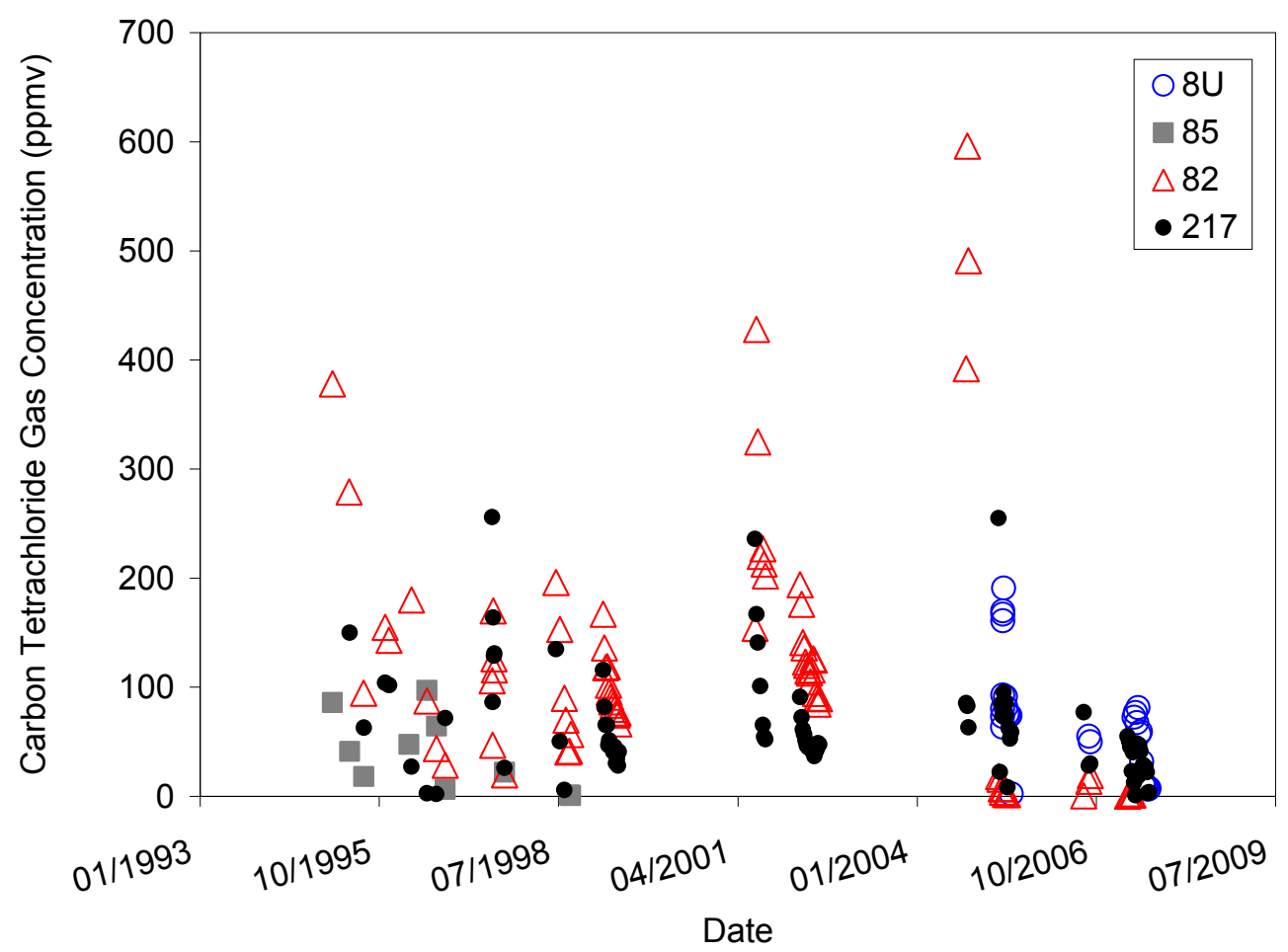

Figure 3.2. Vapor Concentrations as a Function of Time Measured at Wells Screened Above the CCU during SVE Operations at the Z-9 Trench from 1995 through 2008. The 299-W15 prefix has been omitted from all well names.

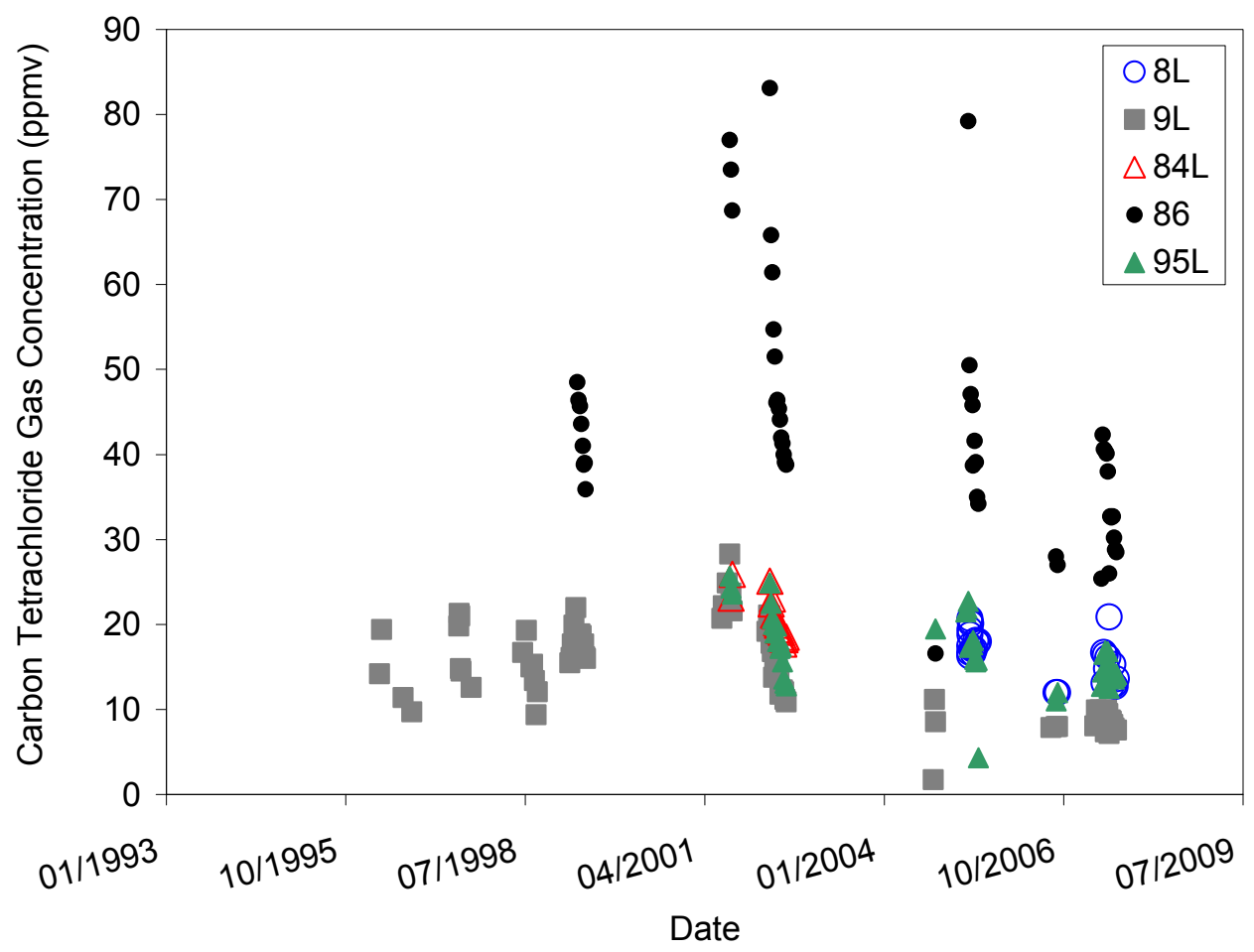

Figure 3.3. Vapor Concentrations as a Function of Time Measured at Wells Screened Below the CCU during SVE Operations at the Z-9 Trench from 1995 through 2008. The 299-W15 prefix has been omitted from all well names. 


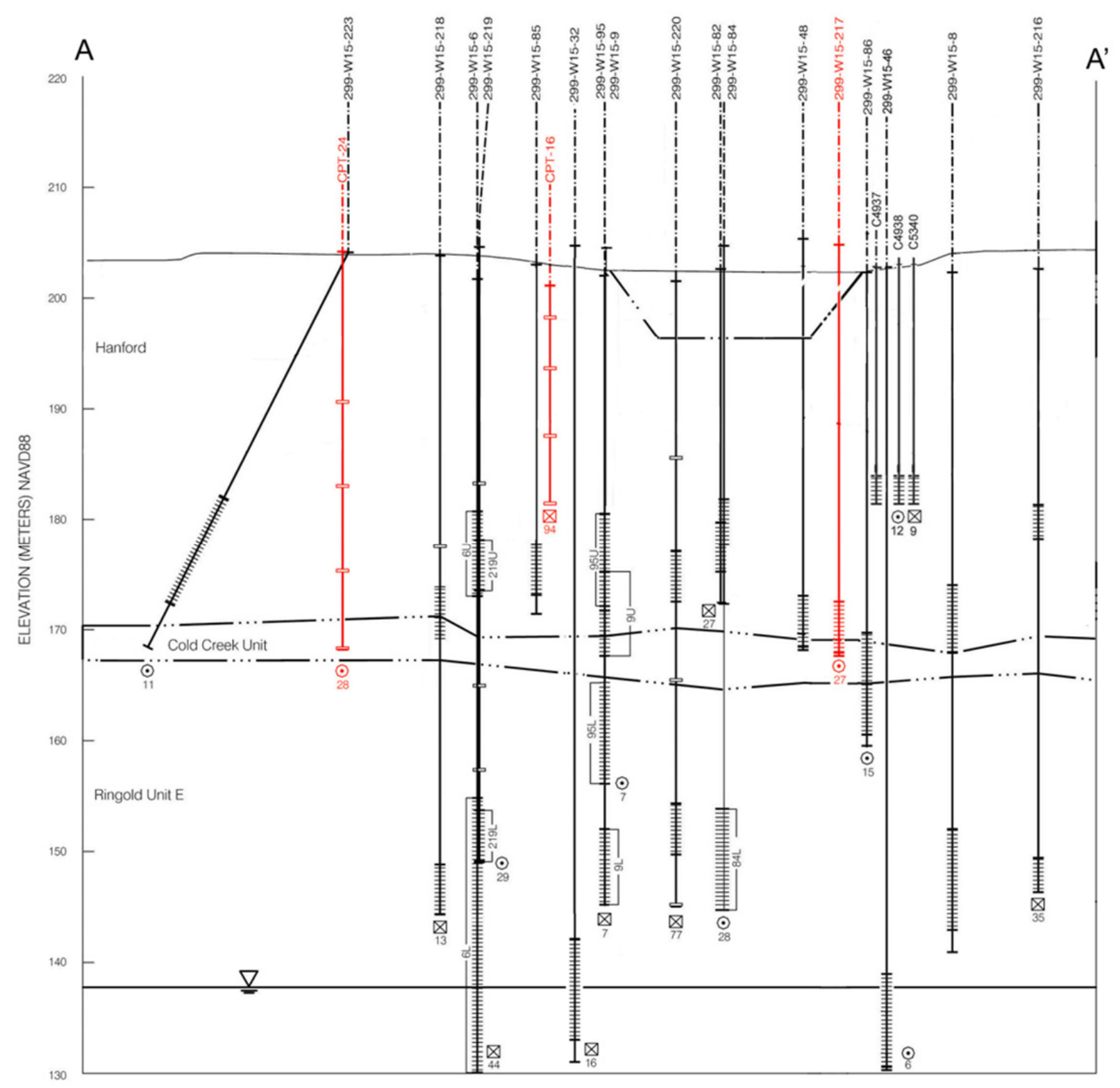

Figure 3.4. Cross-Section A-A' for the Z-9 Trench Indicating Well-Screen Locations, the Trench Location, Groundwater Table Elevation, and Generalized Subsurface Lithologic Units (after DOE-RL 2010)

The wells on-line during the standard operational SVE period (March through August, 2011) are shown in Table 3.1. During this period, data were collected at the SVE system including vapor-phase $\mathrm{CT}$ concentrations, flow rate, vacuum, and temperature. A schematic of the operational and data collection system is shown in Figure 3.5 and described in more detail in Section 3.3. 
Table 3.1. SVE Wells During Annual Cyclic Operations (March through August 2011). The 299-W15 prefix has been omitted from all well names.

\begin{tabular}{cl}
\hline Date & \multicolumn{1}{c}{ Wells Used for Z-9 Trench SVE Operations in 2011 Prior to Single-Well Testing } \\
\hline $3 / 1-6 / 8$ & $9 \mathrm{U}, 9 \mathrm{~L}, 82,217$ \\
$6 / 9-7 / 12$ & $9 \mathrm{U}, 9 \mathrm{~L}, 82,217,48,84 \mathrm{U}, 84 \mathrm{~L}, 86,218 \mathrm{U}, 218 \mathrm{~L}$ \\
$7 / 13-7 / 19$ & 9U, 9L, 82, 217, 48, 84U, 84L, 86, 218U, 218L, 8U, 8L, 32, 85, 95U, 216U, 216L, 219U, \\
& 219L, 220U, 220L, 223 \\
$7 / 20-8 / 16$ & 9U, 9L, 82, 217, 48, 84U, 84L, 86, 218U, 218L, 8U, 8L, 32, 85, 95U, 216U, 216L, 219U, \\
& 219L, 220U, 220L, 223, 95L, C4937 \\
\hline
\end{tabular}

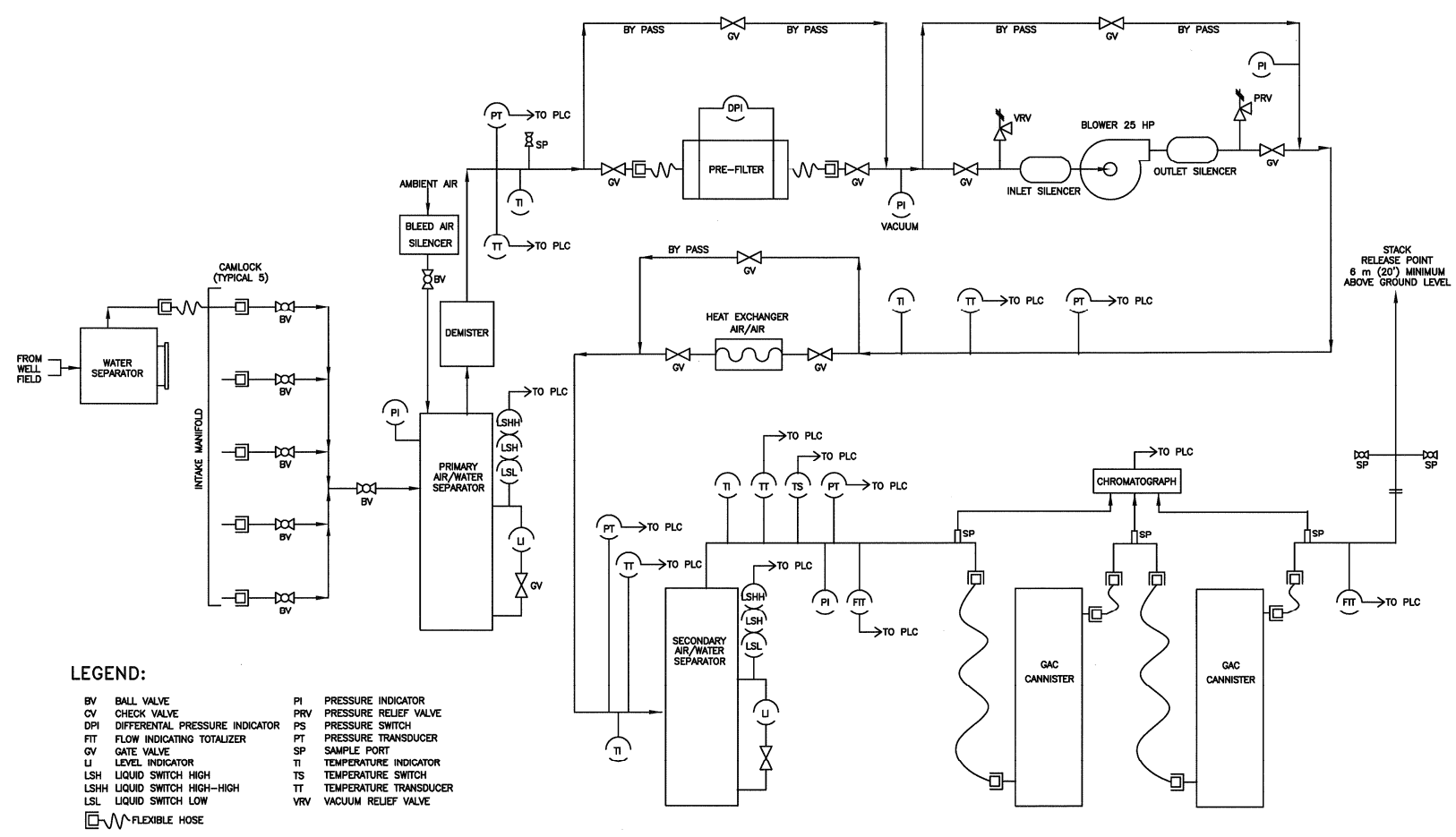

Figure 3.5. Schematic of the Z-9 Trench SVE System (after FHI 2003)

Single-well mass discharge and pneumatic testing was conducted in August and September 2011. Table 3.2 shows the schedule of individual well tests and the surrounding wells where pressure monitoring occurred. During this period, data were collected at the SVE system including vapor-phase CT concentrations, flow rate, vacuum, and temperature. In addition, an independent monitoring system (hereafter, "extraction well monitoring system") was added in-line with the extraction well hose just upstream of the SVE system. The extraction well monitoring system included gas flow rate, vacuum, and temperature sensors and a data logger. Summa canister samples (for CT and other volatile organic compound [VOC] vapor chemical analysis) were also collected from a valve port on this extraction well monitoring system. A cam-lock was installed with a port allowing in-line vacuum monitoring at selected well-heads for each test (10 or 11 at a time). 
Table 3.2. Individual Well and Pneumatic Tomography Testing Wells and Schedule. The 299-W15 prefix has been omitted from all well names.

\begin{tabular}{|c|c|c|c|c|}
\hline Date & Week & Stressed Well & $\begin{array}{c}\text { Wells Monitored for Pressure During Single Extraction } \\
\text { Operations }\end{array}$ & $\begin{array}{l}\text { Wells Monitored During the Recovery Period } \\
\text { Between Single-Well Tests }\end{array}$ \\
\hline $8 / 17$ & 1 & $9 \mathrm{U}$ & $95 \mathrm{U}, 85,84 \mathrm{U}, 82,48,8 \mathrm{U}, 217, \mathrm{C} 4937,218 \mathrm{U}, 219 \mathrm{U}$ & $48,85,218 \mathrm{U}$ \\
\hline $8 / 18$ & 1 & 8L (weekend) & $86,84 \mathrm{~L}, 95 \mathrm{~L}, 216 \mathrm{~L}, 217,218 \mathrm{~L}, 219 \mathrm{~L}, 220 \mathrm{~L}, 48,85,218 \mathrm{U}$ & 86 \\
\hline $8 / 22$ & 2 & $84 \mathrm{U}$ & 95U, 85, 9U, 82, 48, 8U, 217, C4937, 218U, 219U, 84L & $85,219 \mathrm{U}, 217$ \\
\hline $8 / 23$ & 2 & $219 \mathrm{~L}$ & 86, 8L, 84L, 95L, 216L, 218L, 220L,95U, 85, 219U, 217 & 219L, 85 \\
\hline $8 / 24$ & 2 & $95 \mathrm{U}$ & 9U, 85, 84U, 82, 48, 8U, 217, C4937, 218U, 219U,219L, 85 & 9U,219U,85,84U,86,C4937,217 \\
\hline $8 / 25$ & 2 & $\begin{array}{l}95 \mathrm{~L} \\
\text { (weekend) }\end{array}$ & 86, 8U, 8L, 84L, 218L, 219L,9U,219U,85,84U,86,C4937,217 & $95 \mathrm{~L}$ \\
\hline $8 / 29$ & 3 & 48 & $95 \mathrm{U}, 85,84 \mathrm{U}, 82,9 \mathrm{U}, 8 \mathrm{U}, 217, \mathrm{C} 4937,218 \mathrm{U}, 219 \mathrm{U}, 95 \mathrm{~L}$ & 48 \\
\hline $8 / 30$ & 3 & 85 & 95L, 95U, 9U, 84U, 82, 48, 8U, 217, C4937, 218U, 219U & $85,84 \mathrm{U}, 218 \mathrm{U}, 9 \mathrm{U}, 48,217$ \\
\hline $8 / 31$ & 3 & 86 & $48,82,85,8 \mathrm{~L}, 84 \mathrm{~L}, 84 \mathrm{U}, 9 \mathrm{U}, 95 \mathrm{~L}, 218 \mathrm{U}, 219 \mathrm{~L}, 217$ & 86 \\
\hline $9 / 1$ & 3 & $\begin{array}{l}218 \mathrm{U} \\
\text { (weekend) }\end{array}$ & $95 \mathrm{U}, 85,216 \mathrm{U}, 82,86,48,8 \mathrm{U}, 217,219 \mathrm{U}, 220 \mathrm{U}, 9 \mathrm{U}$ & $218 \mathrm{U}, 85,9 \mathrm{U}, 82,218 \mathrm{U}, 86$ \\
\hline $9 / 6$ & 4 & $216 \mathrm{~L}$ & $86,8 \mathrm{~L}, 84 \mathrm{~L}, 95 \mathrm{~L}, 218 \mathrm{~L}, 219 \mathrm{~L}, 220 \mathrm{~L}, 218 \mathrm{U}, 85,9 \mathrm{U}, 219 \mathrm{U}, 82,218 \mathrm{U}$ & $216 \mathrm{~L}, 32$ \\
\hline 9/7 & 4 & $218 \mathrm{~L}$ & $85,86,8 \mathrm{~L}, 9 \mathrm{U}, 84 \mathrm{~L}, 95 \mathrm{~L}, 216 \mathrm{~L}, 218 \mathrm{U}, 32,218 \mathrm{~L}, 219 \mathrm{~L}, 220 \mathrm{~L}$ & $218 \mathrm{~L}$ \\
\hline $9 / 8$ & 4 & 82 (weekend) & 95U, 84U, 9U, 8U, C4937, 218U, 220U,84L,85,216U & $82,95 \mathrm{U}, 9 \mathrm{U}$ \\
\hline $9 / 12$ & 5 & 32 & 86, 8L, 84L, 95L, 216L, 218L, 219L, 220L,95U,9U,82 & $32,9 \mathrm{U}, 95 \mathrm{~L}, 218 \mathrm{~L}$ \\
\hline $9 / 13$ & 5 & 86 & $48,95 \mathrm{U}, 84 \mathrm{U}, 82,9 \mathrm{U}, 8 \mathrm{U}, 217,219 \mathrm{U}, 32,218 \mathrm{~L}, 95 \mathrm{~L}$ & $86,218 \mathrm{~L}, 217$ \\
\hline $9 / 14$ & 5 & $84 \mathrm{~L}$ & 217,86, 84L, 8L, 32, 95L,216L,218L,219L,220L,84U,9U & 84L,216L,219L,220L,95L \\
\hline $9 / 15$ & 5 & $8 \mathrm{U}$ (weekend) & $95 \mathrm{U}, 85,84 \mathrm{U}, 82,48,9 \mathrm{U}, 216 \mathrm{U}, 217, \mathrm{C} 4937,218 \mathrm{U}, 219 \mathrm{U}$ & $8 \mathrm{U}, 217,82,9 \mathrm{U}, 220 \mathrm{U}, 85,86$ \\
\hline 9/19 & 6 & $220 \mathrm{~L}$ & $86,8 \mathrm{~L}, 32,82,8 \mathrm{U}, 220 \mathrm{U}, 217,216 \mathrm{~L}, 218 \mathrm{~L}, 219 \mathrm{~L}, 84 \mathrm{~L}$ & $220 \mathrm{~L}$ \\
\hline $9 / 20$ & 6 & 217 & $95 \mathrm{U}, 85,84 \mathrm{U}, 82,48,8 \mathrm{U}, 9 \mathrm{U}, \mathrm{C} 4937,218 \mathrm{U}, 219 \mathrm{U}$ & 217 \\
\hline $9 / 21$ & 6 & $216 U$ & 95U, 85, 84U, 82, 48, 8U, 217, 9U, 218U, 219U, 220U & $216 \mathrm{U}$ \\
\hline $9 / 22$ & 6 & 223 & $95 \mathrm{U}, 85,216 \mathrm{U}, 82,48,8 \mathrm{U}, 217,218 \mathrm{U}, 219 \mathrm{U}, 220 \mathrm{U}, 9 \mathrm{U}$ & 223 \\
\hline $9 / 26$ & 7 & $220 \mathrm{U}$ & $95 \mathrm{U}, 85,82,48,8 \mathrm{U}, 217, \mathrm{C} 4937,218 \mathrm{U}, 9 \mathrm{U}, 219 \mathrm{U}, 216 \mathrm{U}$ & $220 \mathrm{U}$ \\
\hline $9 / 27$ & 7 & $219 \mathrm{U}$ & $95 \mathrm{U}, 85,84 \mathrm{U}, 82,48,8 \mathrm{U}, 217, \mathrm{C} 4937,218 \mathrm{U}, 220 \mathrm{U}$ & $219 U$ \\
\hline $9 / 28$ & 7 & All Wells & Flow Meter Comparison Testing & \\
\hline
\end{tabular}


The SVE extraction system for the single-well tests was the same as shown in Figure 3.5 except that only one well was connected to the system at a time. The operational and data collection procedure for this element of the test consisted of the following items:

- Configure the SVE system in connection with only one extraction well (open bleed valve to blower).

- Configure monitoring extraction well monitoring system and well-head pressure monitoring and data loggers.

- Begin SVE system and gas extraction, and close bleed valve if possible or set to extraction system vacuum of 10 in $\mathrm{Hg}$ (below shut-off limit for high vacuum).

- Check monitoring systems to ensure data collection and steady operation.

- Collect summa canister sample (and ambient blank or duplicate as needed) at the extraction well port after 10-30 minutes of stable operation.

- Allow operation to occur for approximately 22 hours (or several days for weekend test) before collecting a second summa canister sample.

- Shutdown SVE system, close extraction well valve, and wait for pressure rebound at selected monitoring wells.

- Download pressure data from monitoring wells and extraction well monitoring systems, and reconfigure to setup for the next single-well test.

- Reconfigure SVE system for next single-well test by opening valve to next extraction well.

- Repeat steps for next single-well test, and download SVE system monitoring data on a weekly basis.

In addition to the individual well data collection, barometric data were also collected for use in the pneumatic data analysis. The monitoring well vacuum and pressure system measured pressure within the vadose zone, which may be impacted by both the SVE operation and changes in atmospheric pressures. To account for the barometric pressure changes, the land surface pressure was monitored with a pressure sensor and data logger during the single-well testing period and during the period after the end of SVE operations to monitor subsurface response to barometric pressure change without SVE system gas flow impacts.

\subsection{Equipment and Materials}

The 200-PW-1 SVE system for the Z-9 Trench was used for the test with the additional equipment presented in the following sections.

\subsubsection{Flow and Pressure Monitoring and Data Acquisition Equipment}

During the individual well testing, the flow rate and vacuum were measured at the SVE system using the existing SVE equipment (200-PW-1 OU Z-9 Trench SVE system). The SVE system is equipped with an explosion-proof positive displacement blower unit. The SVE monitoring system included an automated data acquisition and logger system using Setra 0.001 psi pressure transducers, K-type thermocouples, Omega HX93 humidity sensors, a Serta 270 barometric pressure gauge, and several Sierra 600-200 flow meters. In addition, a separate flow meter was required to directly measure flow 
rates and collect samples upstream of the SVE system because a bleed valve opening was required at the SVE system blower to enable extraction from a single well with low flow-rate yields while meeting the system low flow and low vacuum constraints. The additional flow meter allowed quantification of flow and concentration from the stressed well. Comparison of flow rates between the two flow meters was used to correlate the two data sets. These extraction well flow meter, vacuum sensor, and temperature sensor devices were installed in-line with the extraction well before the vapor reached the SVE system blower and monitored with a data logger (Figure 3.6).

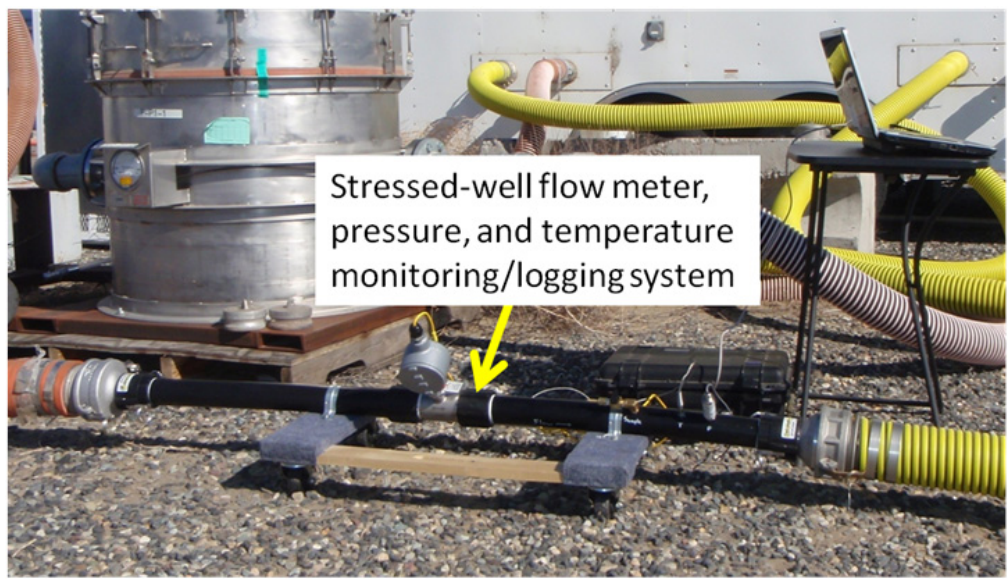

Figure 3.6. Extraction Well Monitoring System. The in-line hose connection to SVE system trailer is shown in the background.

Extraction well airflow was measured with 2-in. $(5.1 \mathrm{~cm})$ diameter Omega model FTB-939 turbine flow meter configured with a 4-20 mA output signal processor (15-250 actual cubic feet per minute $[\mathrm{ACFM}]$ range; $1.0 \%$ of reading accuracy). Extraction vacuum pressure was measured with an Omega model PX209-30VACI pressure transducer with 4-20 mA output (-14.7 to 0 PSI range; $1.0 \%$ full-scale output [FSO] accuracy). In-line air temperature was measured with an Omega model TC-T-NPT-U-72 Type $\mathrm{T}$ thermocouple probe $\left(-200^{\circ} \mathrm{C}\right.$ to $350^{\circ} \mathrm{C}$ range; $\pm 1^{\circ} \mathrm{C}$ accuracy). The flow meter, pressure transducer, and thermocouple sensors were all connected to a Campbell Scientific, Inc. model CR1000 data logger, and data were recorded at 5 -second intervals.

In addition to the vacuum measurements at the SVE system, vacuum/pressure transducers were installed into each well, and data loggers were used to collect vacuum data from up to 11 monitoring well locations during each individual well test (Figure 3.7). Table 3.2 summarizes the schedule of extraction wells, monitoring wells, and wells monitored for pressure rebound after each test.

The monitoring well head pressure monitoring equipment included Dwyer model 616W-2-LCD differential pressure transmitters with 4-20 mA output (0-6 in $\mathrm{H}_{2} \mathrm{O}$ range; $0.25 \%$ FSO accuracy) were used for measuring pressure (vacuum). For the post-test ambient monitoring, pressures were measured with Dwyer model 616W-20B-LCD differential pressure transmitters with 4-20 mA output (-10" to +10" in $\mathrm{H}_{2} \mathrm{O}$ range; $0.25 \%$ FSO accuracy). In both cases, the differential pressure transmitters were configured as with the high pressure port vented to the atmosphere and the low pressure port connected directly to barbed fittings on the well head with 0.25 in. $(6.4 \mathrm{~mm})$ diameter Tygon tubing. Thus, positive current values output by the transmitters correspond to vacuum conditions in the well relative to atmospheric 
pressure. The transmitters were connected to Supco model L420 data loggers ( $\pm 0.05 \mathrm{~mA}$ accuracy), and data were recorded at intervals between 5 and 20 seconds depending upon the length of each test.

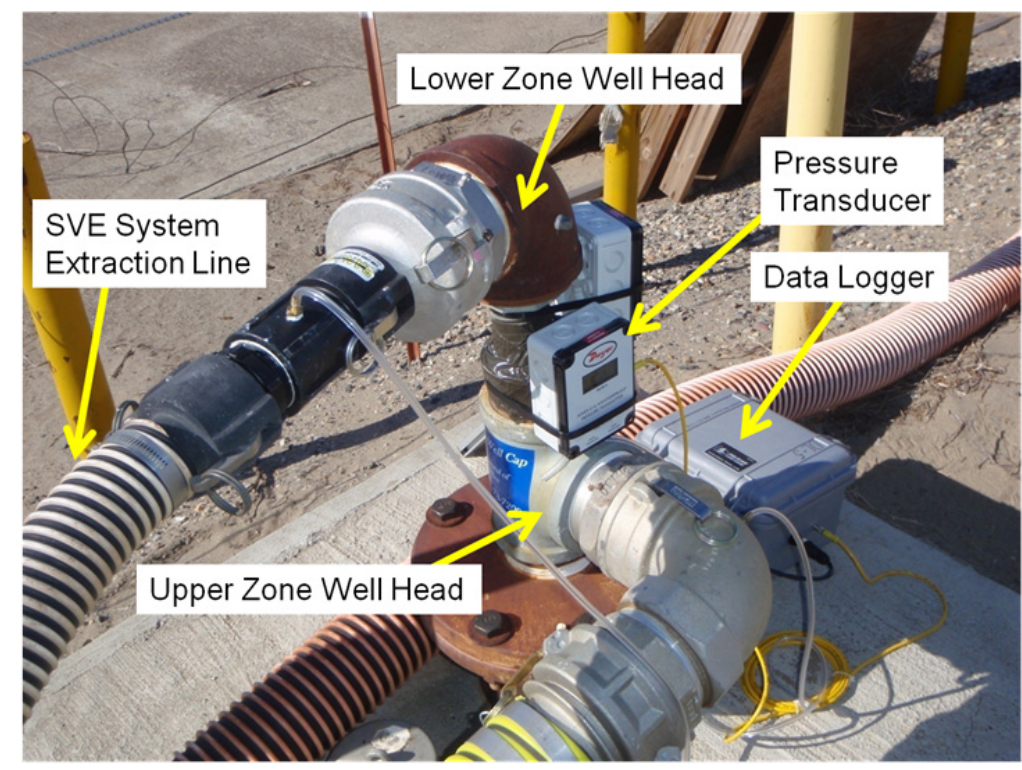

Figure 3.7. Well Head Pressure Monitoring Equipment

Barometric pressure monitoring was conducted at the site during the single-well testing and for several weeks after the shutdown of operations using an Instrumentation Northwest Inc. model PT2X-BV(15 psi range; 0.1\% FSO accuracy) barometric sensor with internal data logger capability.

\subsubsection{Sampling Equipment}

The SVE system is equipped with a vapor discharge in-line automated gas chromatograph (GC) system that was used to monitor the CT concentration during each individual well test. The system automatically switches a valve that allows a portion of the system effluent gas to be routed directly into the GC for analysis. The flow rate and GC are configured within the SVE system downstream of a bleed valve. This valve opens the system to allow ambient air into the flow going through the blower to decrease the vacuum. The blower is designed to operate within a flow rate and vacuum range for extraction of several wells at the same time. The single-well testing was generally at lower flow rates and higher vacuums than the normal operation range, and required the bleed valve to be open for all but four of the single-well tests. The flow rate and GC are configured within the SVE system downstream of the bleed valve, which allowed the inflow of ambient air increasing the total flow rate and causing dilution of the CT concentrations measured at the SVE system GC. The independent measurements of extraction well flow rate (without dilution) were used to calculate dilution associated with the bleed valve for SVE system GC concentration correction (see Section 3.4.3).

The separate flow meter manifold installed to monitor flow from individual wells independently of the SVE system was fitted with a sample port for connection to 6-L stainless-steel summa canisters as gas-sample collection devices. The sampling tube attached to the gas extraction line was attached to the 
summa canister using a gas-tight fitting prior to opening the ball valve for sample collection. Summa canisters were used to collect two samples for each individual well test (Figure 3.8).

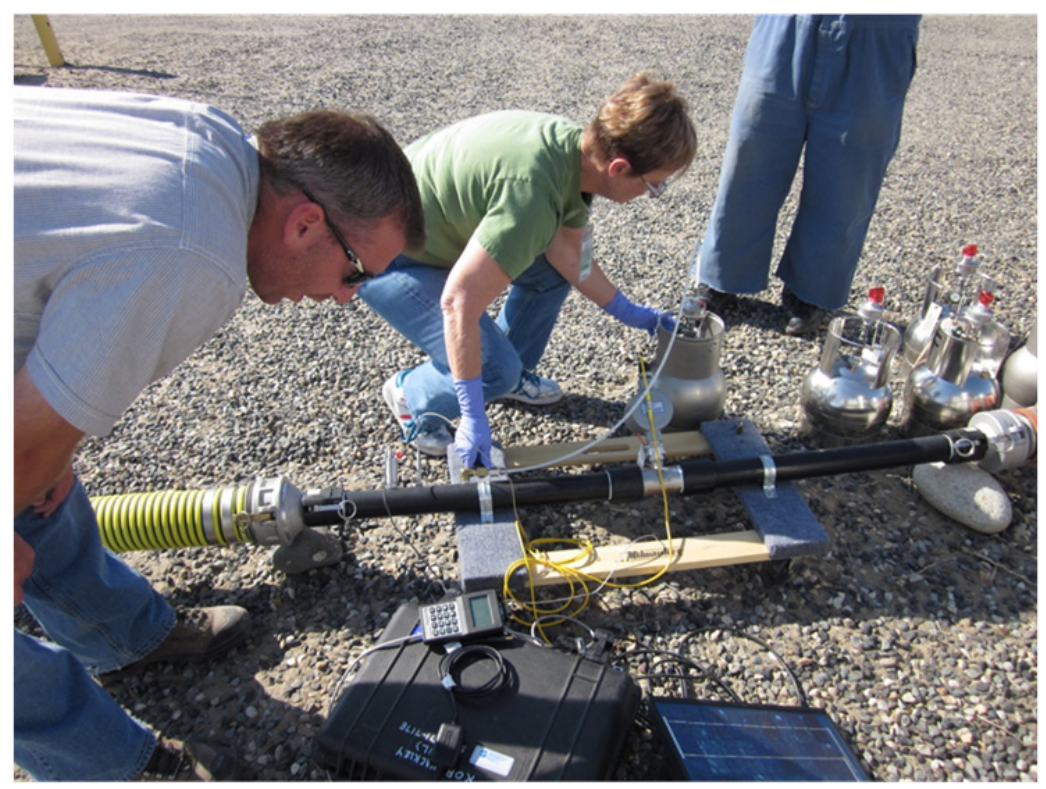

Figure 3.8. Summa Canister Sample Collection for a Single-Well Test at a Port on the Extraction Well Monitoring Apparatus

\subsection{Sampling and Analysis}

The sampling methods, analytical methodology, and data analysis approach are described in the following sections.

\subsubsection{Sampling Method}

The on-line GC analysis for the existing SVE system was configured to automate sample collection as described in Section 3.3.2.

In addition, gas samples were collected in summa canisters and analyzed for CT and tracer compounds at the beginning and end of each individual well test. Summa canister sample collection followed the site-monitoring methods. The SVE system hose was considered to be completely purged after 5-10 minutes of system operation, and the sampling port tube was purged for 3 minutes. The summa canisters were initially under more vacuum than the extraction well hose, which allowed samples to be collected without the use of a vacuum pump. After the summa canister was connected to the sample port, the valve was opened to allow gas to flow into the summa canister from the extraction well line. The sampling time was consistently 5 minutes, which was considered long enough to allow gas to flow into the canister and for pressures to equilibrate with the extraction line. The final canister vacuum was then equal to the vacuum in the vapor extraction line. The final vacuum was recorded on the chain-ofcustody forms and then measured at the laboratory after shipment and before analysis. Field duplicates at a rate of one duplicate per eight extraction well samples and an ambient air (blank) sample at a rate of one 
ambient sample per seven extraction well samples were also collected. The samples were kept at mean ambient temperature and were transported to the laboratory within 24 hours of sampling along with chainof-custody forms.

\subsubsection{Analytical Methodology}

The on-line SVE system GC analysis was used to automate sample collection and analysis at 5-minute time intervals during each of the single-well tests. The SVE system GC (Model 8900) uses a photoionization detector and multipoint sampler (Model 8950) that is calibrated specifically for CT vapor analysis, as described for the SVE operations. The system updates the calibration on a daily basis by injecting a known concentration of an internal standard. The lower detection limit was $5 \mathrm{ppm}$, and the accuracy and precision were approximately $1 \%$ of full scale and $2 \%$ of the measured value, respectively.

Additionally, the summa canister samples collected during each individual well test were analyzed at the laboratory for CT and other VOCs consistent with EPA (1999). CT and other volatile organic chemicals were separated and identified in the GC. All sample transport and analysis met the maximum holding time for the method. The summa sample analysis was calibrated to standards for several volatile compounds. Quality control samples including blanks, laboratory control samples (LCS), and LCS duplicates were also prepared and analyzed as method checks that were run with the field-collected samples. The LCS were prepared samples with known concentrations of several chemicals including CT, methyl ethyl ketone, and dichloroethene to confirm identification and quantification within the quality control tolerance, which was met for all compounds of concern for the site. The method detection limit for CT and most other volatile organics analyzed was 5 ppbv.

\subsubsection{Data Analysis}

Raw data plots for flow, pressure, and CT concentration were compiled for each test. A data correction method was required for the CT concentration data to account for the dilution air added at the SVE system to maintain blower operations within system tolerances. The dilution factor was determined based on the difference between the measured SVE system flow rate and the independent flow-rate measurement from the extraction well flow meter installed for the test. SVE system CT concentration data were corrected based on the ratio of these flow-rate values. Prior to the correction, the comparability of flow-rate measurements for the two flow meters was established from a series of flow tests with no dilution (Figure 3.9). 

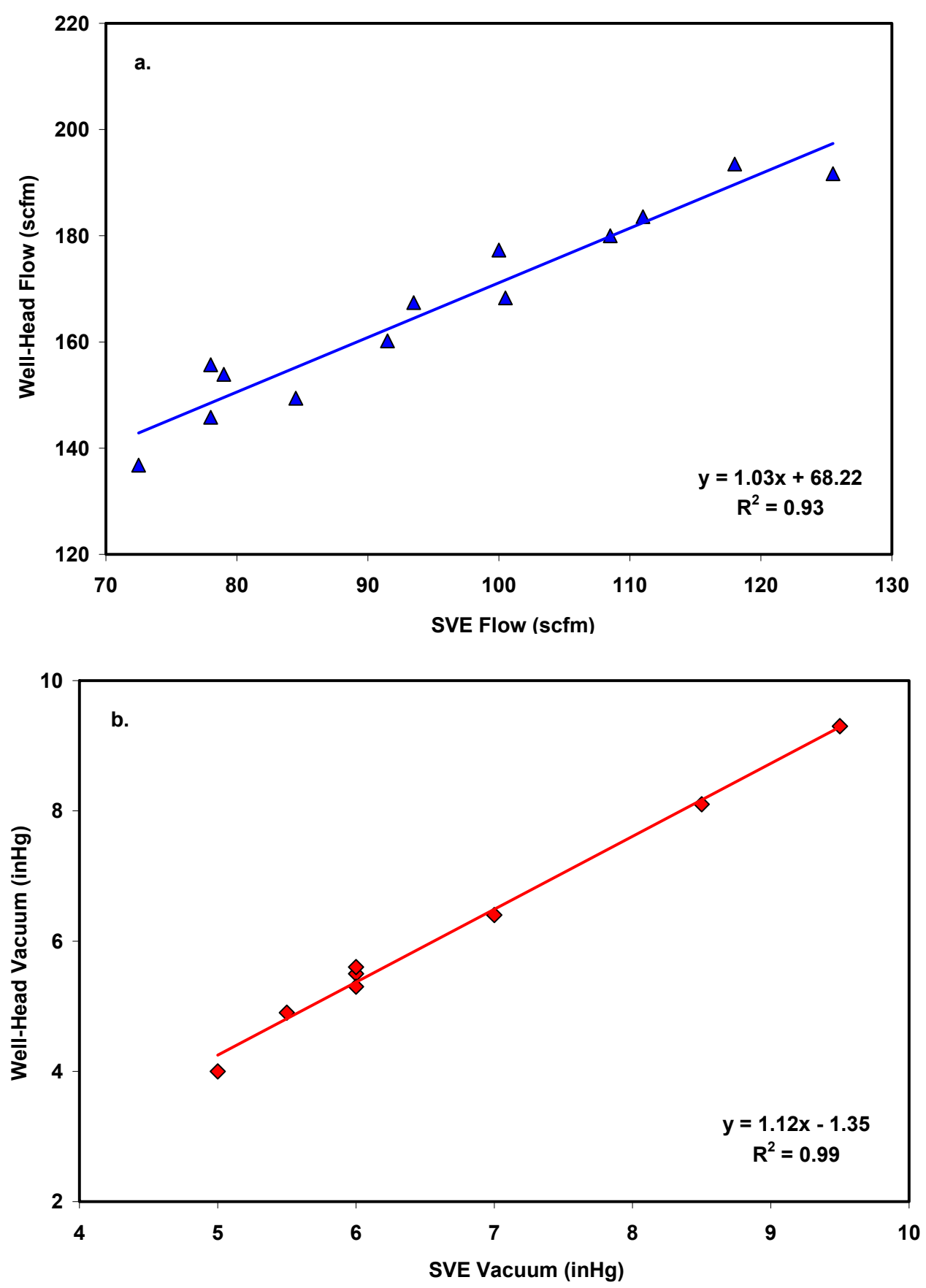

Figure 3.9. Correlation of Flow Rate (a) and Vacuum (b) between the SVE System and Extraction Well Monitoring System for Evaluation of Actual Flow Rate and Concentration Dilution Factors 
The flow meter correlation allow for correction of the SVE system concentration and flow-rate measurements, which were collected on a higher frequency than the summa canister samples. The extraction well vapor mass discharge/flux was calculated over time for each of the single-well tests as the product of the concentration and flow rate at a given time. The correction of the pressure measurements accounting for barometric fluctuations was also conducted for pressure data from each of the single-well tests and is described in Section 4.1.2.2.

\subsection{Data Management}

SVE system data during test operations was downloaded to spreadsheets and compiled in the project files. Data from test-specific data loggers were also downloaded and saved in the original format and transferred to spreadsheets. Laboratory analysis reports were compiled in project files with data transferred to spreadsheets. Spreadsheets were then checked for quality assurance and used for data analysis.

\subsection{Deviations from Work Plan}

Vertical profile mass flux testing specified in the test plan was not conducted because of the inability to establish a contract with the subcontractor for the profiling data collection. 


\subsection{Detailed Results}

Test results are presented in two main sections. The first section presents the data collected, and the second section evaluates these data with respect to the field test objectives.

\subsection{Field Test Data}

Data were collected to evaluate the source mass discharge (Section 4.1.1) and the source size and location (Section 4.1.2).

\subsubsection{Source Mass Discharge}

During the source mass discharge test, the normal SVE system data collection was used. These data provided the CT concentration and soil gas flow profiles that were needed to analyze for the source mass discharge associated with the last rebound (quiescent) period. The method of Brusseau et al. (2010) was used to calculate source mass discharge (termed "MFr" in Brusseau et al. 2010). Information from the current treatability test suggests that background concentrations in the most recent years are nonnegligible. The approach to estimating source mass discharge is based on measuring the contaminant that was released from the source zone during the rebound period. The background concentrations are not part of the mass discharge during the rebound period and must either be negligible or accounted for in the calculation. Site-specific information was applied to refine the calculation of source mass discharge based on an assessment of the background $\mathrm{CT}$ vapor concentrations collected during the treatability tests and from previous operational data. This information was used to establish the nonzero background $\mathrm{CT}$ vapor concentration to use in the $\mathrm{CT}$ mass integration portion of the calculation.

Figure 4.1 shows the maximum rebound $\mathrm{CT}$ vapor concentrations and asymptotic $\mathrm{CT}$ vapor concentrations (concentration at the end of the operational cycle) for the cyclic operational period at the Z-9 Trench. In cycles prior to 2005, the maximum rebound concentration was significantly higher than the asymptotic concentration. During this time, asymptotic concentrations were well above zero, ranging steadily from 20 to 40 ppmv. Since 2005 , both maximum and asymptotic concentrations during operational cycles have declined and there are only small differences between maximum and asymptotic concentrations. Under both pre- and post-2005 conditions, the background (asymptotic) concentration can be subtracted from the rebound concentration profile to better reflect calculation of the diffusive mass discharge from source zones and account for the presence of a background vapor concentrations (i.e., nonzero conditions at the end of an operational cycle).

CT vapor concentration characterization data collected at individual wells periodically during cyclic operations are consistent with data in Figure 4.1. Figure 4.2 shows CT vapor concentrations at individual wells collected during SVE operations for wells screened above the CCU. These data were collected with the SVE system extracting from multiple wells, but with an in-line system to assess concentrations at an individual well as part of standard SVE operations. Prior to 2005, much higher concentrations were observed compared to after 2005 and the magnitude of the rebound for wells screened above the CCU was large. Until recently (after 2009), concentrations at many of the wells screened above the CCU were higher than the concentration in well 86, which is screened completely across the CCU. Figure 4.3 shows the individual data for wells screened below the CCU. The magnitude of contaminant rebound for these 
wells during cyclic operations is much less than observed above the CCU. Additionally, the concentrations in well 86 have remained higher than at the other wells screened below the CCU. These results suggest that initial cyclic SVE operations were still diminishing contaminant mass above or at the top of the CCU and that this contamination is now less significant compared to the contamination remaining in the CCU. Discharge of waste at the surface would be expected to leave the highest residual waste in the upper portion of the vadose zone and within the CCU. The CCU also appears to remain a source of higher vapor-phase concentrations in the Ringold Formation between the CCU and the water table. The single-well test data presented later in this report provide additional information related to evaluating the location of the remaining contaminant source.

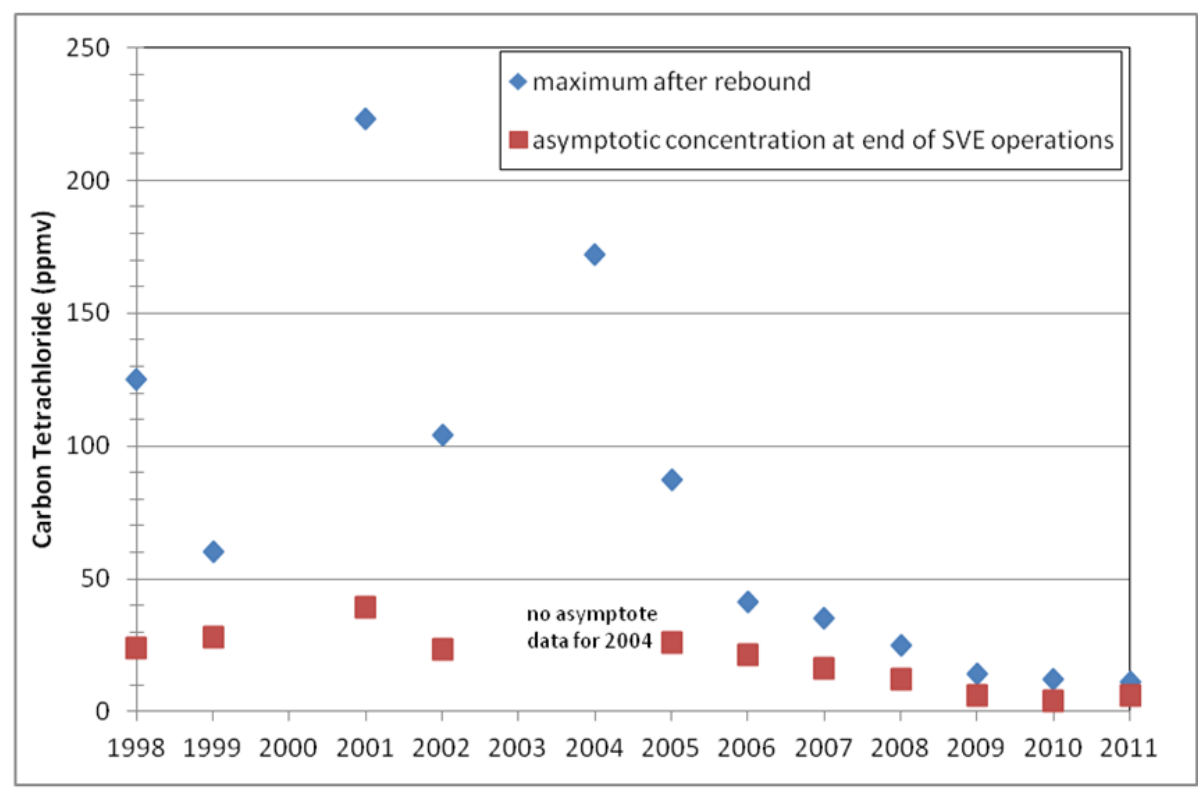

Figure 4.1. Maximum and Asymptotic Carbon Tetrachloride Vapor Concentrations in the SVE Extraction System from 1998 through 2011

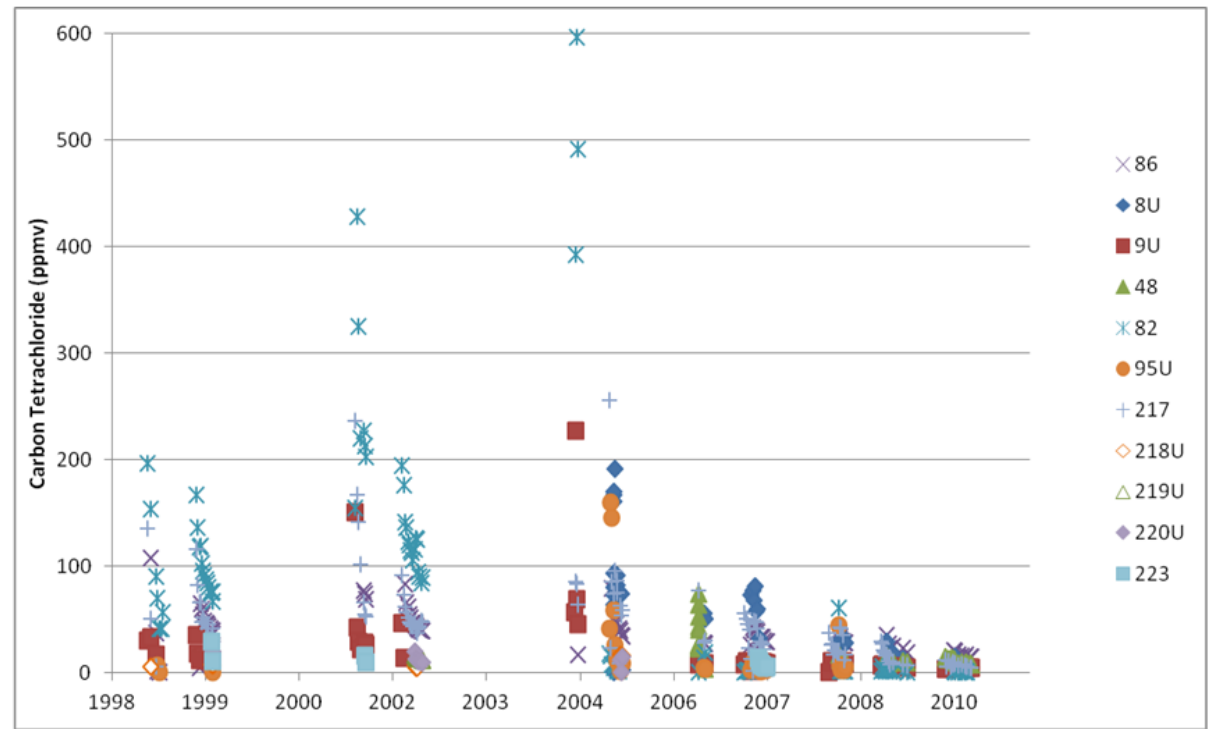

Figure 4.2. Above the CCU, Individual Well Characterization Data, 1998-2010. The 299-W15 prefix has been omitted from all well names. 


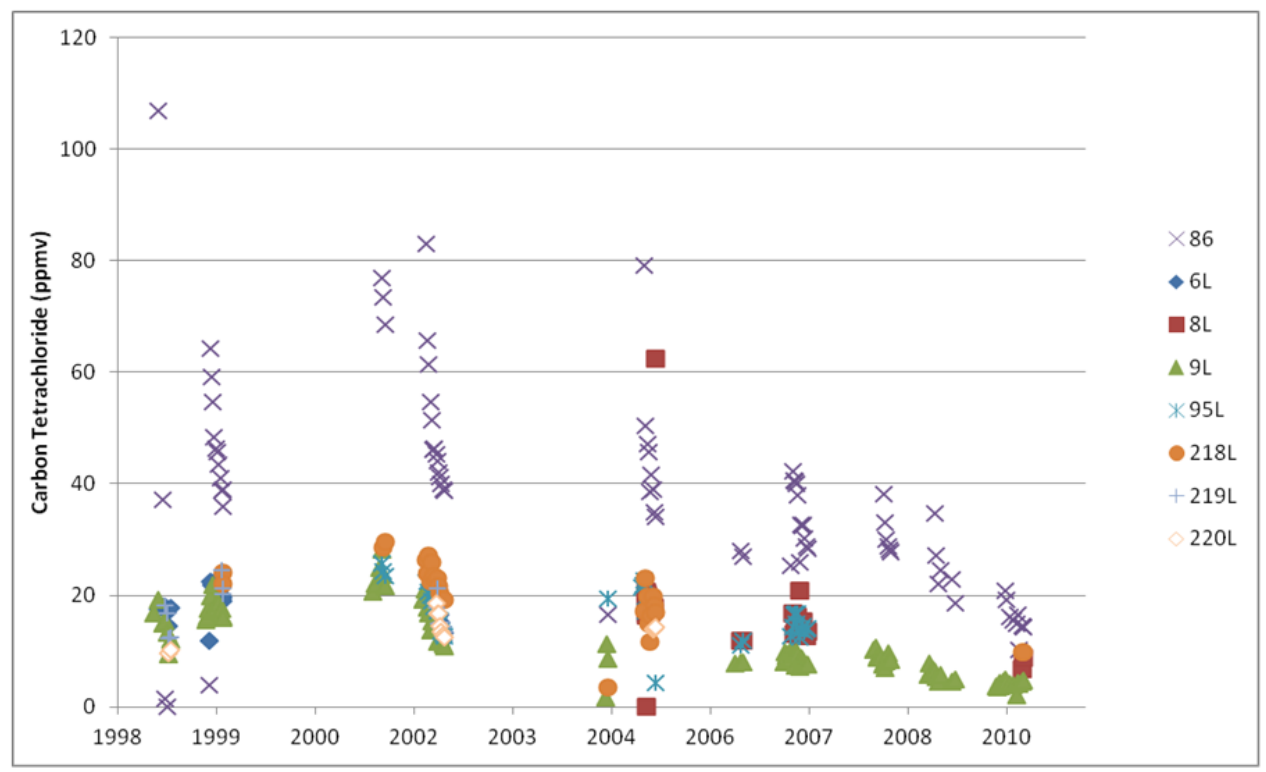

Figure 4.3. Below the CCU, Individual Well Characterization Data, 1998-2010. The 299-W15 prefix has been omitted from all well names.

The above data suggest that the contaminant source continuing into the future is located in the CCU and that more recent vapor concentration data (2009 and later) are more likely to reflect contaminants diffusing out of the $\mathrm{CCU}$ in addition to the background vapor-phase contamination. Figure 4.1 shows that the magnitude of the overall concentration rebound in the SVE system is much lower in recent years than prior to 2005. In addition, the temporal profile of the vapor concentrations extracted by the SVE system has become less dynamic and in 2009 and 2011, did not show the characteristic progression from high initial concentrations to lower asymptotic concentrations during an operational cycle (Figure 4.4).

Because of the uncharacteristic response in 2009 and 2011, these data were not used in estimating a source mass discharge. Note that the 2009 and 2011 response may in part be due to inconsistent operational conditions. Table 4.1 lists the computed source mass discharge for all of the other years where data is available with the exception of 2004, when the system was not operated long enough to extract the volume of soil gas required for the analysis (Brusseau et al. 2010). The system was not operated in 2000 and 2003. The computed source mass discharge data are plotted over time in Figure 4.5. 

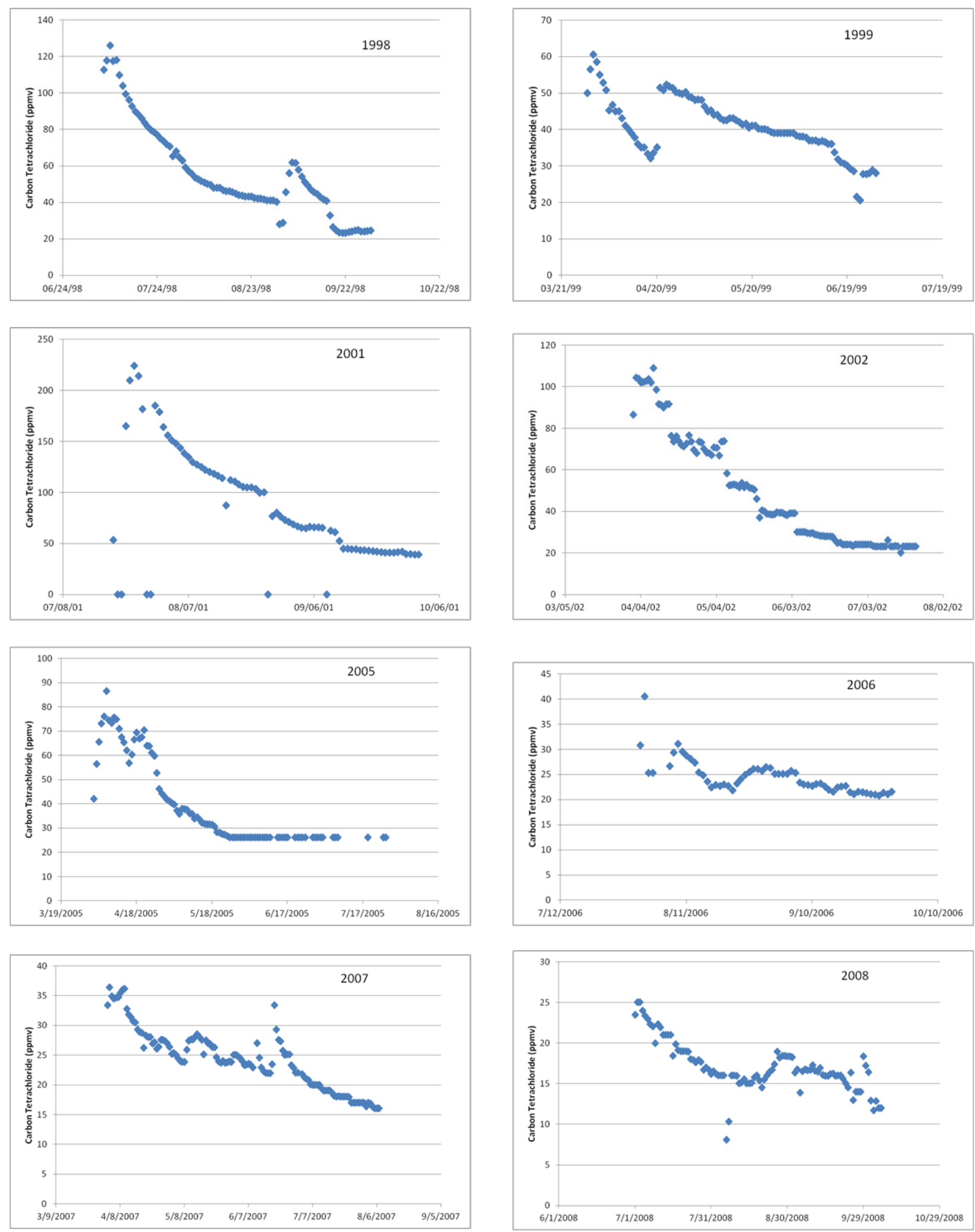

Figure 4.4. SVE System Extracted CT Concentrations, 1998-2011 (continued next page) 

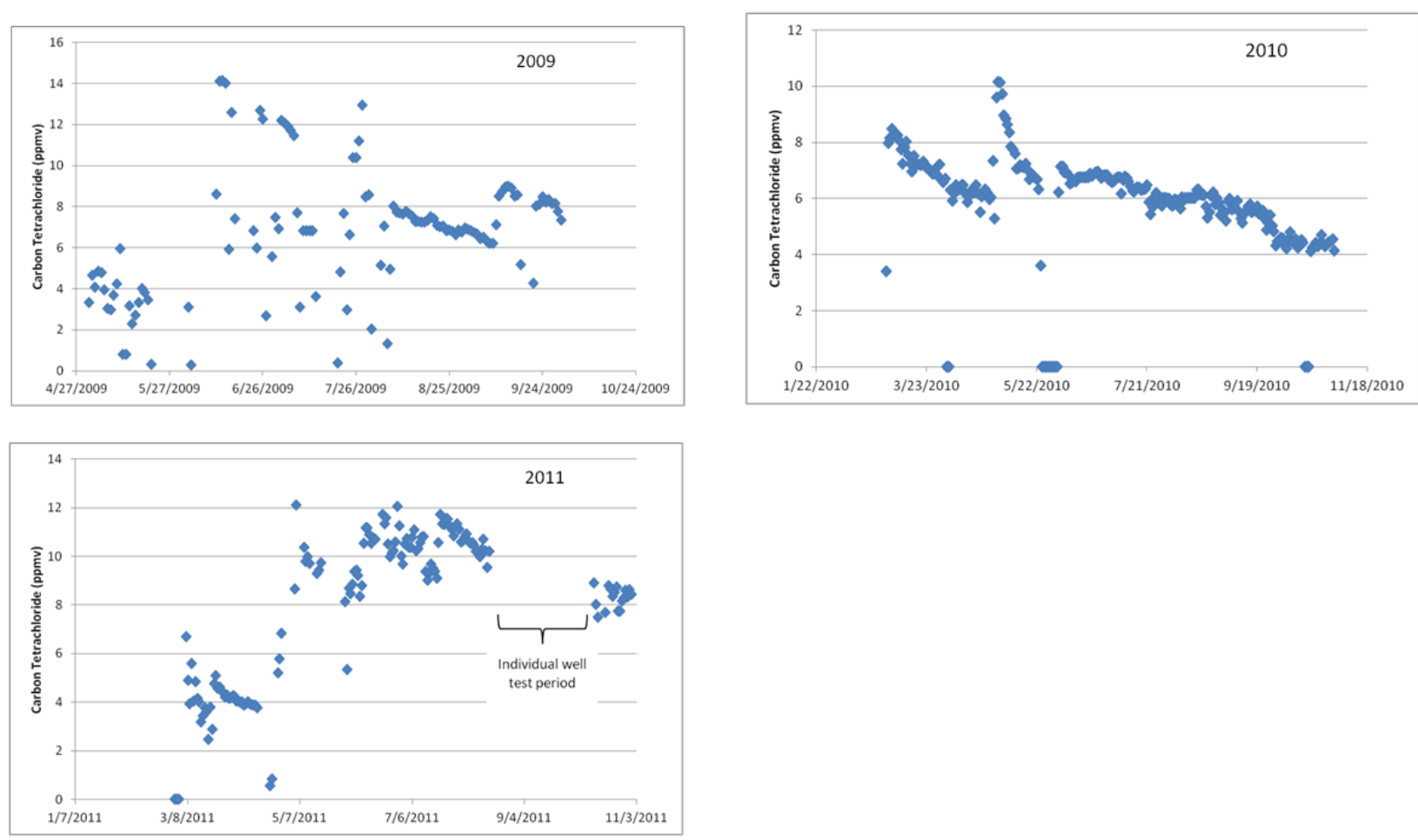

Figure 4.4. (contd)

Table 4.1. Computed Source Mass Discharge

\begin{tabular}{cc}
\hline Year & $\begin{array}{c}\text { Source Mass } \\
\text { Discharge }(\mathrm{g} / \mathrm{d})\end{array}$ \\
\hline 1997 & 820 \\
1998 & 780 \\
1999 & 350 \\
2001 & 520 \\
2002 & 1300 \\
2005 & 730 \\
2006 & 60 \\
2007 & 270 \\
2008 & 150 \\
2010 & 70 \\
\hline
\end{tabular}




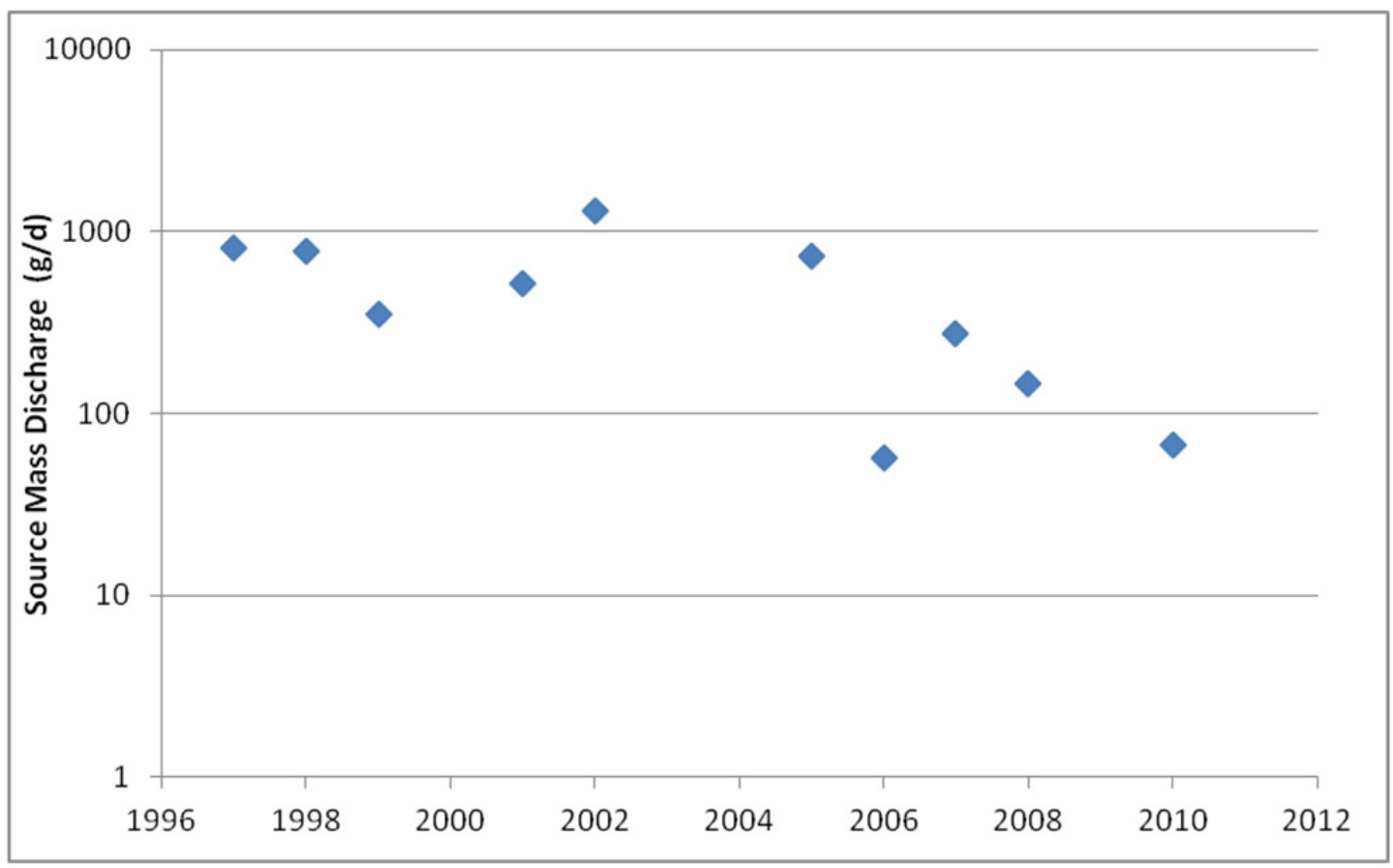

Figure 4.5. Time Series of Computed Source Mass Discharge, 1997-2010

\subsubsection{Source Size and Location: Single-Well Test}

Several types of data were collected for the single-well tests as described in the next sections.

\subsubsection{Concentration and Flow Data}

The single-well tests were conducted from August 16 through September 27, 2011, during the end of the operational cycle for 2011. The single-well tests were scheduled with (when possible) alternating tests above and below the CCU (or alternating locations across the site) to minimize interference between tests. To evaluate any potential changes in the site conditions during the test period (e.g., change in concentration due to rebound during the testing), the full SVE system was restarted after the individual well testing using the same well configuration as before the single-well tests (i.e., all wells on). The comparison of flow rate and concentration measured at the SVE system before and after the single-well testing is presented in Figure 4.6. These results show that no significant changes in concentration occurred during the single-well testing, suggesting that conditions over the duration of the single-well tests were relatively steady.

The data collected for each single-well test are shown in the following set of figures and tables. A summary of the data collected during the single-well testing is presented in Table 4.2, indicating wells that required the bleed valve to be open during the test. In addition, the flow rate, concentration, and vacuum data were averaged over the single-well test timeframe for comparison between well locations. 
Date/Time (After)

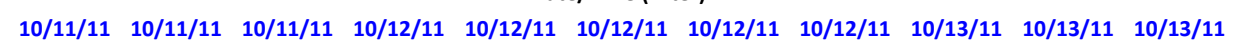

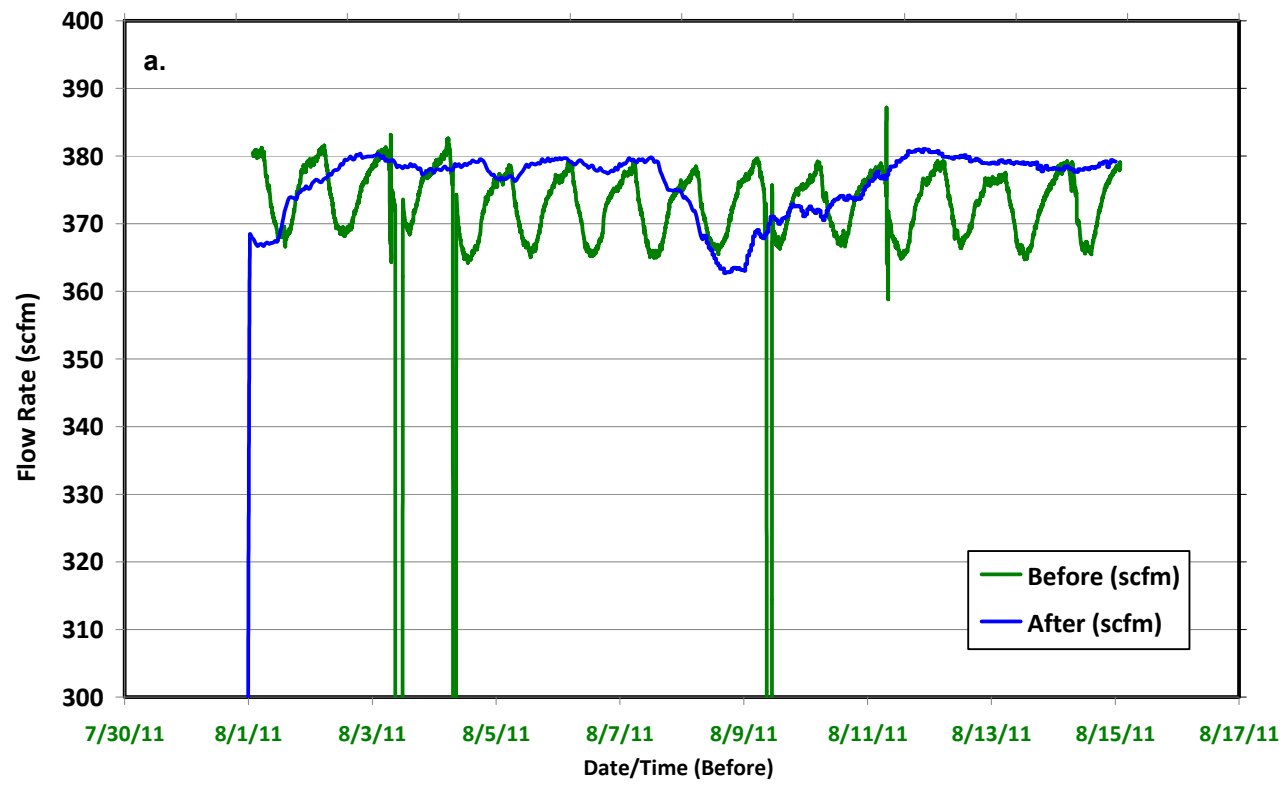

Date/Time (After)

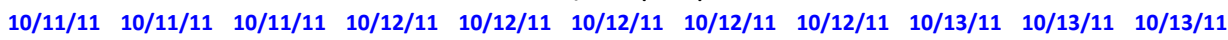

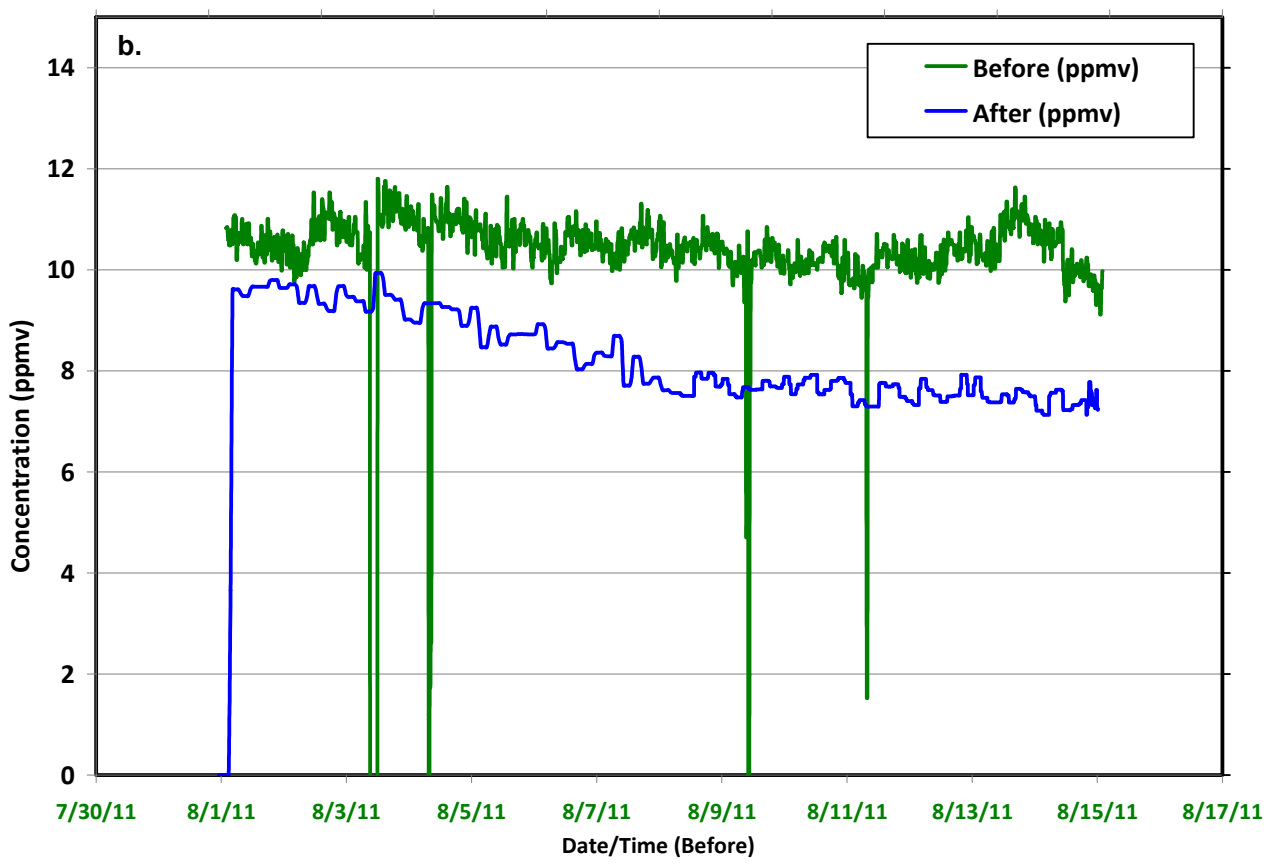

Figure 4.6. Comparison of Flow Rates (a) and CT Concentrations (b) from the SVE System Before and After the Single-Well Testing Period 
Table 4.2. Summary of Average Values Monitored during Individual Testing After Concentration and Flow-Rate Corrections. Well names highlighted yellow and blue are above and below the CCU, respectively. The 299-W15 prefix has been omitted from all well names.

\begin{tabular}{|c|c|c|c|c|c|c|}
\hline $\begin{array}{l}\text { Start } \\
\text { Date }\end{array}$ & Stressed Well & $\begin{array}{l}\text { Bleed } \\
\text { Valve }\end{array}$ & $\begin{array}{l}\text { Mean Flow } \\
\text { Rate (scfm) }\end{array}$ & $\begin{array}{l}\text { Mean Vac } \\
\text { (in } \mathrm{Hg} \text { ) }\end{array}$ & $\begin{array}{l}\text { Mean Conc } \\
\text { (ppmv) }\end{array}$ & $\begin{array}{c}\text { Mean Conc } \\
(\mathrm{mg} / \mathrm{L})\end{array}$ \\
\hline $8 / 17$ & $9 \mathrm{U}$ & Open & 78.7 & 6.61 & 5.95 & 0.04 \\
\hline $8 / 18$ & 8L (weekend) & Open & 36.1 & 6.11 & 7.54 & 0.05 \\
\hline $8 / 22$ & $84 \mathrm{U}$ & Closed & 151.1 & 7.31 & 3.10 & 0.02 \\
\hline $8 / 23$ & $219 \mathrm{~L}$ & Open & 58.1 & 6.03 & 11.48 & 0.07 \\
\hline $8 / 24$ & $95 \mathrm{U}$ & Closed & 157.6 & 6.78 & 3.10 & 0.02 \\
\hline $8 / 25$ & 95L (weekend) & Open & 144.5 & 6.87 & 11.07 & 0.07 \\
\hline $8 / 29$ & 48 & Open & 116.0 & 6.53 & 11.70 & 0.07 \\
\hline $8 / 30$ & 85 & Open & 132.5 & 7.38 & 1.70 & 0.01 \\
\hline $8 / 31$ & 86 & Open & 107.8 & 6.51 & 19.77 & 0.12 \\
\hline $9 / 1$ & 218U (weekend) & Open & 87.3 & 7.92 & 2.34 & 0.01 \\
\hline $9 / 6$ & $216 \mathrm{~L}$ & Open & 36.4 & 7.67 & 3.82 & 0.02 \\
\hline 9/7 & $218 \mathrm{~L}$ & Open & 80.6 & 6.95 & 6.86 & 0.04 \\
\hline $9 / 8$ & 82 (weekend) & Open & NA & 7.35 & NA & NA \\
\hline $9 / 12$ & 32 & Open & 134.6 & 8.01 & 5.14 & 0.03 \\
\hline $9 / 13$ & 86 & Open & 118.0 & 7.21 & 17.23 & 0.11 \\
\hline $9 / 14$ & $84 \mathrm{~L}$ & Open & 79.7 & 7.11 & 10.55 & 0.07 \\
\hline $9 / 15$ & 8U (weekend) & Open & 72.0 & 8.06 & 11.41 & 0.07 \\
\hline 9/19 & $220 \mathrm{~L}$ & Open & 75.2 & 7.92 & 7.05 & 0.04 \\
\hline $9 / 20$ & 217 & Closed & 134.2 & 8.97 & 10.11 & 0.06 \\
\hline $9 / 21$ & $216 \mathrm{U}$ & Open & 81.9 & 5.47 & 5.49 & 0.03 \\
\hline $9 / 22$ & 223 & Closed & 151.6 & 7.82 & 4.47 & 0.03 \\
\hline $9 / 26$ & $220 \mathrm{U}$ & Open & 101.3 & 8.04 & 8.86 & 0.06 \\
\hline $9 / 27$ & $219 \mathrm{U}$ & Open & 94.0 & 8.49 & 2.18 & 0.01 \\
\hline
\end{tabular}

A summary of the summa canister sample analysis results is presented in Table 4.3, including the samples collected at the beginning (start sample) and end (stop sample) of each individual well test, the ambient blank samples, and duplicate or replicate samples. The summa concentrations, in general, were consistent with the SVE system in-line GC analysis results. The blank samples ranged from nondetection to $0.016 \mathrm{ppmv}$. The duplicate or replicate samples were collected in series within a few minutes of each other. However, these samples were generally collected at the beginning of a new test and some variability was observed. Based on the SVE system GC results, variability appears to be mostly associated with actual variations in vapor concentrations (Table 4.4). 
Table 4.3. Summary of the Summa Canister Sample Analysis Results

\begin{tabular}{|c|c|c|c|c|c|}
\hline Sample ID & Collection Date & CT (ppmv) & Location & Sample Name & Sample Type \\
\hline $\mathrm{B} 2 \mathrm{H} 2 \mathrm{~N} 2$ & 8/17/2011 10:07 & 2.46 & 299-W15-9U & 299-W15-9U-1 & Start Sample \\
\hline $\mathrm{B} 2 \mathrm{H} 2 \mathrm{~N} 3$ & 8/18/2011 7:41 & 5.64 & 299-W15-9U & 299-W15-9U-2 & Stop Sample \\
\hline $\mathrm{B} 2 \mathrm{H} 2 \mathrm{P} 1$ & $8 / 18 / 20117: 47$ & 0.0126 & - & Ambient Field Blank-4 & Blank \\
\hline $\mathrm{B} 2 \mathrm{H} 2 \mathrm{P} 8$ & 8/18/2011 9:28 & 5.69 & 299-W15-8L & 299-W15-8L-1 & Start Sample \\
\hline $\mathrm{B} 2 \mathrm{H} 2 \mathrm{P} 0$ & $8 / 18 / 20119: 36$ & 2.26 & 299-W15-8L & $\begin{array}{c}\text { 299-W15-8L-3 } \\
\text { (duplicate) }\end{array}$ & Duplicate \\
\hline В2H2P9 & $8 / 22 / 20119: 38$ & 9.71 & 299-W15-8L & 299-W15-8L-2 & Stop Sample \\
\hline B2H2R3 & $8 / 22 / 20119: 47$ & 0 & - & Ambient Field Blank-5 & Blank \\
\hline $\mathrm{B} 2 \mathrm{H} 2 \mathrm{~N} 8$ & $8 / 22 / 2011 \quad 10: 51$ & 1.61 & 299-W15-84U & 299-W15-84U-1 & Start Sample \\
\hline $\mathrm{B} 2 \mathrm{H} 2 \mathrm{R} 2$ & $8 / 22 / 201110: 56$ & 1.51 & 299-W18-84U & $\begin{array}{l}\text { 299-W18-84U-3 } \\
\text { (duplicate) }\end{array}$ & Duplicate \\
\hline $\mathrm{B} 2 \mathrm{H} 2 \mathrm{~N} 9$ & $8 / 23 / 20118: 01$ & 3.59 & 299-W15-84U & 299-W15-84U-2 & Stop Sample \\
\hline B2H2T2 & $8 / 23 / 20119: 30$ & 12.8 & 299-W15-219L & 299-W15-219L-1 & Start Sample \\
\hline В2H2T3 & 8/24/2011 8:14 & 12.8 & 299-W15-219L & 299-W15-219L-2 & Stop Sample \\
\hline B2H2P4 & $8 / 24 / 201110: 18$ & 1.34 & 299-W15-95U & 299-W15-95U-1 & Start Sample \\
\hline B2H2P5 & 8/25/2011 8:07 & 4.24 & 299-W15-95U & 299-W15-95U-2 & Stop Sample \\
\hline B2H2R6 & $8 / 25 / 20119: 23$ & 11.5 & 299-W15-95L & 299-W15-95L-1 & Start Sample \\
\hline B2H2R7 & $8 / 29 / 20118: 22$ & 11.5 & 299-W15-95L & 299-W15-95L-2 & Stop Sample \\
\hline B2H2T5 & $8 / 29 / 20119: 20$ & 0 & - & Ambient Field Blank-6 & Blank \\
\hline $\mathrm{B} 2 \mathrm{H} 2 \mathrm{~N} 4$ & $8 / 29 / 20119: 30$ & 12.8 & 299-W15-48 & 299-W15-48-1 & Start Sample \\
\hline В2H2T4 & $8 / 29 / 20119: 36$ & 13 & $299-W 15-48$ & $\begin{array}{l}\text { 299-W15-48-3 } \\
\text { (duplicate) }\end{array}$ & Duplicate \\
\hline $\mathrm{B} 2 \mathrm{H} 2 \mathrm{~N} 5$ & $8 / 30 / 20117: 39$ & 12.4 & 299-W15-48 & $299-W 15-48-2$ & Stop Sample \\
\hline $\mathrm{B} 2 \mathrm{H} 2 \mathrm{P} 2$ & $8 / 30 / 20119: 15$ & 0.628 & 299-W15-85 & $299-W 15-85-1$ & Start Sample \\
\hline $\mathrm{B} 2 \mathrm{H} 2 \mathrm{P} 3$ & $8 / 31 / 20117: 46$ & 2.42 & 299-W15-85 & $299-W 15-85-2$ & Stop Sample \\
\hline $\mathrm{B} 2 \mathrm{H} 2 \mathrm{R} 4$ & $8 / 31 / 20119: 48$ & 37.5 & $299-W 15-86$ & 299-W15-86-1 & Start Sample \\
\hline $\mathrm{B} 2 \mathrm{H} 2 \mathrm{R} 5$ & 9/1/2011 7:49 & 24.9 & 299-W15-86 & 299-W15-86-2 & Stop Sample \\
\hline $\mathrm{B} 2 \mathrm{H} 2 \mathrm{~V} 0$ & 9/1/2011 9:41 & 2.36 & 299-W15-218U & 299-W15-218U-1 & Start Sample \\
\hline $\mathrm{B} 2 \mathrm{H} 2 \mathrm{~V} 1$ & $9 / 6 / 20117: 50$ & 3.94 & 299-W15-218U & 299-W15-218U-2 & Stop Sample \\
\hline $\mathrm{B} 2 \mathrm{H} 2 \mathrm{~V} 7$ & 9/6/20119:36 & 0.0122 & - & Ambient Field Blank-7 & Blank \\
\hline $\mathrm{B} 2 \mathrm{H} 2 \mathrm{R} 8$ & 9/6/2011 9:44 & 5.2 & 299-W15-216L & 299-W15-216L-1 & Start Sample \\
\hline $\mathrm{B} 2 \mathrm{H} 2 \mathrm{~V} 6$ & 9/6/2011 9:49 & 5.01 & 299-W15-216L & $\begin{array}{l}\text { 299-W15-216L-3 } \\
\text { (duplicate) }\end{array}$ & Duplicate \\
\hline B2H2R9 & 9/7/2011 7:55 & 6.63 & 299-W15-216L & 299-W15-216L-2 & Stop Sample \\
\hline В2Н2T0 & 9/7/2011 8:49 & 5.99 & 299-W15-218L & 299-W15-218L-1 & Start Sample \\
\hline B2H2T1 & 9/8/2011 8:06 & 6.66 & 299-W15-218L & 299-W15-218L-2 & Stop Sample \\
\hline $\mathrm{B} 2 \mathrm{H} 2 \mathrm{~N} 6$ & 9/8/2011 9:27 & 1.39 & 299-W15-82 & 299-W15-82-1 & Start Sample \\
\hline $\mathrm{B} 2 \mathrm{H} 2 \mathrm{~N} 7$ & 9/12/2011 7:55 & 2.94 & 299-W15-82 & 299-W15-82-2 & Stop Sample \\
\hline В2H566 & 9/12/2011 9:05 & 0 & - & Ambient Field Blank-8 & Blank \\
\hline В2H2T6 & 9/12/2011 9:15 & 3.28 & $299-W 15-32$ & 299-W15-32-1 & Start Sample \\
\hline В2H564 & 9/12/2011 9:21 & 24.3 & 299-W15-32 & $\begin{array}{l}\text { 299-W15-32-3 } \\
\text { (duplicate) }\end{array}$ & Duplicate \\
\hline В2H2T7 & 9/13/2011 7:58 & 5.85 & 299-W15-32 & 299-W15-32-2 & Stop Sample \\
\hline
\end{tabular}


Table 4.3. (contd)

\begin{tabular}{|c|c|c|c|c|c|}
\hline Sample ID & Collection Date & CT (ppmv) & Location & Sample Name & Sample Type \\
\hline B2H565 & 9/13/2011 9:59 & 3.29 & 299-W15-86 & 299-W15-86-1 & Start Sample \\
\hline B2HRJ3 & 9/14/2011 8:19 & 0 & 299-W15-86 & $299-W 15-86-2$ & Stop Sample \\
\hline $\mathrm{B} 2 \mathrm{H} 2 \mathrm{R} 0$ & 9/14/2011 10:17 & 10.3 & 299-W15-84L & 299-W15-84L-1 & Start Sample \\
\hline $\mathrm{B} 2 \mathrm{H} 2 \mathrm{R} 1$ & 9/15/2011 8:06 & 11.3 & 299-W15-84L & 299-W15-84L-2 & Stop Sample \\
\hline $\mathrm{B} 2 \mathrm{H} 2 \mathrm{~N} 0$ & 9/15/2011 9:13 & 5.65 & 299-W15-8U & 299-W15-8U-1 & Start Sample \\
\hline $\mathrm{B} 2 \mathrm{H} 2 \mathrm{~N} 1$ & 9/19/2011 7:54 & 11.8 & 299-W15-8U & 299-W15-8U-2 & Stop Sample \\
\hline B2H567 & 9/19/2011 10:00 & 0 & - & Ambient Field Blank-9 & Blank \\
\hline B2HRJ4 & 9/19/2011 10:11 & 3.96 & 299-W15-220L & 299-W15-220L-1 & Start Sample \\
\hline B2HRJ5 & 9/19/2011 10:17 & 2.44 & 299-W15-220L & $\begin{array}{l}\text { 299-W15-220L-3 } \\
\text { (duplicate) }\end{array}$ & Duplicate \\
\hline B2HRM1 & 9/20/2011 8:03 & 8.11 & 299-W15-220L & 299-W15-220L-2 & Stop Sample \\
\hline В2H2T8 & 9/20/2011 9:13 & 1.17 & 299-W15-217 & 299-W15-217-1 & Start Sample \\
\hline В2H2T9 & 9/21/2011 8:01 & 3.16 & 299-W15-217 & 299-W15-217-2 & Stop Sample \\
\hline B2H2P6 & 9/21/2011 11:04 & 3.77 & 299-W15-216U & 299-W15-216U-1 & Start Sample \\
\hline В2H2P7 & 9/22/2011 7:50 & 5.03 & 299-W15-216U & 299-W15-216U-2 & Stop Sample \\
\hline $\mathrm{B} 2 \mathrm{H} 2 \mathrm{~V} 8$ & $9 / 22 / 201110: 01$ & 5.44 & 299-W15-223 & 299-W15-223-1 & Start Sample \\
\hline $\mathrm{B} 2 \mathrm{H} 2 \mathrm{~V} 9$ & 9/26/2011 7:59 & 1.28 & 299-W15-223 & 299-W15-223-2 & Stop Sample \\
\hline B2H568 & 9/26/2011 9:10 & 0.0162 & -- & $\begin{array}{l}\text { Ambient Field } \\
\text { Blank-10 }\end{array}$ & Blank \\
\hline $\mathrm{B} 2 \mathrm{H} 2 \mathrm{~V} 4$ & 9/26/2011 9:19 & 7.58 & $299-W 15-220 U$ & 299-W15-220U-1 & Start Sample \\
\hline $\mathrm{B} 2 \mathrm{H} 2 \mathrm{~V} 5$ & 9/27/2011 7:57 & 5.53 & 299-W15-220U & 299-W15-220U-2 & Stop Sample \\
\hline $\mathrm{B} 2 \mathrm{H} 2 \mathrm{~V} 2$ & 9/27/2011 9:21 & 1.68 & 299-W15-219U & 299-W15-219U-1 & Start Sample \\
\hline $\mathrm{B} 2 \mathrm{H} 2 \mathrm{~V} 3$ & 9/28/2011 7:49 & 2.44 & 299-W15-219U & 299-W15-219U-2 & Stop Sample \\
\hline
\end{tabular}


Table 4.4. Summary of the Summa Canister Duplicate or Replicate Sample Analysis Results

\begin{tabular}{|c|c|c|c|c|c|}
\hline Sample ID & $\begin{array}{l}\text { Collection } \\
\text { Date }\end{array}$ & $\mathrm{CT}$ (ppmv) & $\begin{array}{c}\text { Comparability (\% } \\
\text { Difference) }\end{array}$ & Sample Name & Sample Type \\
\hline $\mathrm{B} 2 \mathrm{H} 2 \mathrm{P} 8$ & $\begin{array}{l}8 / 18 / 2011 \\
9: 28\end{array}$ & 5.69 & $\begin{array}{c}\text { High Initial } \\
\text { Variability }\end{array}$ & 299-W15-8L-1 & Start Sample \\
\hline B2H2P0 & $\begin{array}{l}8 / 18 / 2011 \\
9: 36\end{array}$ & 2.26 & 60 & 299-W15-8L-3 (duplicate) & Duplicate \\
\hline $\mathrm{B} 2 \mathrm{H} 2 \mathrm{~N} 8$ & $\begin{array}{l}8 / 22 / 2011 \\
10: 51\end{array}$ & 1.61 & Comparable & 299-W15-84U-1 & Start Sample \\
\hline $\mathrm{B} 2 \mathrm{H} 2 \mathrm{R} 2$ & $\begin{array}{l}8 / 22 / 2011 \\
10: 56\end{array}$ & 1.51 & 6 & 299-W18-84U-3 (duplicate) & Duplicate \\
\hline $\mathrm{B} 2 \mathrm{H} 2 \mathrm{~N} 4$ & $\begin{array}{l}8 / 29 / 2011 \\
9: 30\end{array}$ & 12.8 & Comparable & 299-W15-48-1 & Start Sample \\
\hline $\mathrm{B} 2 \mathrm{H} 2 \mathrm{~T} 4$ & $\begin{array}{l}8 / 29 / 2011 \\
9: 36\end{array}$ & 13 & 2 & 299-W15-48-3 (duplicate) & Duplicate \\
\hline $\mathrm{B} 2 \mathrm{H} 2 \mathrm{R} 8$ & 9/6/2011 9:44 & 5.2 & Comparable & 299-W15-216L-1 & Start Sample \\
\hline $\mathrm{B} 2 \mathrm{H} 2 \mathrm{~V} 6$ & 9/6/20119:49 & 5.01 & 4 & $\begin{array}{l}\text { 299-W15-216L-3 } \\
\text { (duplicate) }\end{array}$ & Duplicate \\
\hline В2H2Т6 & $\begin{array}{l}9 / 12 / 2011 \\
9: 15\end{array}$ & 3.28 & $\begin{array}{l}\text { Potential Analysis } \\
\text { Issue }\end{array}$ & 299-W15-32-1 & Start Sample \\
\hline B2H564 & $\begin{array}{l}9 / 12 / 2011 \\
9: 21\end{array}$ & 24.3 & 87 & 299-W15-32-3 (duplicate) & Duplicate \\
\hline B2HRJ4 & $\begin{array}{l}\text { 9/19/2011 } \\
10: 11\end{array}$ & 3.96 & $\begin{array}{l}\text { High Initial } \\
\text { Variability }\end{array}$ & 299-W15-220L-1 & Start Sample \\
\hline B2HRJ5 & $\begin{array}{l}9 / 19 / 2011 \\
10: 17\end{array}$ & 2.44 & 38 & $\begin{array}{l}\text { 299-W15-220L-3 } \\
\text { (duplicate) }\end{array}$ & Duplicate \\
\hline
\end{tabular}

The figures below (Figures 4.7 through 4.27) illustrate the transient behavior of CT concentration during each of the individual well tests by plotting the SVE system flow rate and concentration along with the summa canister sample results. CT concentrations in these figures have been corrected to account for dilution in cases where ambient air inflow was needed to maintain SVE blower operations. Tests requiring correction can be identified as those where the individual well extraction flow rate is different than the SVE system flow rate. Generally, the flow rates were extremely stable after an initial period of variation to establish a flow rate resulting in vacuum values that were comparable between tests. The magnitude of discharge from each well varied over time but not significantly. Results of laboratory analysis for samples collected at the beginning and end of each test are also shown on the figures for comparison to the on-line GC data from the SVE system. As mentioned above, some of the summa canister samples collected at the beginning of single-well tests were impacted by early time system variability. 


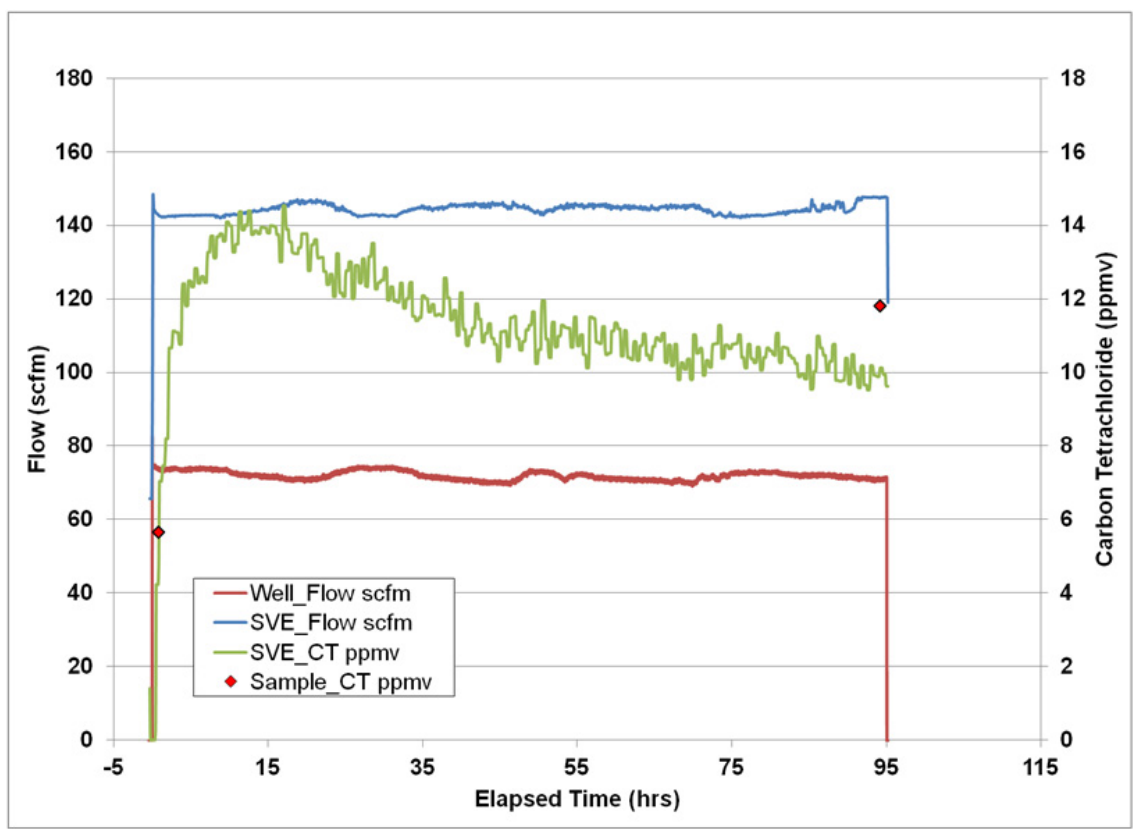

Figure 4.7. Well 299-W15-8U Single-Well Extraction SVE System CT Concentration and Flow-Rate and Extraction Well Monitoring System Flow-Rate Transient Data

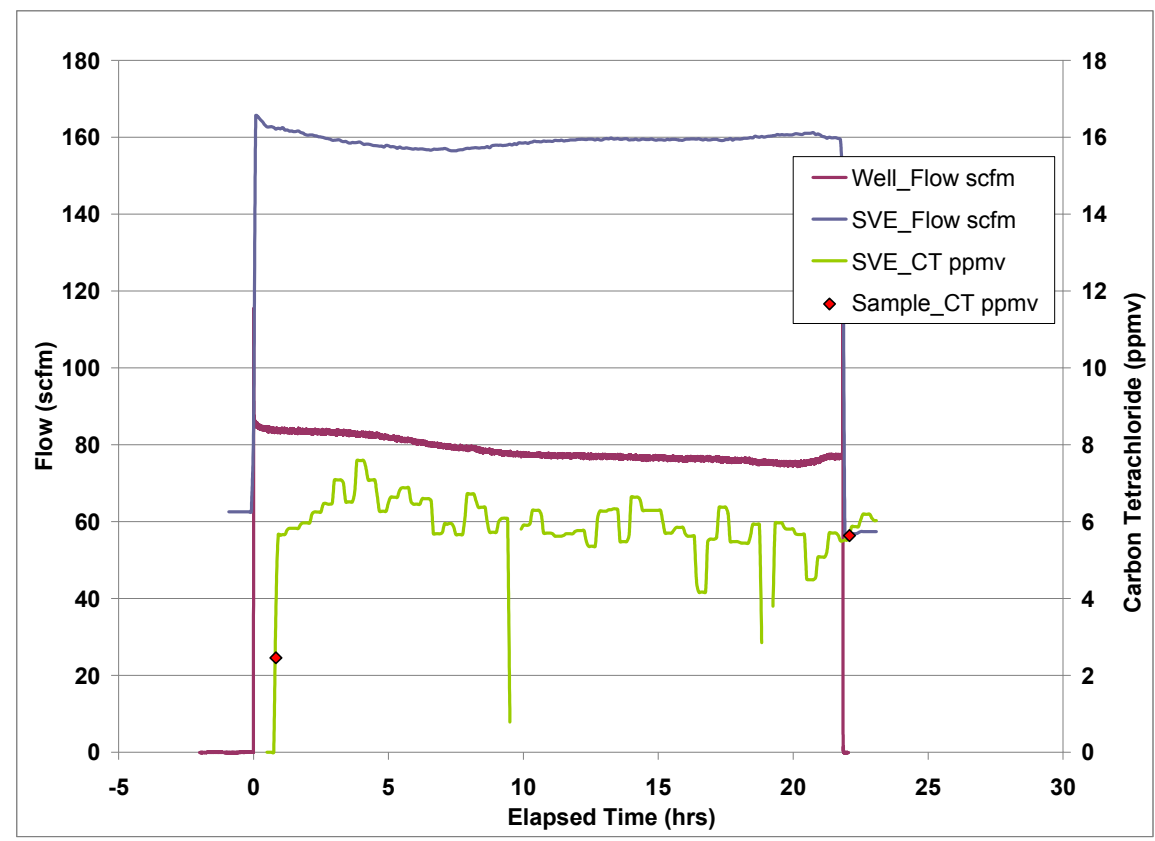

Figure 4.8. Well 299-W15-9U Single-Well Extraction SVE System CT Concentration and Flow-Rate and Extraction Well Monitoring System Flow-Rate Transient Data 


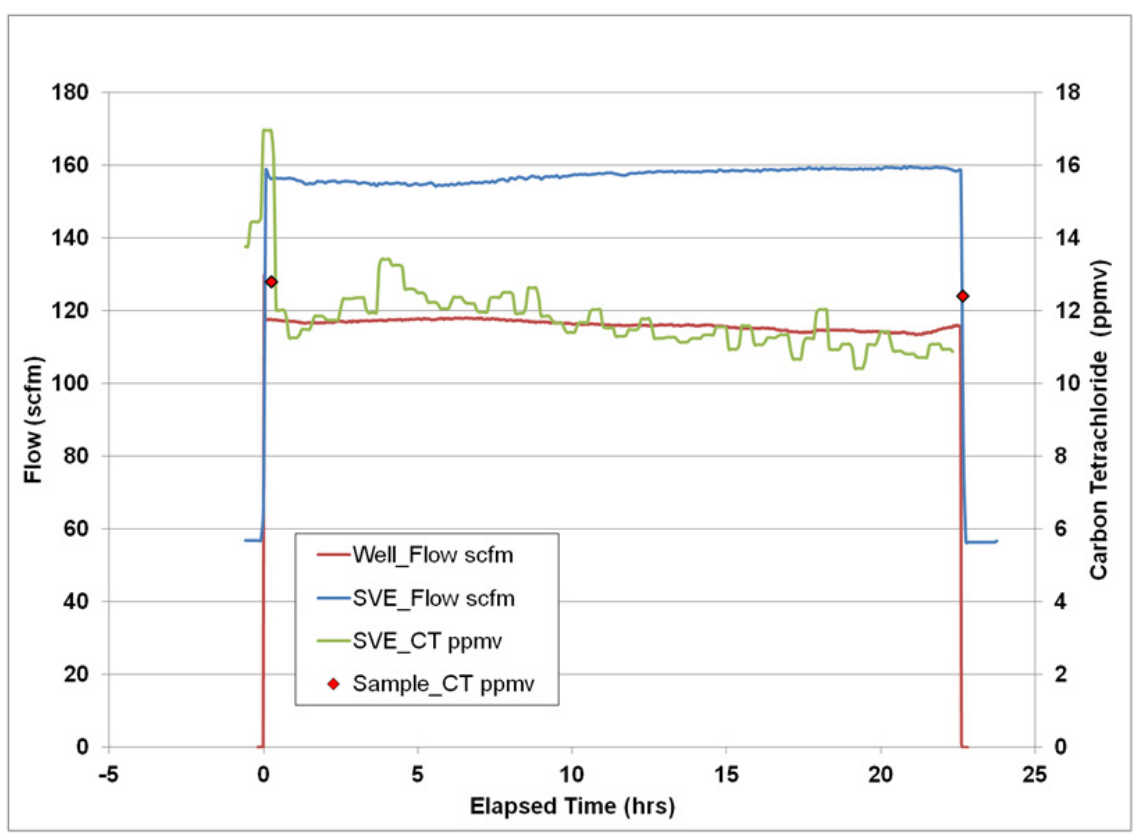

Figure 4.9. Well 299-W15-48 Single-Well Extraction SVE System CT Concentration and Flow-Rate and Extraction Well Monitoring System Flow-Rate Transient Data

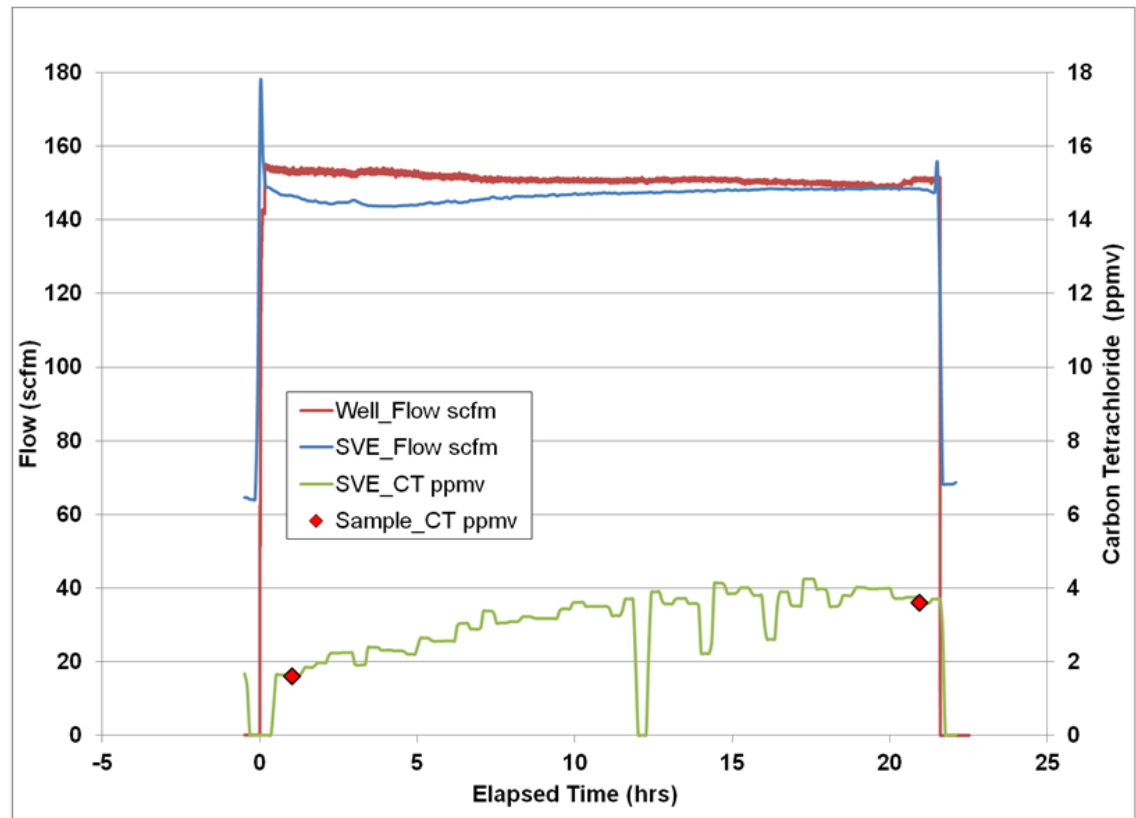

Figure 4.10. Well 299-W15-84U Single-Well Extraction SVE System CT Concentration and Flow-Rate and Extraction Well Monitoring System Flow-Rate Transient Data 


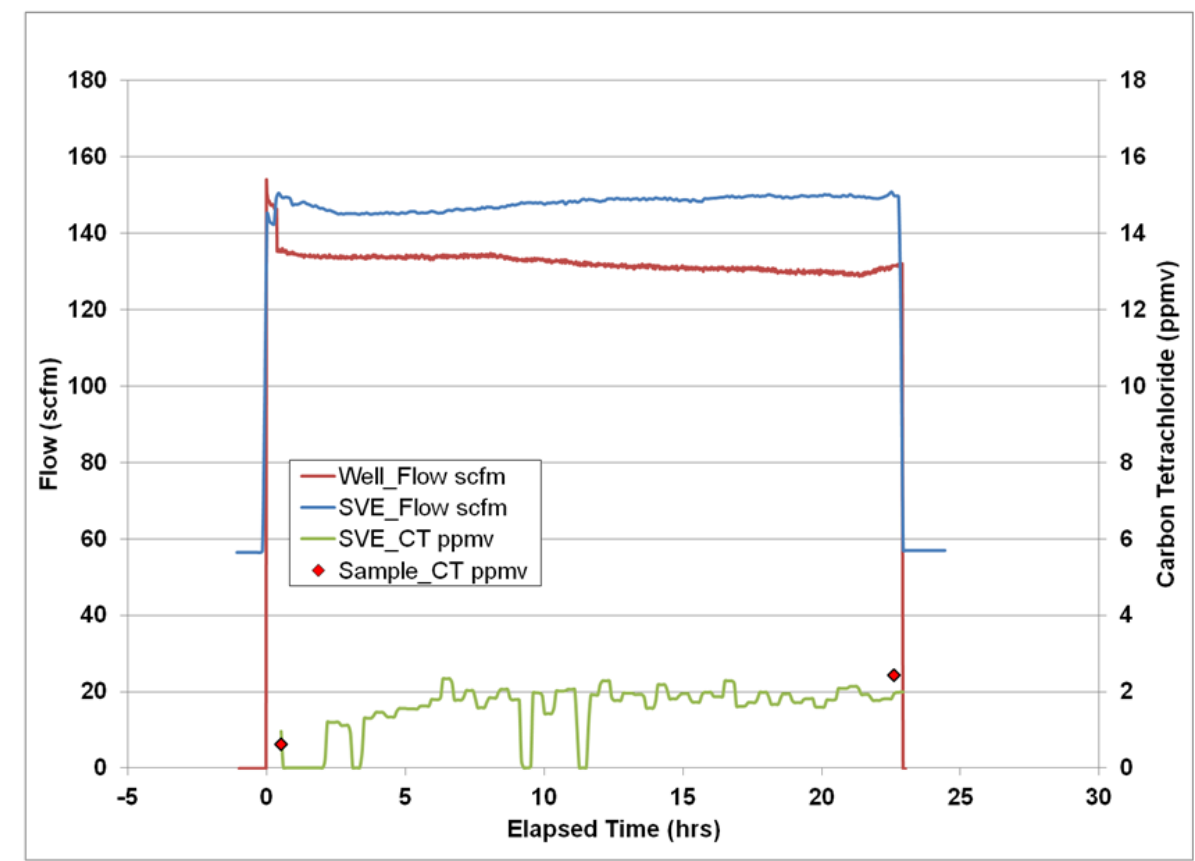

Figure 4.11. Well 299-W15-85 Single-Well Extraction SVE System CT Concentration and Flow-Rate and Extraction Well Monitoring System Flow-Rate Transient Data

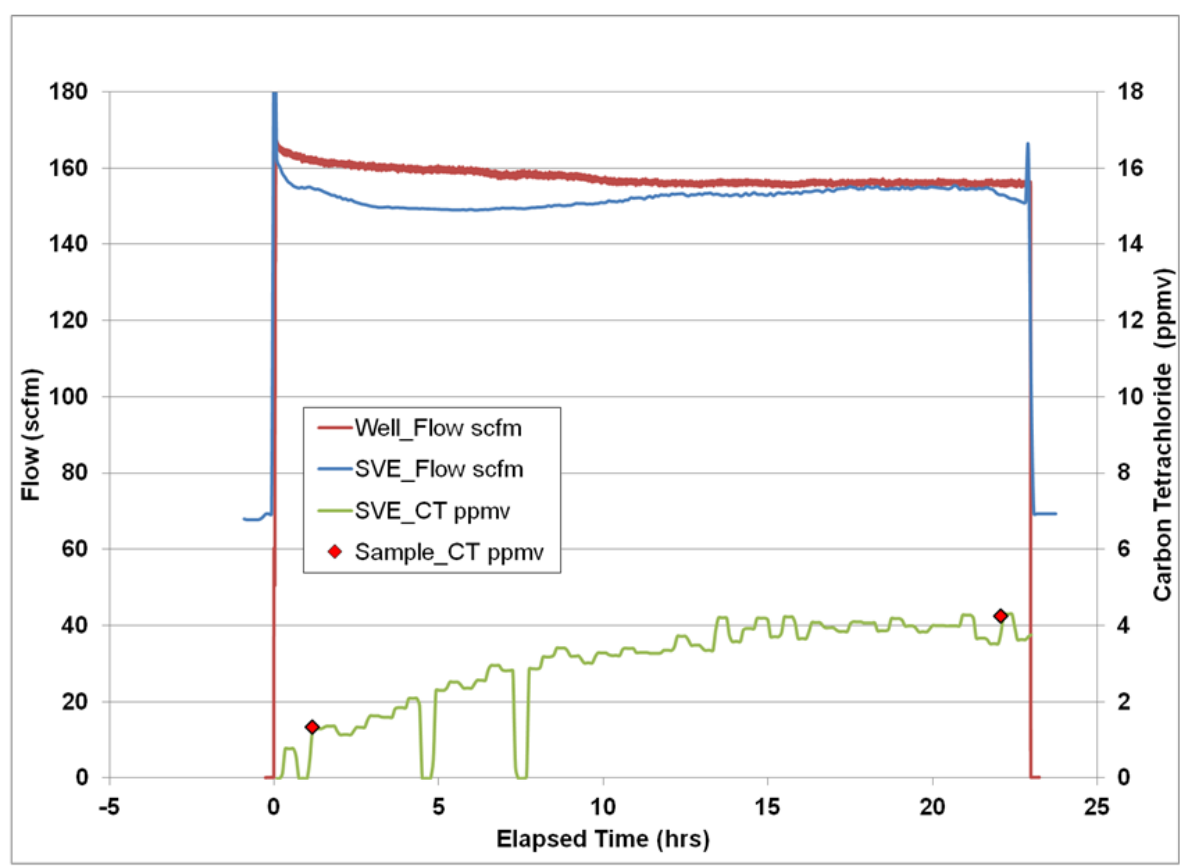

Figure 4.12. Well 299-W15-95U Single-Well Extraction SVE System CT Concentration and Flow-Rate and Extraction Well Monitoring System Flow-Rate Transient Data 


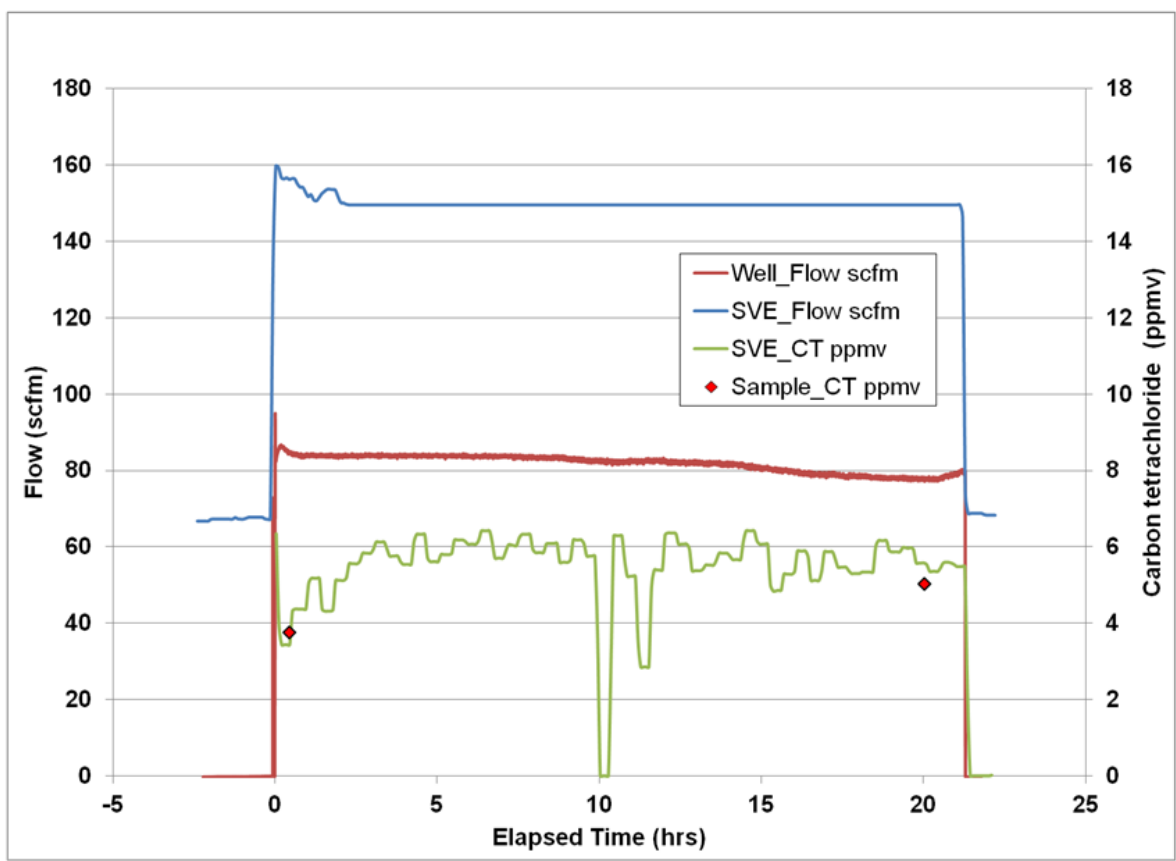

Figure 4.13. Well 299-W15-216U Single-Well Extraction SVE System CT Concentration and FlowRate and Extraction Well Monitoring System Flow-Rate Transient Data

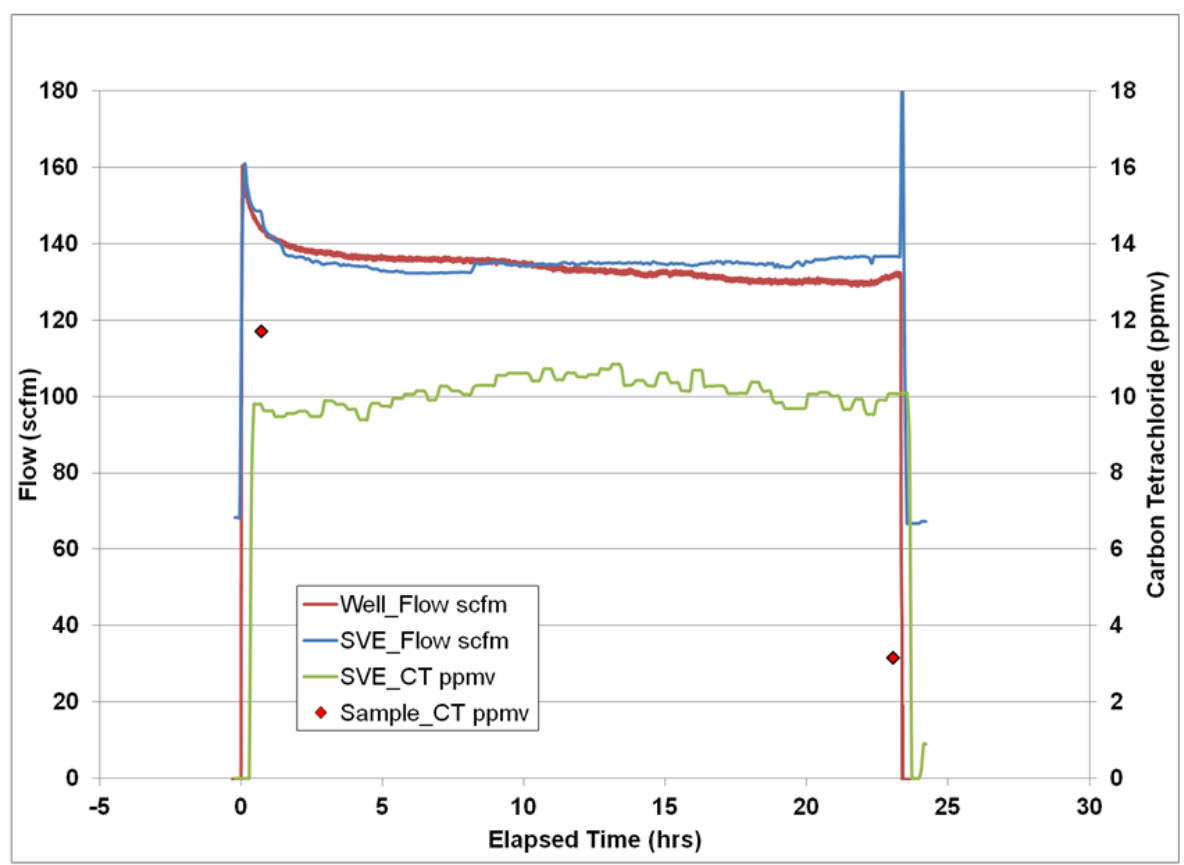

Figure 4.14. Well 299-W15-217 Single-Well Extraction SVE System CT Concentration and Flow-Rate and Extraction Well Monitoring System Flow-Rate Transient Data 


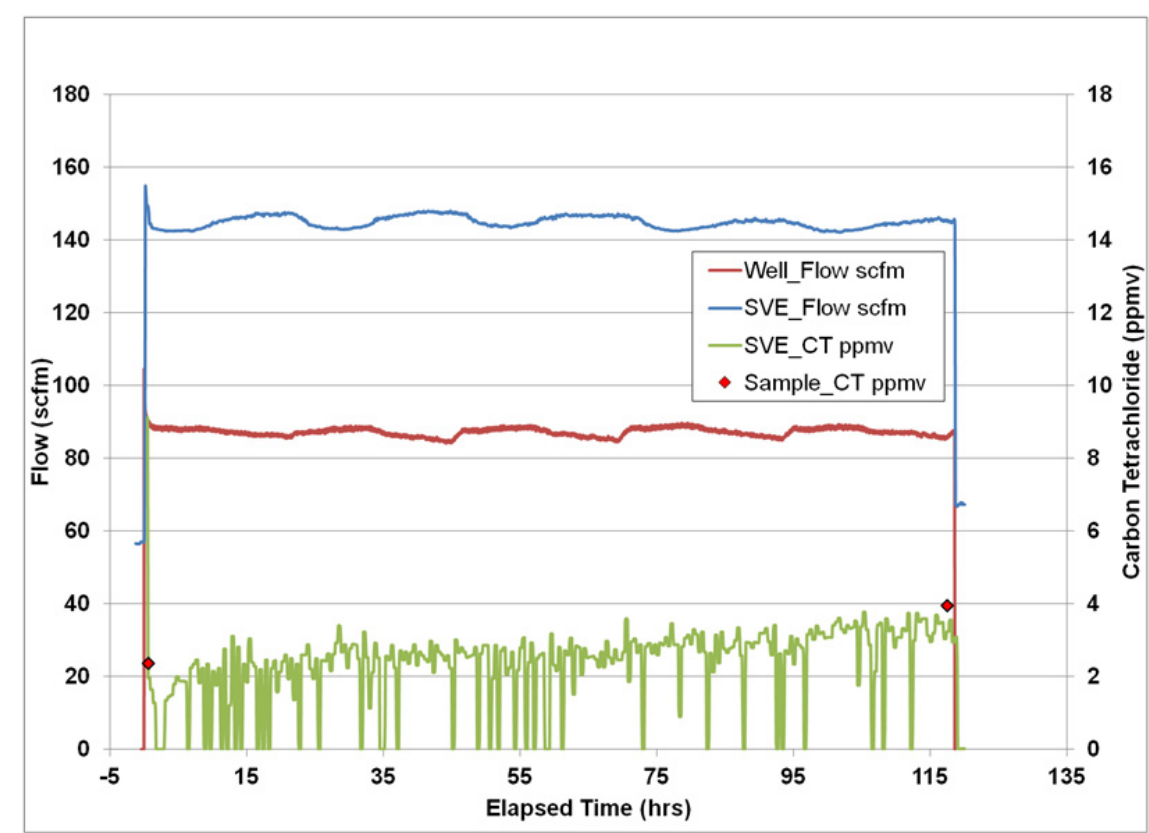

Figure 4.15. Well 299-W15-218U Single-Well Extraction SVE System CT Concentration and FlowRate and Extraction Well Monitoring System Flow-Rate Transient Data

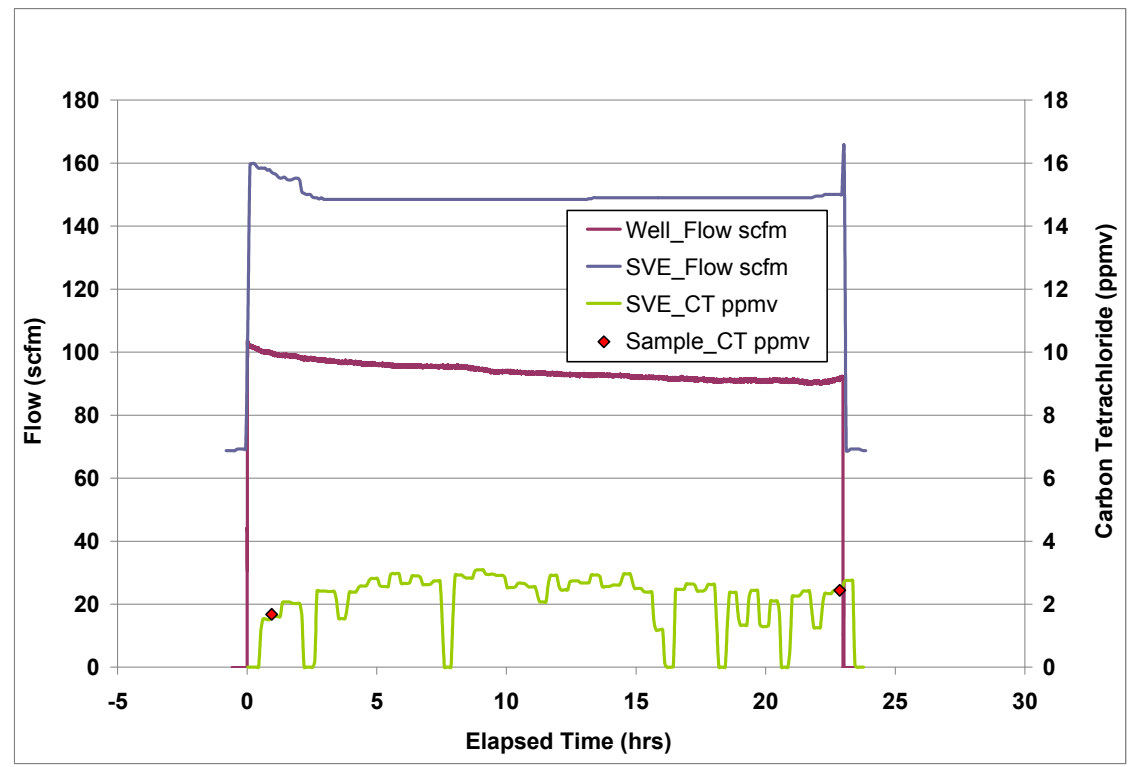

Figure 4.16. Well 299-W15-219U Single-Well Extraction SVE System CT Concentration and FlowRate and Extraction Well Monitoring System Flow-Rate Transient Data 


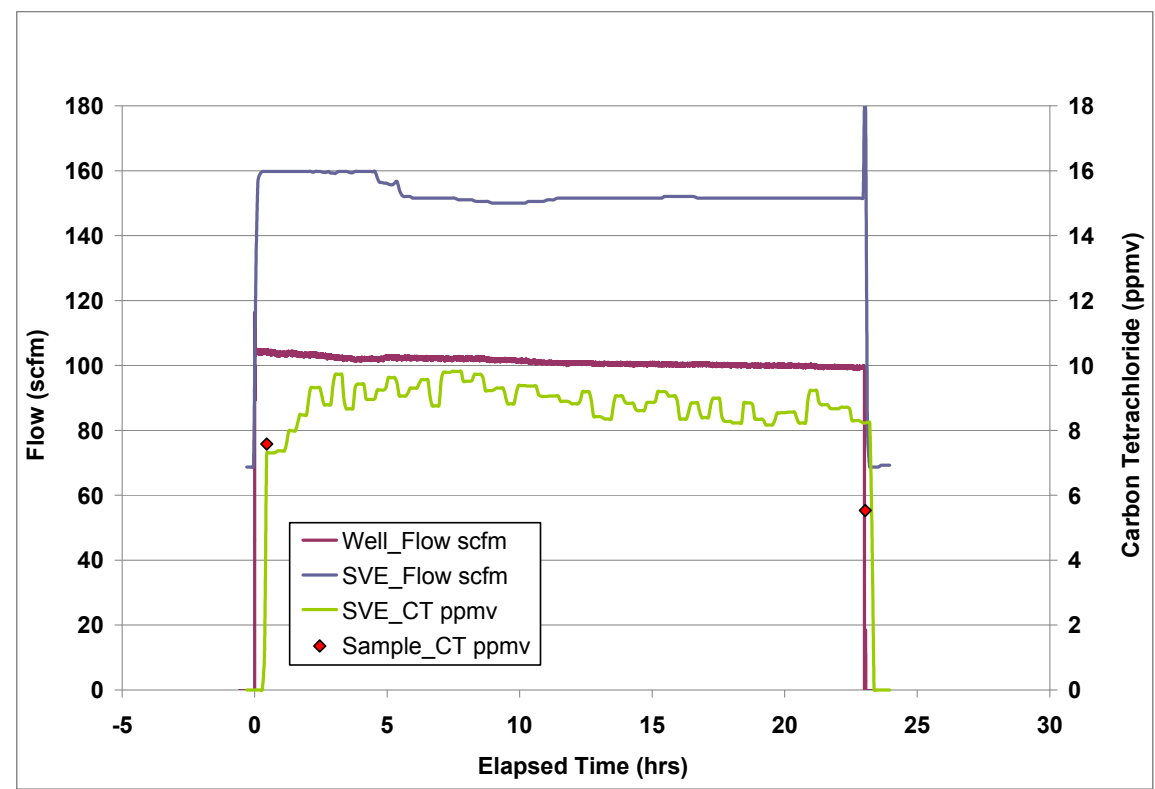

Figure 4.17. Well 299-W15-220U Single-Well Extraction SVE System CT Concentration and FlowRate and Extraction Well Monitoring System Flow-Rate Transient Data

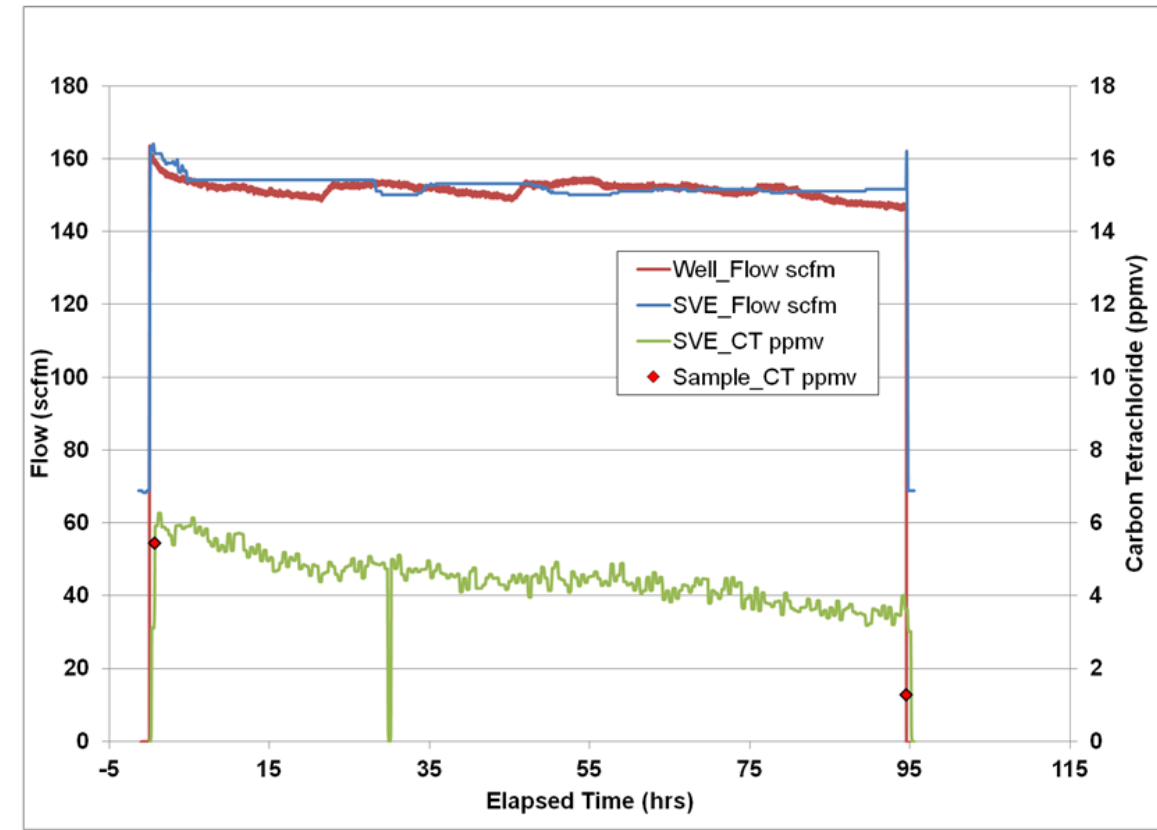

Figure 4.18. Well 299-W15-223 Single-Well Extraction SVE System CT Concentration and Flow-Rate and Extraction Well Monitoring System Flow-Rate Transient Data 


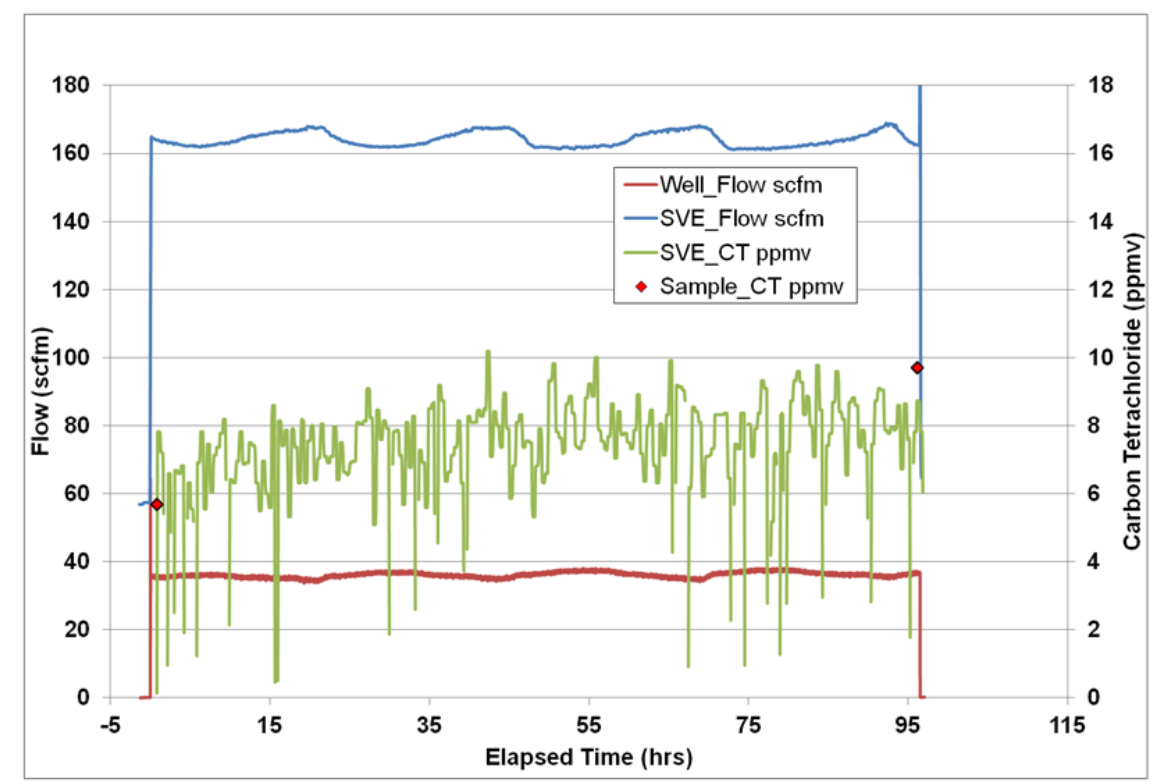

Figure 4.19. Well 299-W15-8L Single-Well Extraction SVE System CT Concentration and Flow-Rate and Extraction Well Monitoring System Flow-Rate Transient Data

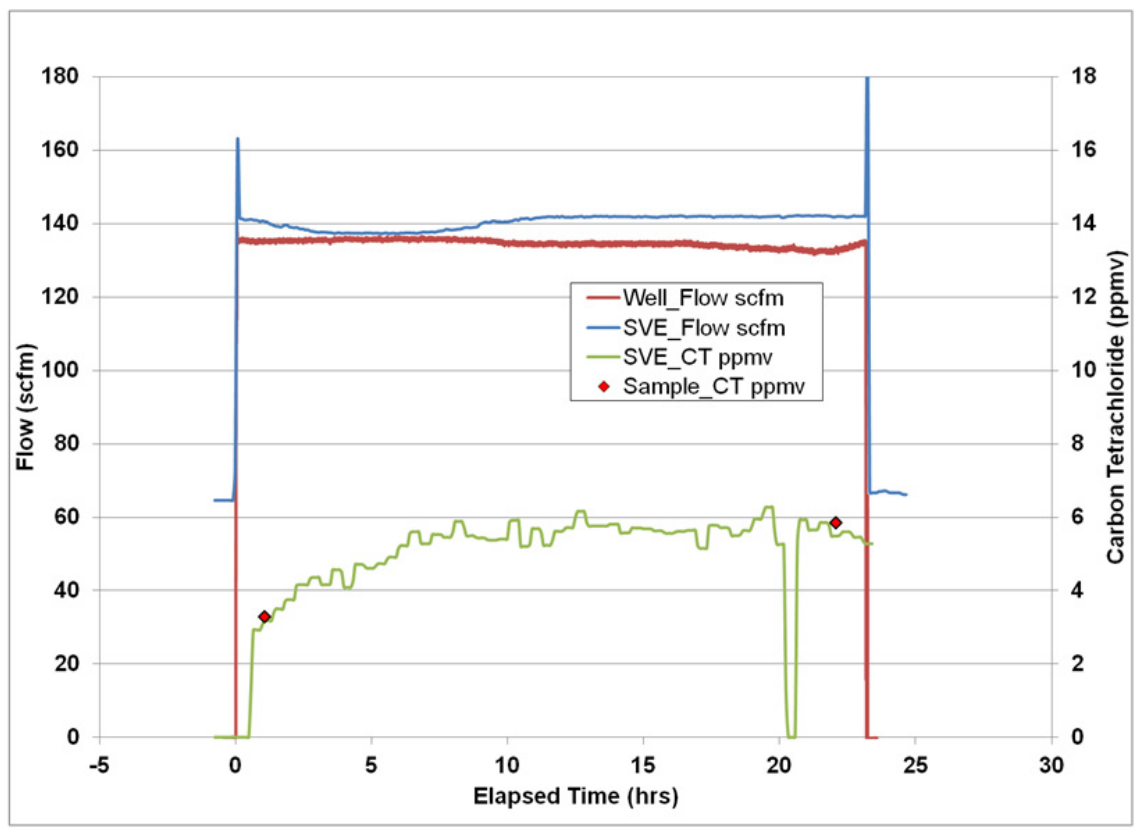

Figure 4.20. Well 299-W15-32 Single-Well Extraction SVE System CT Concentration and Flow-Rate and Extraction Well Monitoring System Flow-Rate Transient Data 


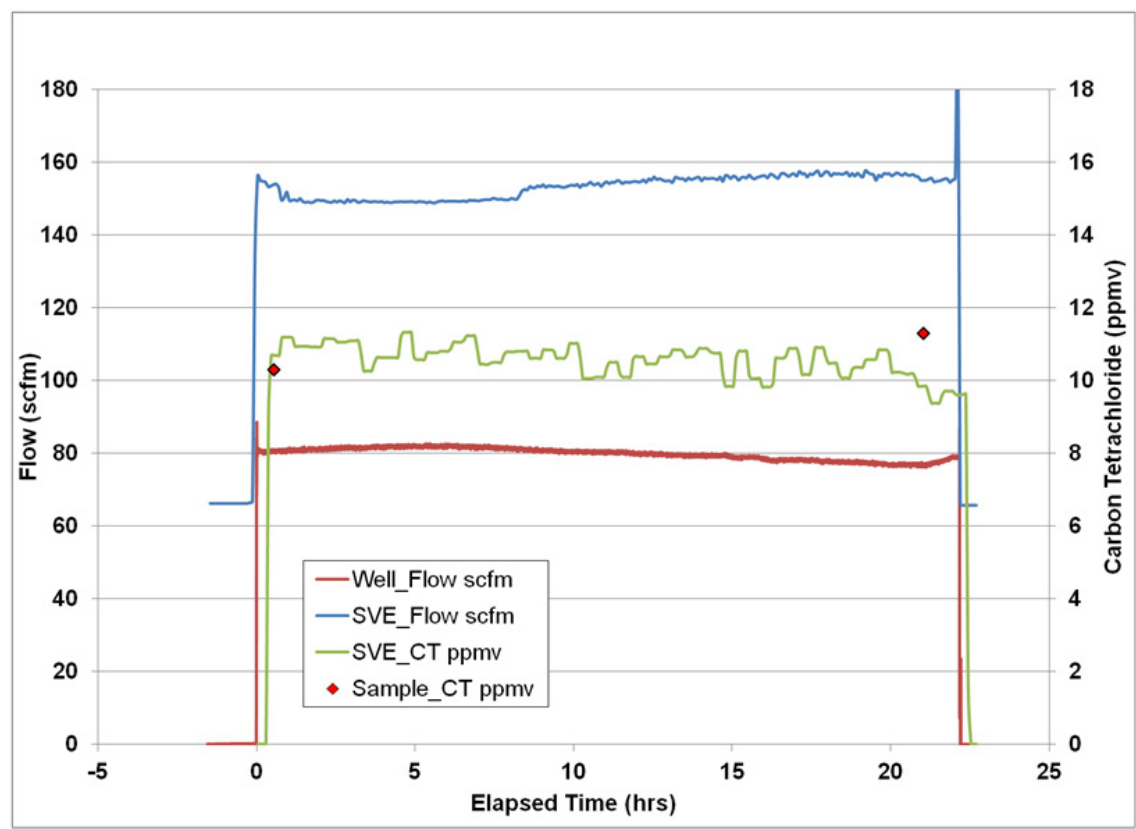

Figure 4.21. Well 299-W15-84L Single-Well Extraction SVE System CT Concentration and Flow-Rate and Extraction Well Monitoring System Flow-Rate Transient Data

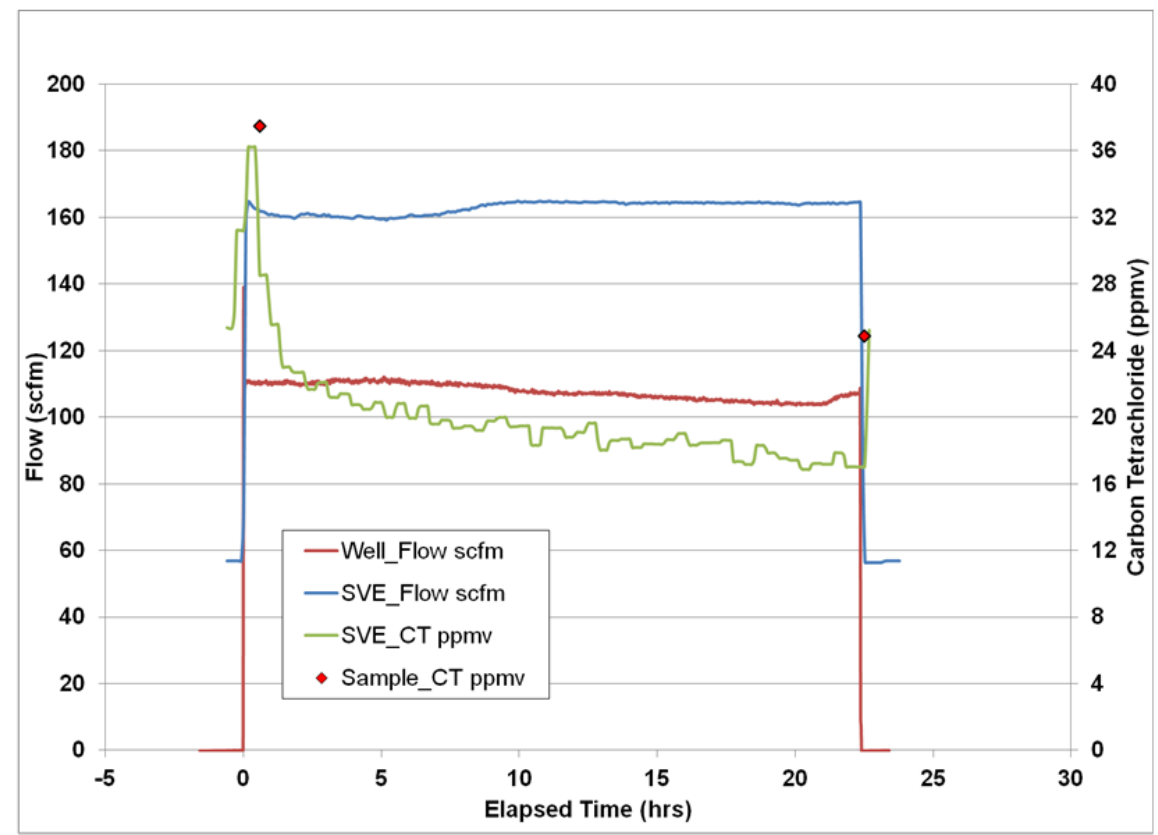

Figure 4.22. Well 299-W15-86 (note different scale than other plots) Single-Well Extraction SVE System CT Concentration and Flow-Rate and Extraction Well Monitoring System FlowRate Transient Data 


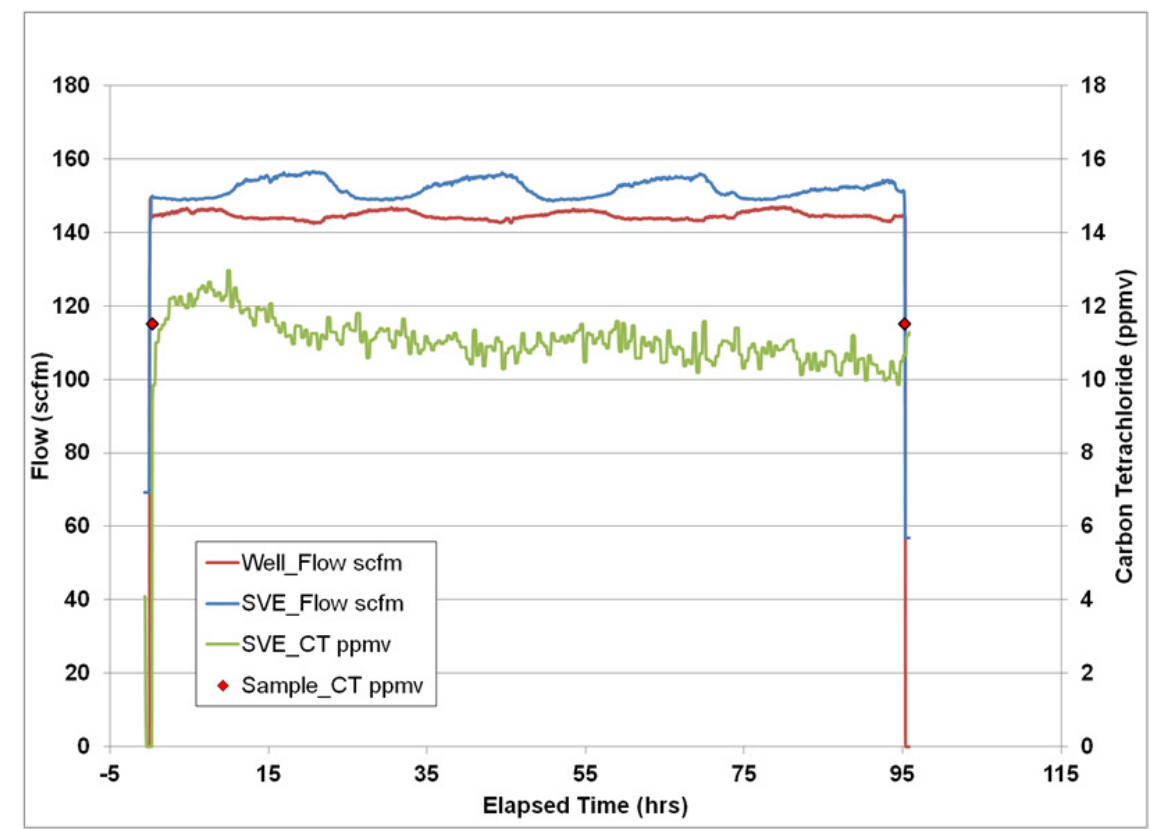

Figure 4.23. Well 299-W15-95L Single-Well Extraction SVE System CT Concentration and Flow-Rate and Extraction Well Monitoring System Flow-Rate Transient Data

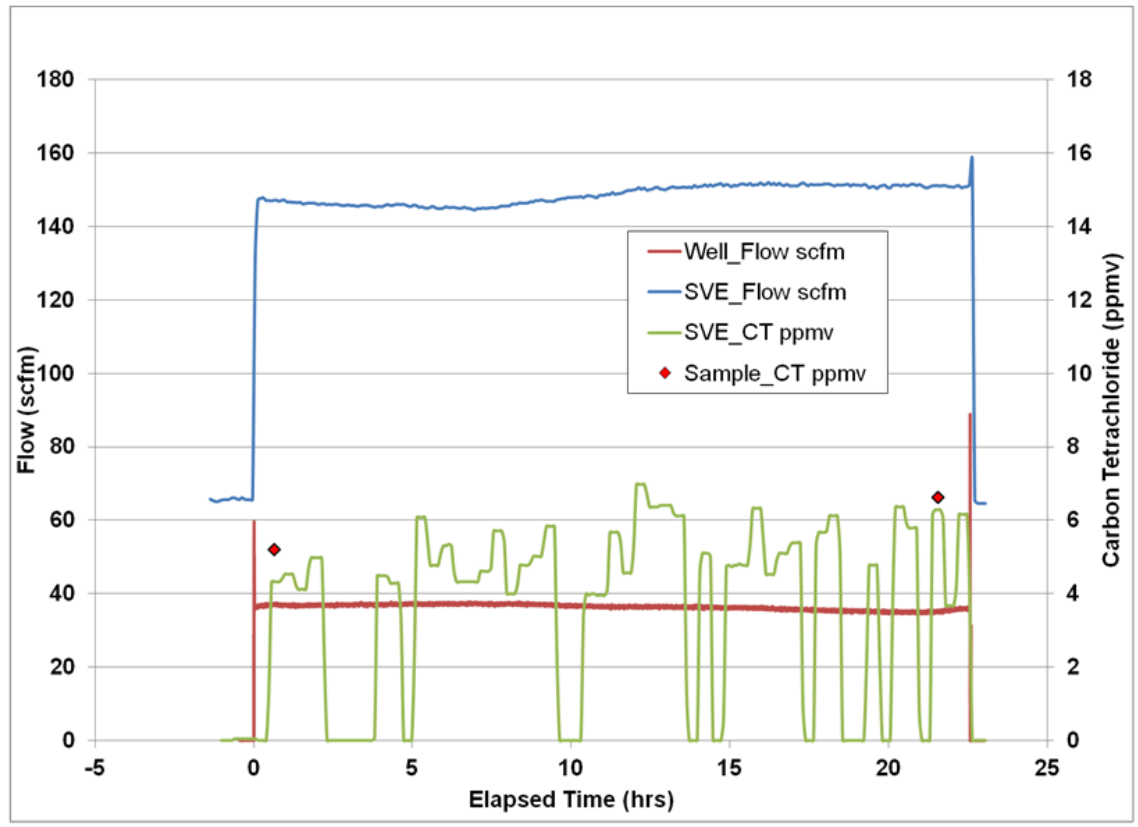

Figure 4.24. Well 299-W15-216L Single-Well Extraction SVE System CT Concentration and FlowRate and Extraction Well Monitoring System Flow-Rate Transient Data 


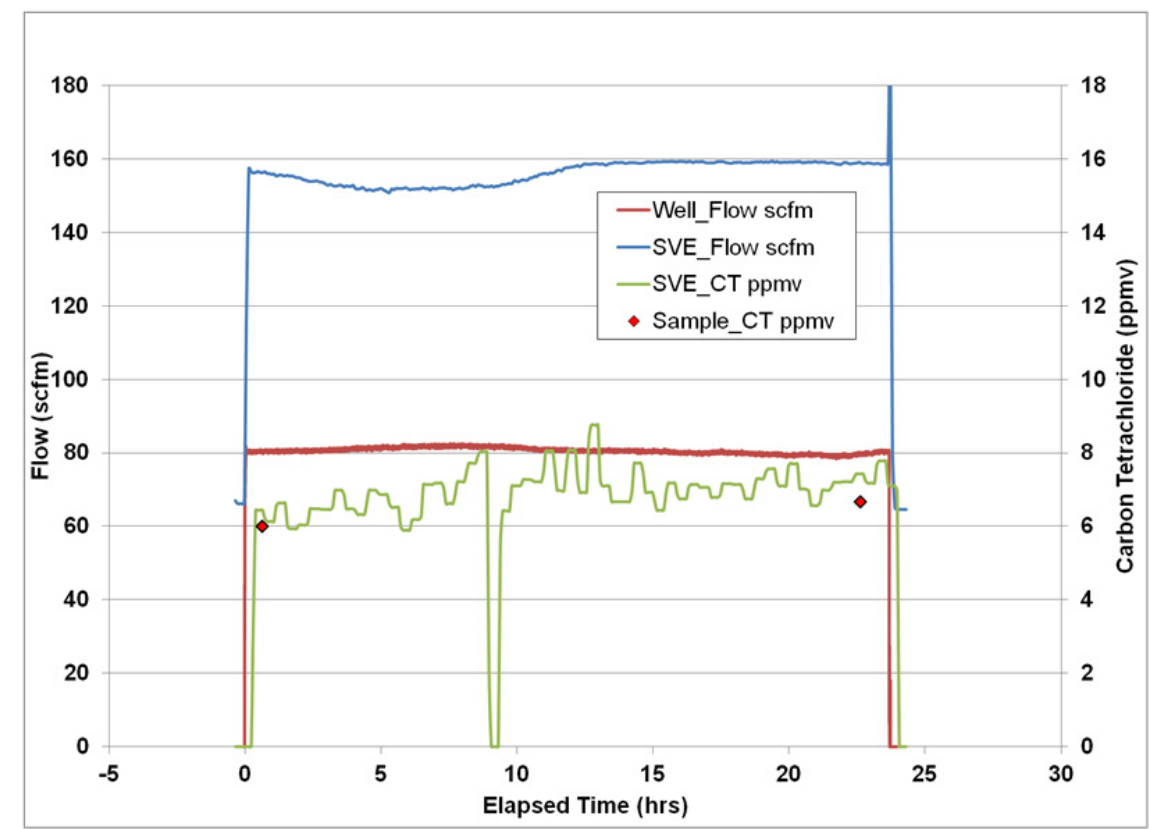

Figure 4.25. Well 299-W15-218L Single-Well Extraction SVE System CT Concentration and FlowRate and Extraction Well Monitoring System Flow-Rate Transient Data

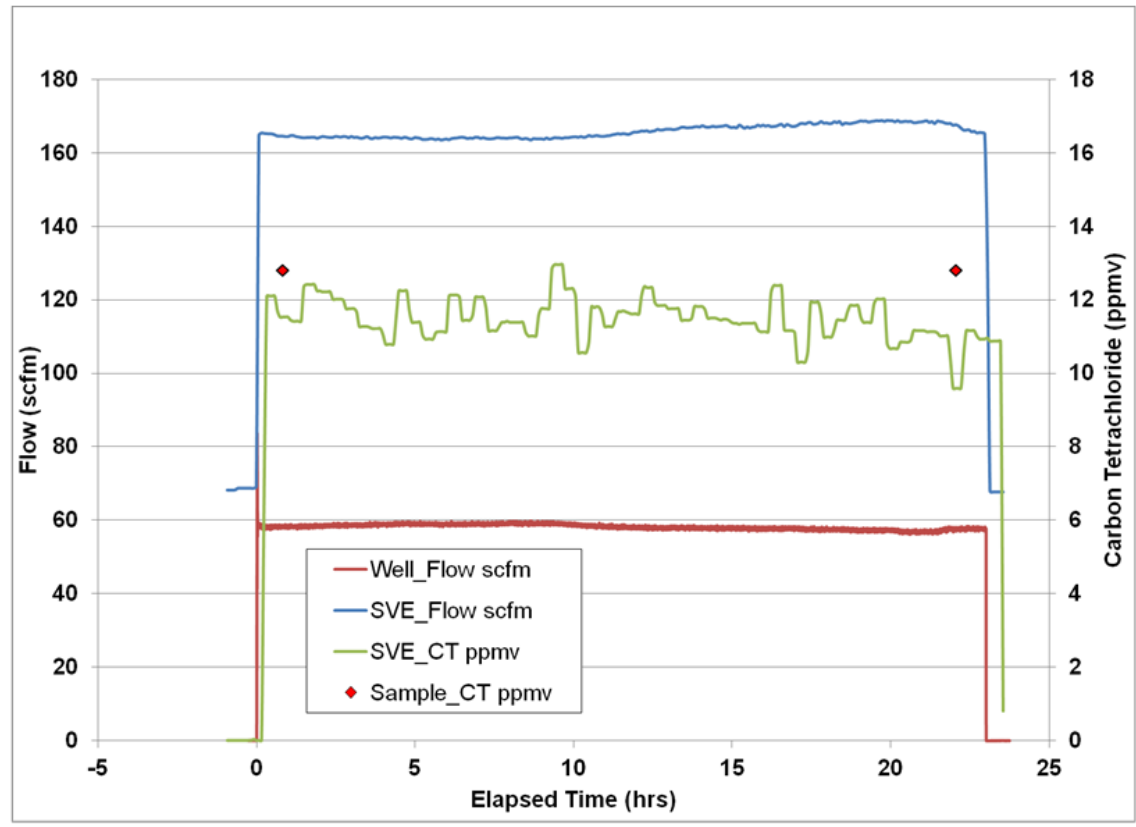

Figure 4.26. Well 299-W15-219L Single-Well Extraction SVE System CT Concentration and FlowRate and Extraction Well Monitoring System Flow-Rate Transient Data 


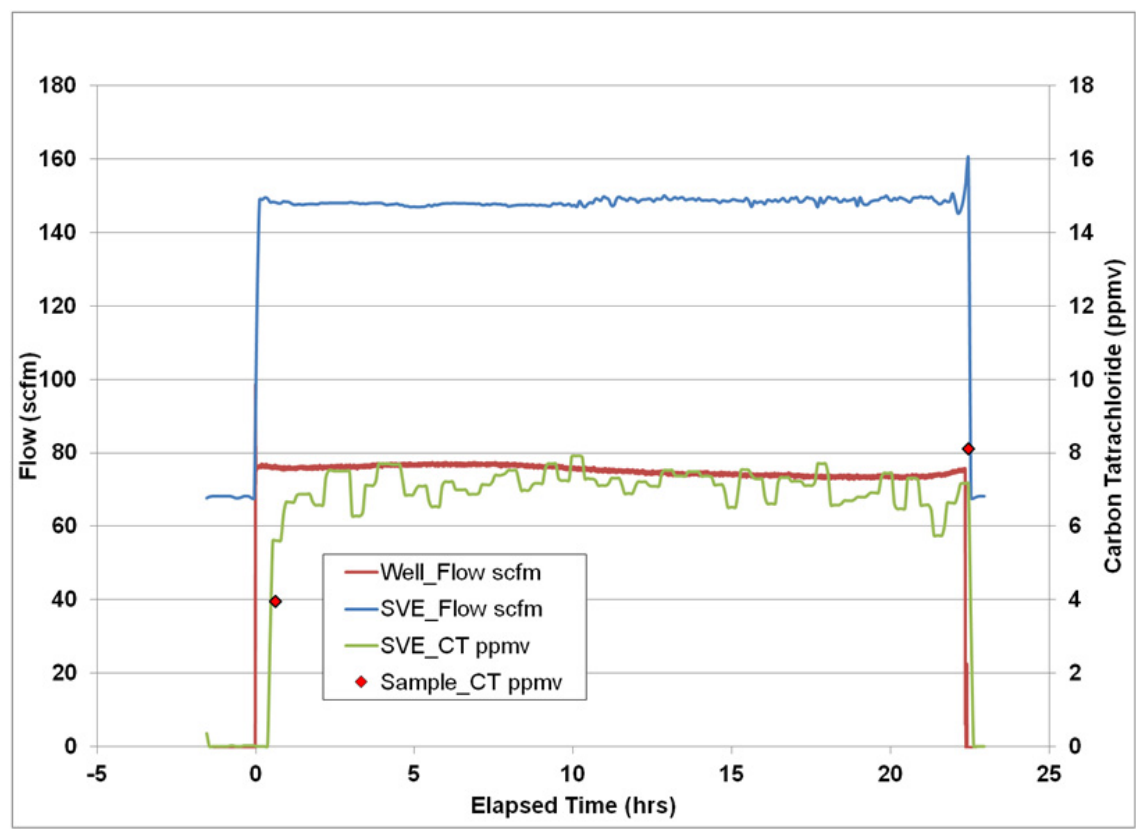

Figure 4.27. Well 299-W15-220L Single-Well Extraction SVE System CT Concentration and FlowRate and Extraction Well Monitoring System Flow-Rate Transient Data

The general results that can be observed from the transient plots of the single-well test data are that the data did not vary significantly over time or between different wells. In general, the concentrations varied between 2 and 12 ppmv for all wells, except well 86 (the only well screened across the CCU). Transient trends in concentration were not observed for many of the wells. However, measureable increases in concentration over time were observed at some wells (8U, 84U, 95U, and 32), and decreases in concentration over time were observed at other wells (8U, 48, and 86). Also, flow rates for individual wells varied from approximately 80 to $160 \mathrm{scfm}$ but were very stable over time during each test. Table 4.5 summarizes the average concentration, flow rate, and mass discharge (product of concentration and flow rate) for each of the single-well tests. These data have been sorted by magnitude of mass discharge for those wells above and below the CCU, respectively (except for well 86). The single-well test at well 86 was repeated, and the two tests had comparable mass discharge rates. One observation, based on Table 4.5, is that the highest concentration and mass discharge occurs at wells that are screened close to or into the CCU (i.e., 48, 217, 86, and 95L). 
Table 4.5. Summary of Individual Test Results Averaged over the Test Period. Mass discharge is the product of discharge and concentration, and the results are sorted by the relative mass discharge for individual wells in comparison to the sum of the mass discharge above and below the CCU, respectively. Note that these mass discharge values are under extraction conditions and are not directly comparable to the source mass discharge value calculated for rebound (no-flow) conditions. The 299-W15 prefix has been omitted from all well names.

\begin{tabular}{|c|c|c|c|c|c|c|}
\hline $\begin{array}{l}\text { Stressed } \\
\text { Well }\end{array}$ & $\begin{array}{c}\text { Above/Below } \\
\text { CCU }\end{array}$ & $\begin{array}{l}\text { Flow Rate } \\
\text { (scfm) }\end{array}$ & $\begin{array}{l}\text { CT Conc } \\
\text { (ppmv) }\end{array}$ & $\begin{array}{l}\text { CT Conc } \\
(\mathrm{mg} / \mathrm{L})\end{array}$ & $\begin{array}{c}\text { Mass } \\
\text { Discharge } \\
\text { (g/day) }\end{array}$ & $\begin{array}{c}\text { Relative \% } \\
\text { Mass } \\
\text { Discharge }\end{array}$ \\
\hline 48 & Above & 116.0 & 11.70 & 0.07 & 347.6 & 18 \\
\hline 217 & Above & 134.2 & 10.11 & 0.06 & 347.3 & 18 \\
\hline $220 \mathrm{U}$ & Above & 101.3 & 8.86 & 0.06 & 229.7 & 12 \\
\hline $8 \mathrm{U}$ & Above & 72.0 & 11.41 & 0.07 & 210.3 & 11 \\
\hline 223 & Above & 151.6 & 4.47 & 0.03 & 173.5 & 9 \\
\hline $95 \mathrm{U}$ & Above & 157.6 & 3.10 & 0.02 & 125.1 & 6 \\
\hline $84 \mathrm{U}$ & Above & 151.1 & 3.10 & 0.02 & 119.9 & 6 \\
\hline $9 \mathrm{U}$ & Above & 78.7 & 5.95 & 0.04 & 119.8 & 6 \\
\hline $216 \mathrm{U}$ & Above & 81.9 & 5.49 & 0.03 & 115.2 & 6 \\
\hline 85 & Above & 132.5 & 1.70 & 0.01 & 57.5 & 3 \\
\hline $219 U$ & Above & 94.0 & 2.18 & 0.01 & 52.5 & 3 \\
\hline $218 \mathrm{U}$ & Above & 87.3 & 2.34 & 0.01 & 52.3 & 3 \\
\hline Total & Above & & & & 1951 & 100 \\
\hline 86 & Across & 107.8 & 19.77 & 0.12 & 545.3 & \\
\hline 86 (repeat) & Across & 118.0 & 17.23 & 0.11 & 520.3 & \\
\hline $95 \mathrm{~L}$ & Below & 144.5 & 11.07 & 0.07 & 409.6 & 30 \\
\hline $84 \mathrm{~L}$ & Below & 79.7 & 10.55 & 0.07 & 215.3 & 16 \\
\hline 32 & Below & 134.6 & 5.14 & 0.03 & 177.3 & 13 \\
\hline $219 \mathrm{~L}$ & Below & 58.1 & 11.48 & 0.07 & 170.7 & 13 \\
\hline $218 \mathrm{~L}$ & Below & 80.6 & 6.86 & 0.04 & 141.5 & 10 \\
\hline $220 \mathrm{~L}$ & Below & 75.2 & 7.05 & 0.04 & 135.6 & 10 \\
\hline $8 \mathrm{~L}$ & Below & 36.1 & 7.54 & 0.05 & 69.7 & 5 \\
\hline $216 \mathrm{~L}$ & Below & 36.4 & 3.82 & 0.02 & 35.6 & 3 \\
\hline Total & Below & & & & 1355 & 100 \\
\hline
\end{tabular}

\subsubsection{Pneumatic Data}

Subsurface pressure in terms of vacuum was monitored within several wells during each of the singlewell tests. The flow rate and vacuum at the extraction well were monitored by the well-head monitoring system, and 10 or 11 additional vacuum transducers were monitored with data loggers. Alternating tests between above and below the $\mathrm{CCU}$ or at different locations across the site allowed both extraction (during test) and recovery (post-test) pressures to be monitored. These data were used in the transient pneumatic 
analysis of air permeability (discussed below). Table 3.2 summarizes the test stress well and monitoring well configurations for both extraction and recovery.

Barometric pressure fluctuations were observed to have a significant influence over the subsurface pressures during the testing. These fluctuations were removed using Multiple Regression in Excel (MRCX v. 1.1) (Mackley et al. 2010) to interpret the pressure response from the pneumatic stress induced during each of the individual well tests. Barometric pressure and temperature were monitored and recorded at the land surface with sensors connected to a data logger and from the Hanford Weather Station. Barometric pressure changes are presented in Figure 4.28 to illustrate the significant magnitude and frequency (i.e., on the order of minutes to hours) during September and October months when the pneumatic testing was conducted.

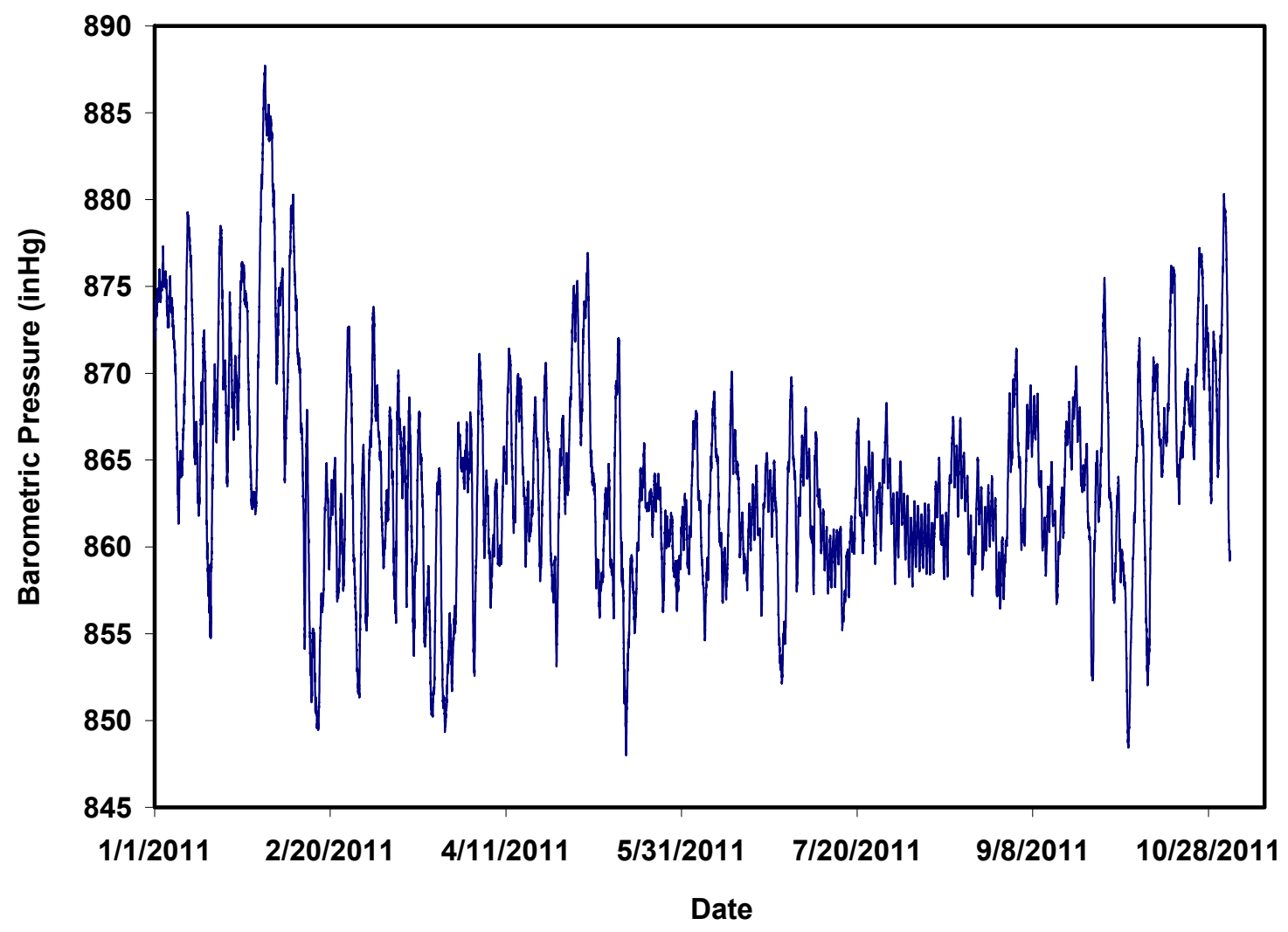

Figure 4.28. Hanford Meteorological Station Barometric Pressure Data

The barometric pressure for each of the test wells was also measured over a time period when the SVE system was inactive, through pressure/vacuum monitoring with the well valve closed to the atmosphere. A correlation between barometric pressure and subsurface pressure at each monitoring well was quantified using multiple-regression convolution/deconvolution techniques (e.g., Spane 1999; Mackley et al. 2010). Rasmussen and Crawford (1997) described a multiple-regression technique for removing barometric pressure responses with convolution in the time domain using impulse response functions discussed in Furbish (1991). The multiple regression convolution and deconvolution technique for barometric correction originally presented in Rasmussen and Crawford (1997) involves using linear regression of time-lagged input stresses and observed well pressures to predict well responses 
(convolution). Predicted well responses can then be removed from the observed well responses (deconvolution) to produce a corrected time series. This multiple-regression technique has been used successfully by others (e.g., Spane 1999, 2002) to correct for barometric effects. This analysis determined the barometric response function for each well, which was used to remove the barometric effects from the vacuum data collected at each well during each individual well test. Removal of the barometric pressure effects facilitated the evaluation of vacuum increase (i.e., pressure drawdown $=$ initial pressure - stress-test pressure) at monitoring well locations in direct response to extraction well discharges, which were used to determine the permeability of sediments using pneumatic test analysis techniques (discussed below). Figure 4.29 illustrates the barometric correction of the raw pressure monitoring data and the impact of the correction on the prediction of permeability.

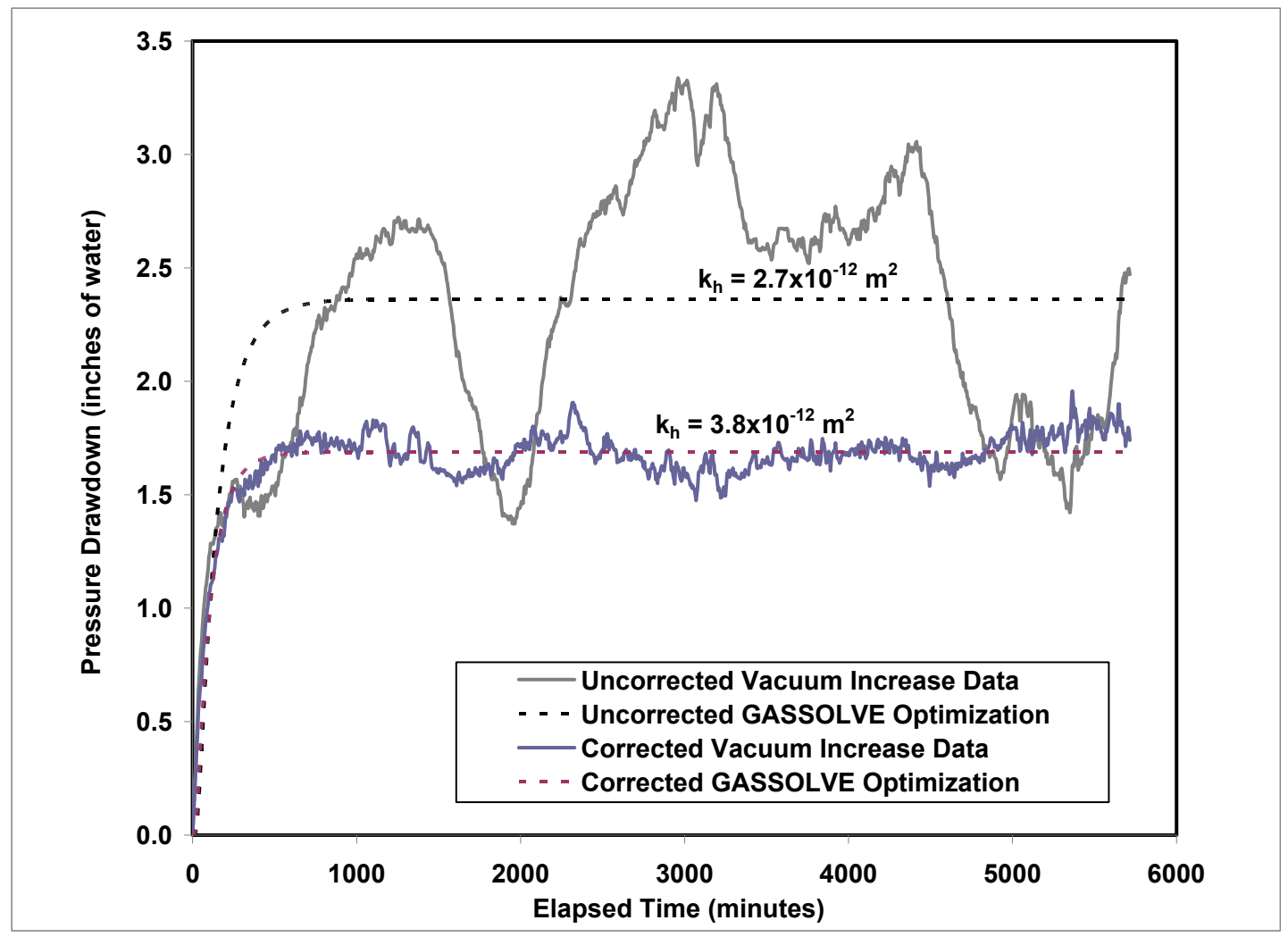

Figure 4.29. Barometric Correction (monitoring well 299-W15-48 data during extraction well test at 299-W15-8U)

Pressure responses and flow rates in the extraction/injection wells and other monitoring wells were interpreted using standard pneumatic testing procedures to evaluate the air permeability near each well, in different directions, and at different vertical elevations. GASSOLVE (Falta 1996) has been developed to solve the most commonly used analytical solutions for SVE pneumatic testing. The GASSOLVE program was used to evaluate the vadose zone permeability using the data collected during each of the individual well tests. However, as these analytical solutions do not account explicitly for subsurface heterogeneity, comparison of gas permeability and flow/pressure response data from different monitoring locations was used to evaluate vertical anisotropy and lateral variations in permeability at the site when appropriate data were available. Both steady-state and transient analyses were conducted. Table 4.6 shows the results of the steady-state pneumatic data analysis where the monitored pressure at the 
extraction well was only used for the analysis, which was used to evaluate local permeability near each well. The anisotropic values, in general, are slightly higher than the isotropic values because the isotropic model assumes there is also vertical permeability allowing the gas flow. If all of the results above the CCU (i.e., Hanford formation) are considered separately from those below the CCU (i.e., Ringold Formation), the spatial variability within each of these units was not significantly variable. Above the $\mathrm{CCU}$, the isotropic mean $\left(5 \mathrm{E}-12 \mathrm{~m}^{2}\right)$ is higher than the isotropic mean $\left(1 \mathrm{E}-12 \mathrm{~m}^{2}\right)$ for below the CCU. The range is approximately a factor of five above the $\mathrm{CCU}$, which is relatively low for permeability given the typical impact of sediment and water content. Both lower permeability and higher variability were observed below the CCU. Although an expected range in permeability was observed for tests conducted within each of these two higher permeability units, spatial analysis did not reveal any significant trend in the permeabilities, which suggests that each unit can be evaluated as a contiguous formation with respect to gas flow and contaminant transport. Despite the observed range and variability in permeability, effectively homogeneous permeabilities can be determined as the statistical mean values for the Hanford (above the $\mathrm{CCU}$ ) and the Ringold (below the $\mathrm{CCU}$ ) Formations, respectively.

Table 4.6. Summary Results of Steady-State Pneumatic Testing Permeability $\left(\mathrm{m}^{2}\right)$ Estimates. The 299-W15 prefix has been omitted from all well names.

\begin{tabular}{|c|c|c|c|}
\hline \multirow[b]{2}{*}{$\begin{array}{c}\text { Stress and } \\
\text { Observation Well }\end{array}$} & Isotropic & Anisotropic & \multirow[b]{2}{*}{ Relationship to the $\mathrm{CCU}$} \\
\hline & Permeability $\left(\mathrm{m}^{2}\right)$ & $\begin{array}{c}\text { Horizontal } \\
\text { Permeability }\left(\mathrm{m}^{2}\right)\end{array}$ & \\
\hline $8 \mathrm{U}$ & $5.241 \mathrm{E}-12$ & $6.725 \mathrm{E}-12$ & Above \\
\hline $9 \mathrm{U}$ & $4.257 \mathrm{E}-12$ & $5.041 \mathrm{E}-12$ & Above \\
\hline 48 & $7.427 \mathrm{E}-12$ & $9.257 \mathrm{E}-12$ & Above \\
\hline $84 \mathrm{U}$ & $7.880 \mathrm{E}-12$ & $1.022 \mathrm{E}-11$ & Above \\
\hline 85 & $6.691 \mathrm{E}-12$ & $8.641 \mathrm{E}-12$ & Above \\
\hline $95 \mathrm{U}$ & $6.062 \mathrm{E}-12$ & $7.626 \mathrm{E}-12$ & Above \\
\hline 217 & $6.355 \mathrm{E}-12$ & $8.026 \mathrm{E}-12$ & Above \\
\hline $218 U$ & $7.912 \mathrm{E}-12$ & $1.034 \mathrm{E}-11$ & Above \\
\hline $219 U$ & $3.851 \mathrm{E}-12$ & $5.077 \mathrm{E}-12$ & Above \\
\hline 223 & $5.699 \mathrm{E}-12$ & $7.273 \mathrm{E}-12$ & Above \\
\hline $216 U$ & $1.712 \mathrm{E}-12$ & $1.733 \mathrm{E}-12$ & Above \\
\hline $220 \mathrm{U}$ & $3.613 \mathrm{E}-12$ & $5.007 \mathrm{E}-12$ & Above \\
\hline 86 & $3.858 \mathrm{E}-12$ & $4.772 \mathrm{E}-12$ & Across \\
\hline $8 \mathrm{~L}$ & $1.186 \mathrm{E}-13$ & $1.179 \mathrm{E}-13$ & Below \\
\hline $219 \mathrm{~L}$ & $2.022 \mathrm{E}-12$ & $9.838 \mathrm{E}-14$ & Below \\
\hline $95 \mathrm{~L}$ & $6.794 \mathrm{E}-14$ & $9.931 \mathrm{E}-13$ & Below \\
\hline $216 \mathrm{~L}$ & $3.032 \mathrm{E}-13$ & $3.028 \mathrm{E}-13$ & Below \\
\hline $218 \mathrm{~L}$ & $1.162 \mathrm{E}-12$ & $6.294 \mathrm{E}-14$ & Below \\
\hline 32 & $2.514 \mathrm{E}-12$ & $1.166 \mathrm{E}-13$ & Below \\
\hline $84 \mathrm{~L}$ & $2.067 \mathrm{E}-13$ & $2.064 \mathrm{E}-13$ & Below \\
\hline $220 \mathrm{~L}$ & $2.572 \mathrm{E}-12$ & $2.576 \mathrm{E}-12$ & Below \\
\hline
\end{tabular}

Transient permeability analysis was also conducted for wells with appropriate data (only above the $\mathrm{CCU}$ ) by optimization of the gas flow solution to find the permeability allowing the closest match to all of the transient pressure data, and the results were comparable to the steady-state results. 
Table 4.7 contains a summary table of the transient analysis permeability results. A comparison of the transient analysis is presented in Figure 4.30.

Table 4.7. Transient Analysis Results (where $\mathrm{Kh}$ is the horizontal permeability, $\mathrm{Kz}$ is the vertical permeability, $\theta_{\mathrm{g}}$ is the gravimetric moisture content used in the analysis, and RSS is the residual sum of square error between the estimated and observed pressures). The 299-W15 prefix has been omitted from all well names.

\begin{tabular}{|c|c|c|c|c|c|c|c|}
\hline Stress Well & Obs Well & $\theta_{\mathrm{g}}$ & $\mathrm{Kh} / \mathrm{Kz}$ & $\mathrm{Kh}\left(\mathrm{m}^{2}\right)$ & $\mathrm{Kz}\left(\mathrm{m}^{2}\right)$ & RSS & $\%$ Error \\
\hline $8 \mathrm{U}$ & 48 & 0.4 & 1 & $3.79 \mathrm{E}-12$ & $3.79 \mathrm{E}-12$ & $1.73 \mathrm{E}-04$ & 3.8 \\
\hline $8 \mathrm{U}$ & 48 & 0.4 & 10 & $2.05 \mathrm{E}-11$ & $2.05 \mathrm{E}-12$ & $2.08 \mathrm{E}-04$ & 4.1 \\
\hline $8 \mathrm{U}$ & 82 & 0.04 & 1 & $6.35 \mathrm{E}-13$ & $6.35 \mathrm{E}-13$ & $7.38 \mathrm{E}-04$ & 2.5 \\
\hline $8 \mathrm{U}$ & 82 & 0.1 & 10 & $4.68 \mathrm{E}-12$ & $4.68 \mathrm{E}-13$ & $9.77 \mathrm{E}-04$ & 2.9 \\
\hline $8 \mathrm{U}$ & 85 & 0.03 & 1 & $3.18 \mathrm{E}-13$ & $3.18 \mathrm{E}-13$ & $1.50 \mathrm{E}-03$ & 3.8 \\
\hline $8 \mathrm{U}$ & 85 & 0.1 & 10 & $5.15 \mathrm{E}-12$ & $5.15 \mathrm{E}-13$ & $6.83 \mathrm{E}-04$ & 3.1 \\
\hline $8 \mathrm{U}$ & $95 \mathrm{U}$ & 0.1 & 1 & 7.60E-13 & $7.60 \mathrm{E}-13$ & $5.13 \mathrm{E}-04$ & 4.6 \\
\hline $8 \mathrm{U}$ & $95 \mathrm{U}$ & 0.3 & 10 & $8.16 \mathrm{E}-12$ & $8.16 \mathrm{E}-13$ & 3.99E-04 & 4.2 \\
\hline $8 \mathrm{U}$ & 217 & 0.15 & 1 & $1.09 \mathrm{E}-12$ & $1.09 \mathrm{E}-12$ & $2.79 \mathrm{E}-03$ & 1.9 \\
\hline $8 \mathrm{U}$ & 217 & 0.25 & 10 & $6.50 \mathrm{E}-12$ & $6.50 \mathrm{E}-13$ & $3.99 \mathrm{E}-04$ & 1.0 \\
\hline $8 \mathrm{U}$ & $8 \mathrm{U}$ & 0.2 & 1 & $5.47 \mathrm{E}-12$ & $5.47 \mathrm{E}-12$ & 4.64E-01 & 1.8 \\
\hline $8 \mathrm{U}$ & $8 \mathrm{U}$ & 0.2 & 10 & $7.01 \mathrm{E}-12$ & $7.01 \mathrm{E}-13$ & 4.29E-01 & 1.8 \\
\hline $8 \mathrm{U}$ & $218 \mathrm{U}$ & 0.01 & 1 & $1.11 \mathrm{E}-13$ & $1.11 \mathrm{E}-13$ & $2.67 \mathrm{E}-03$ & 4.1 \\
\hline $8 \mathrm{U}$ & $218 U$ & 0.06 & 10 & $3.27 \mathrm{E}-12$ & $3.27 \mathrm{E}-13$ & 7.14E-04 & 2.9 \\
\hline $8 \mathrm{U}$ & $219 U$ & 0.02 & 1 & $1.54 \mathrm{E}-13$ & $1.54 \mathrm{E}-13$ & $5.27 \mathrm{E}-03$ & 9.7 \\
\hline $8 \mathrm{U}$ & $219 \mathrm{U}$ & 0.1 & 10 & $4.09 \mathrm{E}-12$ & $4.09 \mathrm{E}-13$ & $4.38 \mathrm{E}-03$ & 8.7 \\
\hline $9 \mathrm{U}$ & $8 \mathrm{U}$ & 0.2 & 1 & $1.34 \mathrm{E}-12$ & $1.34 \mathrm{E}-12$ & $2.91 \mathrm{E}-04$ & 7.9 \\
\hline $9 \mathrm{U}$ & $8 \mathrm{U}$ & 0.5 & 10 & $1.44 \mathrm{E}-11$ & $1.44 \mathrm{E}-12$ & 7.96E-05 & 4.8 \\
\hline $9 \mathrm{U}$ & 82 & 0.4 & 1 & 3.34E-12 & $3.34 \mathrm{E}-12$ & $7.10 \mathrm{E}-05$ & 3.7 \\
\hline $9 \mathrm{U}$ & 82 & 0.5 & 10 & $1.93 \mathrm{E}-11$ & $1.93 \mathrm{E}-12$ & $3.61 \mathrm{E}-04$ & 6.9 \\
\hline $9 \mathrm{U}$ & $9 \mathrm{U}$ & 0.2 & 1 & $4.50 \mathrm{E}-12$ & 4.50E-12 & $1.12 \mathrm{E}-01$ & 2.1 \\
\hline $9 \mathrm{U}$ & $9 \mathrm{U}$ & 0.2 & 10 & $5.27 \mathrm{E}-12$ & $5.27 \mathrm{E}-13$ & $1.28 \mathrm{E}-01$ & 1.9 \\
\hline $9 \mathrm{U}$ & 85 & 0.4 & 1 & $4.91 \mathrm{E}-12$ & $4.91 \mathrm{E}-12$ & $1.40 \mathrm{E}-03$ & 4.5 \\
\hline $9 \mathrm{U}$ & 85 & 0.5 & 10 & $1.36 \mathrm{E}-11$ & $1.36 \mathrm{E}-12$ & $2.38 \mathrm{E}-04$ & 1.9 \\
\hline $9 \mathrm{U}$ & $218 \mathrm{U}$ & 0.05 & 1 & $1.23 \mathrm{E}-12$ & $1.23 \mathrm{E}-12$ & $1.88 \mathrm{E}-03$ & 4.3 \\
\hline $9 \mathrm{U}$ & $218 \mathrm{U}$ & 0.1 & 10 & $6.88 \mathrm{E}-12$ & $6.88 \mathrm{E}-13$ & $6.06 \mathrm{E}-04$ & 2.7 \\
\hline 48 & $8 \mathrm{U}$ & 0.5 & 1 & $4.96 \mathrm{E}-12$ & $4.96 \mathrm{E}-12$ & $1.04 \mathrm{E}-03$ & 8.5 \\
\hline 48 & $8 \mathrm{U}$ & 0.5 & 10 & $2.66 \mathrm{E}-11$ & $2.66 \mathrm{E}-12$ & $1.89 \mathrm{E}-03$ & 11.0 \\
\hline 48 & 48 & 0.2 & 1 & 8.30E-12 & 8.30E-12 & $1.05 \mathrm{E}-01$ & 2.0 \\
\hline 48 & 48 & 0.2 & 10 & $1.03 \mathrm{E}-11$ & $1.03 \mathrm{E}-12$ & $1.37 \mathrm{E}-01$ & 2.1 \\
\hline 48 & 82 & 0.3 & 1 & $3.03 \mathrm{E}-12$ & $3.03 \mathrm{E}-12$ & 2.99E-04 & 3.6 \\
\hline 48 & 82 & 0.45 & 10 & $1.36 \mathrm{E}-11$ & $1.36 \mathrm{E}-12$ & 4.89E-05 & 1.3 \\
\hline 48 & 85 & 0.2 & 1 & $2.48 \mathrm{E}-12$ & $2.48 \mathrm{E}-12$ & 4.54E-04 & 5.0 \\
\hline 48 & 85 & 0.4 & 10 & $1.62 \mathrm{E}-11$ & $1.62 \mathrm{E}-12$ & $5.77 \mathrm{E}-05$ & 1.9 \\
\hline 48 & 217 & 0.5 & 1 & $5.51 \mathrm{E}-12$ & $5.51 \mathrm{E}-12$ & $9.91 \mathrm{E}-04$ & 7.6 \\
\hline 48 & 217 & 0.5 & 10 & $2.85 \mathrm{E}-11$ & $2.85 \mathrm{E}-12$ & $2.17 \mathrm{E}-03$ & 10.6 \\
\hline 48 & $218 \mathrm{U}$ & 0.05 & 1 & $7.22 \mathrm{E}-13$ & $7.22 \mathrm{E}-13$ & $1.06 \mathrm{E}-03$ & 5.8 \\
\hline 48 & $218 \mathrm{U}$ & 0.15 & 10 & $9.01 \mathrm{E}-12$ & $9.01 \mathrm{E}-13$ & $1.59 \mathrm{E}-04$ & 2.9 \\
\hline
\end{tabular}




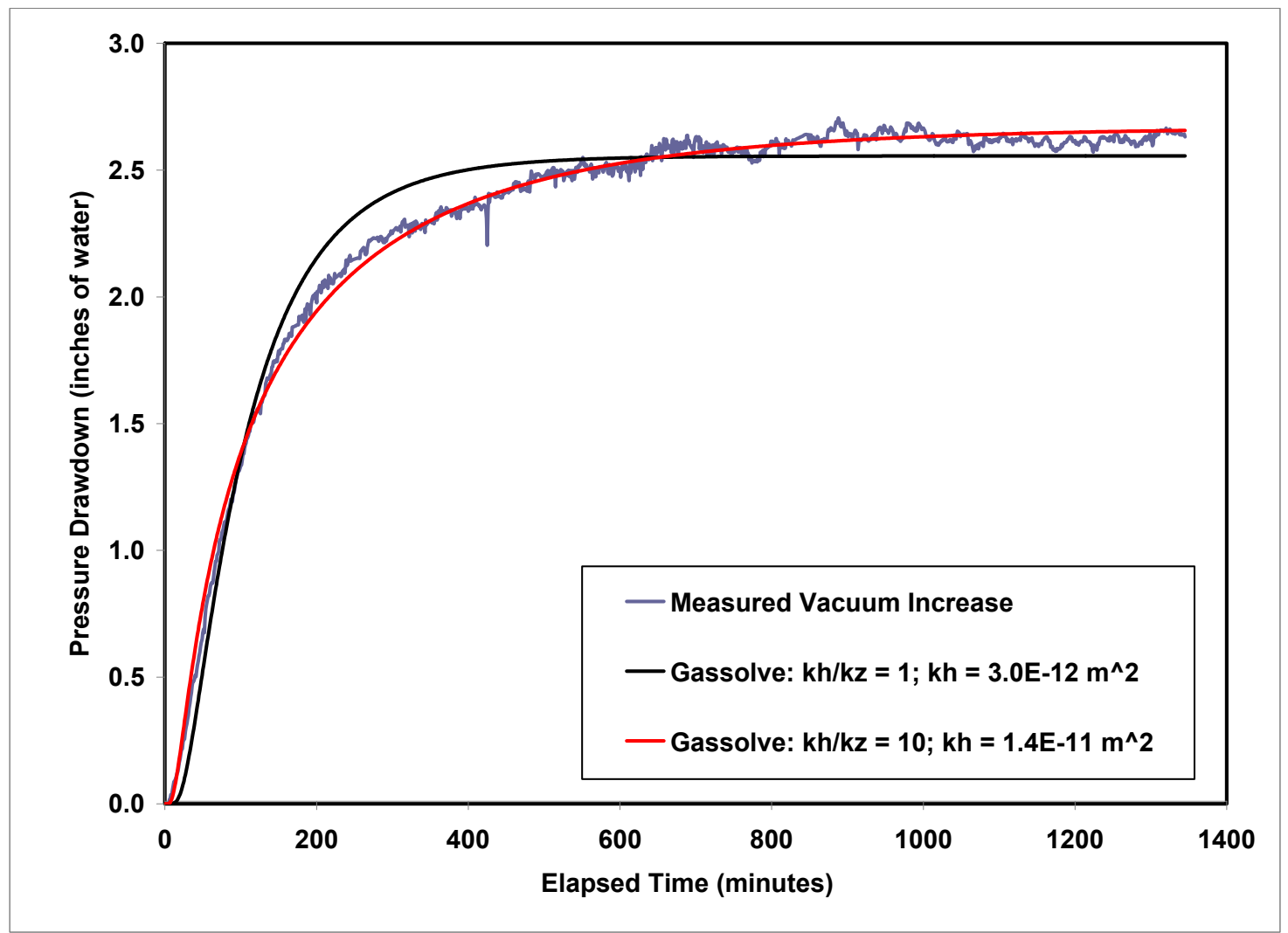

Figure 4.30. Comparison of Type-Curve Fits With and Without Anisotropy (monitoring well 299-W1582 data during extraction test at well 299-W15-48)

The transient results illustrate the need to consider anisotropy $(\mathrm{Kh} / \mathrm{Kz}=10)$ for the wells above the CCU. The isotropic permeabilities are similar to the anisotropic permeabilities for observation wells that are close to the stress well, whereas estimated isotropic $(\mathrm{Kh} / \mathrm{Kz}=1)$ permeability decreases with distance from the stress well. Gas flow and the resulting vacuum gradient tends to contact and be impacted more by anisotropic features, such as silt lenses and elevated water content zones, with increasing distance from the well because the volume of the subsurface tested increases. As mentioned above, the isotropic model assumes gas flow toward the well occurs both laterally and vertically from the surface. At large distances from the stress well, the total volume of flow increases with the size of the swept volume, the vertical component of flow is significant, acts to recharge the gas, and decreases the vacuum. Equal vertical and horizontal permeability and gas flow from the surface would have reduced the vacuum increases with increasing distance from the extraction well. However, the observed magnitude of vacuum across large distances at this site suggests that the vertical permeability and flow are less than the horizontal permeability. The transient GASSOLVE results above the CCU using the anisotropic configuration generally improved the match to the data compared to the match with the analysis using the isotropic case (Figure 4.30). In addition, elevated water content observations in the upper part of the vadose zone as shown in Figure 4.31, suggest that high water contents filling pore space could result in a limitation of airflow that would decrease vertical permeability above the CCU and result in some anisotropy. 


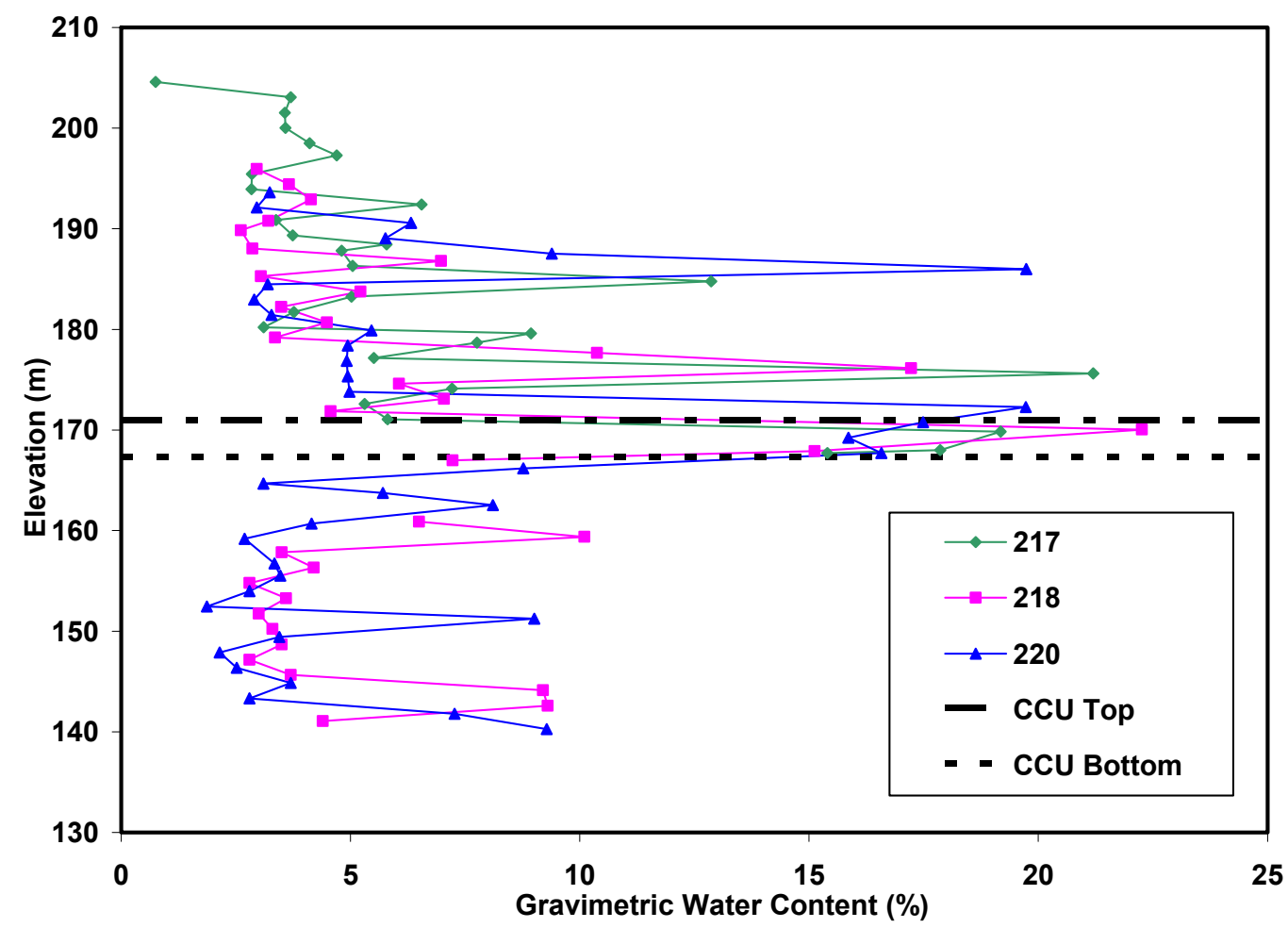

Figure 4.31. Measured Water Content as a Function of Elevation (Last et al. 2006). The 299-W15 prefix has been omitted from all well names.

\subsection{Data Assessment with Respect to Field Test Objectives}

Two basic types of data assessment were conducted, as described in the following sections. The overall source strength in terms of source mass discharge was evaluated using an established method (Brusseau et al. 2010), but with refinements based on the site-specific conditions (see Section 4.1). Single-well test data were used to refine the estimated size and location of the remaining CT contamination source in the vadose zone. The single-well tests were designed to provide an alternative to use of SVE system operational data for interrogating the subsurface and identify the location and magnitude of remaining CT sources.

\subsubsection{Source Mass Discharge}

As described in Section 4.1.1, data collected during the historical cyclic operational periods were analyzed to determine the remaining source strength in terms of source mass discharge using the method of Brusseau et al. (2010) with refinements based on site-specific data (Table 4.1 and Figure 4.5, Section 4.1.1). These analyses show a steady reduction of the computed source mass discharge over time with a most recent computed source mass discharge (2010) of about $70 \mathrm{~g} / \mathrm{d}$. The computed source mass discharge can be used in combination with the source size estimate from the single-well test data to estimate the future impact to groundwater using the approach described in Carroll et al. (2012). This approach considers the three-dimensional aspects of the site and vapor transport and links the groundwater impact to a measure of the source mass discharge (MFr) that can be directly obtained from the SVE operational data. 
These site data also suggest that the current contaminant rebound from the remaining source has been small relative to the background (asymptotic) concentrations at the site in recent years. This result suggests that the remaining, persistent source has become more diffusion-limited over time. Because the difference between rebound (maximum) concentrations and asymptotic concentrations during an operational period are small, there may be uncertainty in the computed source mass discharge. In part, the low rebound is due to the relatively shorter rebound periods and more regular operation of the SVE system in recent years. Thus, the site should consider operating the SVE system in a manner that improves the estimate of the source mass discharge using the method of Brusseau et al. (2010). This type of operation should consider a longer rebound period and selection of the most appropriate SVE operational wells based on the single-well test data analysis (see Section 2.2).

\subsubsection{Source Size and Location}

Evaluation of data with respect to the source size and location was conducted based on transient and spatial analyses.

\subsubsection{Transient Analysis}

Figures 4.7 through 4.27 illustrate the transient behavior of concentrations during each single-well test. The vapor mass discharge results were similar because the flow rate was essentially constant during each test. Moment analysis was used to evaluate data at single-well tests that exhibited a transient behavior. Moment analysis is a technique for evaluating statistics for distributed functions. Concentration data for tracers undergoes spatial and temporal spreading associated with dilution and dispersion transport processes. The location, transport, and arrival of a tracer can be quantified by the statistics of the center of mass of the tracer. In general, the temporal moments obtained from concentration or mass discharge data obtained at one location (such as a monitoring well) may be used to evaluate the total mass passing that location $\left(0^{\text {th }}\right.$ moment $)$, the mean arrival time $\left(1^{\text {st }}\right.$ moment $)$, and the degree of spreading or dispersion $\left(2^{\text {nd }}\right.$ moment $)$. The $0^{\text {th }}\left(\mu_{0}\right)$ and $1^{\text {st }}\left(\mu_{1}{ }^{\prime}\right)$ moments of mass discharge can be calculated from temporal mass discharge data as shown in Equation (4.1):

$$
\begin{gathered}
\mu_{0}=\sum_{i=2}^{n}\left(\frac{M F_{i}+M F_{i-1}}{2}\right)\left(t_{i}-t_{i-1}\right) \\
\mu_{1}{ }^{\prime}=\frac{\sum_{i=2}^{n}\left(\frac{t_{i} M F_{i}+t_{i-1} M F_{i-1}}{2}\right)\left(t_{i}-t_{i-1}\right)}{\mu_{0}}
\end{gathered}
$$

where $\mathrm{MF}_{\mathrm{i}}$ is the mass discharge at time $\mathrm{t}_{\mathrm{i}}$ and $\mathrm{n}$ is the total number of data points. The normalized $1^{\text {st }}$ moment determines the average time of arrival of the mean mass discharge. Comparison of arrival times from the source zone and transport velocity from radius of influence evaluations can be used to determine the distance between a well screen and a source zone.

Many individual tests produced relatively steady concentration and mass discharge results over time, supporting the conceptualization of a relatively uniform, low concentration, and large source area within the CCU. However, a few wells such as $86,8 \mathrm{U}$, and 32 demonstrated some minor transient behavior, 
which could be evaluated using moment analysis. Both wells 86 and $8 \mathrm{U}$ showed a spike in concentration and mass discharge followed by a decline to a lower, steady level. This response suggests that extracted soil gas included vapor from a high concentration source followed by dilution from outside a source zone. However, the peak observed at well 86 is essentially at the start of the test, suggesting that this well is screened within the source zone (i.e., the CCU), and the moment analysis of travel time is not applicable. For well 8U, moment analysis suggests that the high vapor concentration arrived at well $8 \mathrm{U}$ within 1.9 days. The pore velocity was then estimated and multiplied by these travel times to determine a distance of approximately $10 \mathrm{~m}$ from the well to the source. A similar analysis using the delay in travel time from the maximum concentration or mass discharge resulted in a distance of $3.75 \mathrm{~m}$ from well $8 \mathrm{U}$. The difference between these travel time estimates is due to the concentration tailing during the latter part of the test that skews the mean arrival to a later time compared to the arrival of the peak concentration. These results at well 8U suggest that high vapor concentrations near the well (e.g., within the CCU adjacent to well $8 \mathrm{U}$ and/or between wells 86 and $8 \mathrm{U}$ ) was extracted, but later the extracted soil gas was from areas with lower concentrations, diluting the extracted CT vapor concentration. However, without similar dynamic responses in nearby wells, only limited conclusions can be drawn from moment analysis of the dynamic response at well $8 \mathrm{U}$.

In recent operational cycles, well 86 (screened across the $\mathrm{CCU}$ ) has emerged as having the highest vapor concentrations and has had the smallest decline in concentrations over time (Section 4.1.1). The character of the single-well response (Section 4.1.2); i.e., the early time peak concentration followed by declining concentration suggests that well 86 is in a source zone where initial data reflect concentrations adjacent to the well and later time data decline due to dilution with soil gas extracted farther away from the source. Because the CCU has lower permeability than the Hanford or Ringold Formation zones, the later time data represent soil gas from above and below these zones where data from other wells show lower CT concentrations than what is observed in well 86. These data support the conclusion that the $\mathrm{CCU}$ is a remaining source zone.

Another transient trend observed in Figures 4.7 through 4.27 was an increase in concentration during the test for well 32 . Well 32 is screened across the water table and the groundwater underlying the site also contains CT concentrations. Thus, this well can be used to evaluate the possibility that $\mathrm{CT}$ concentrations below the $\mathrm{CCU}$ are attributed to groundwater concentrations rather than the CCU. However, if concentration trends observed at well 32 were due to groundwater contributions, the increases in concentration over time at well 32 would suggest a significant lateral variability in groundwater concentration around and at some distance from well 32, which is unlikely. It is more likely that the concentration gradient that is measured over time due to extraction at well 32 is from vertical soil gas movement and associated with soil-gas concentrations within the Ringold Formation zone. This interpretation suggests that the transient response in concentration at well 32 is due to transport of CT from a vadose zone source (i.e., the CCU source) toward the groundwater.

\subsubsection{Spatial Analysis}

Data collected during the single-well testing (shown in Section 4.1.2) show small dynamic responses in concentration and associated mass discharge at some individual wells and no transient response in many wells. Figures 4.32 through 4.34 summarize the spatial CT concentration response in each tested well above the $\mathrm{CCU}$, below the $\mathrm{CCU}$, and in cross-sectional views, respectively. Figures 4.32 through 4.34 show the concentration and the area of interrogation for each test, which is calculated as the 
spherical volume of subsurface swept by the end of the single-well test by integration of the gas volume extracted. The figures illustrate the similarity in concentrations and the extent of coverage for the testing. Large coverage zones are associated with individual well tests that were conducted longer than 1 day.

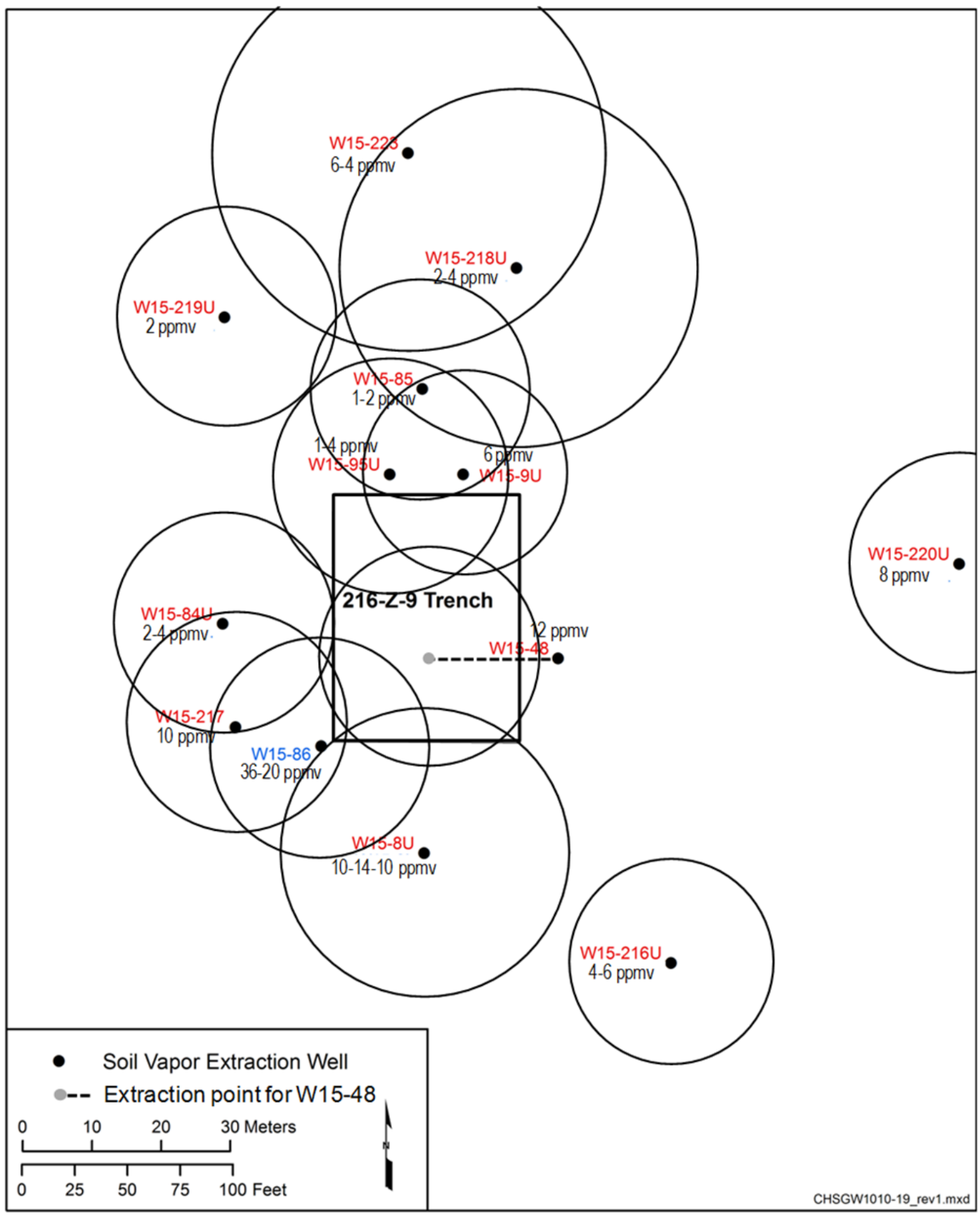

Figure 4.32. Summary of Single-Well Test Data for Above the CCU and at Well 86 (across the CCU). Note that well open intervals are not all at the same elevation. Circles around each well show the radius from which soil gas was withdrawn based on assumption of an ideal spherical zone of influence from the center of the well screen. Where a single concentration is shown, concentration remained essentially constant for the duration of the soil gas extraction period of the test. Ranges indicate when concentration conditions changed during extraction. The 299- prefix has been omitted from all well names. 


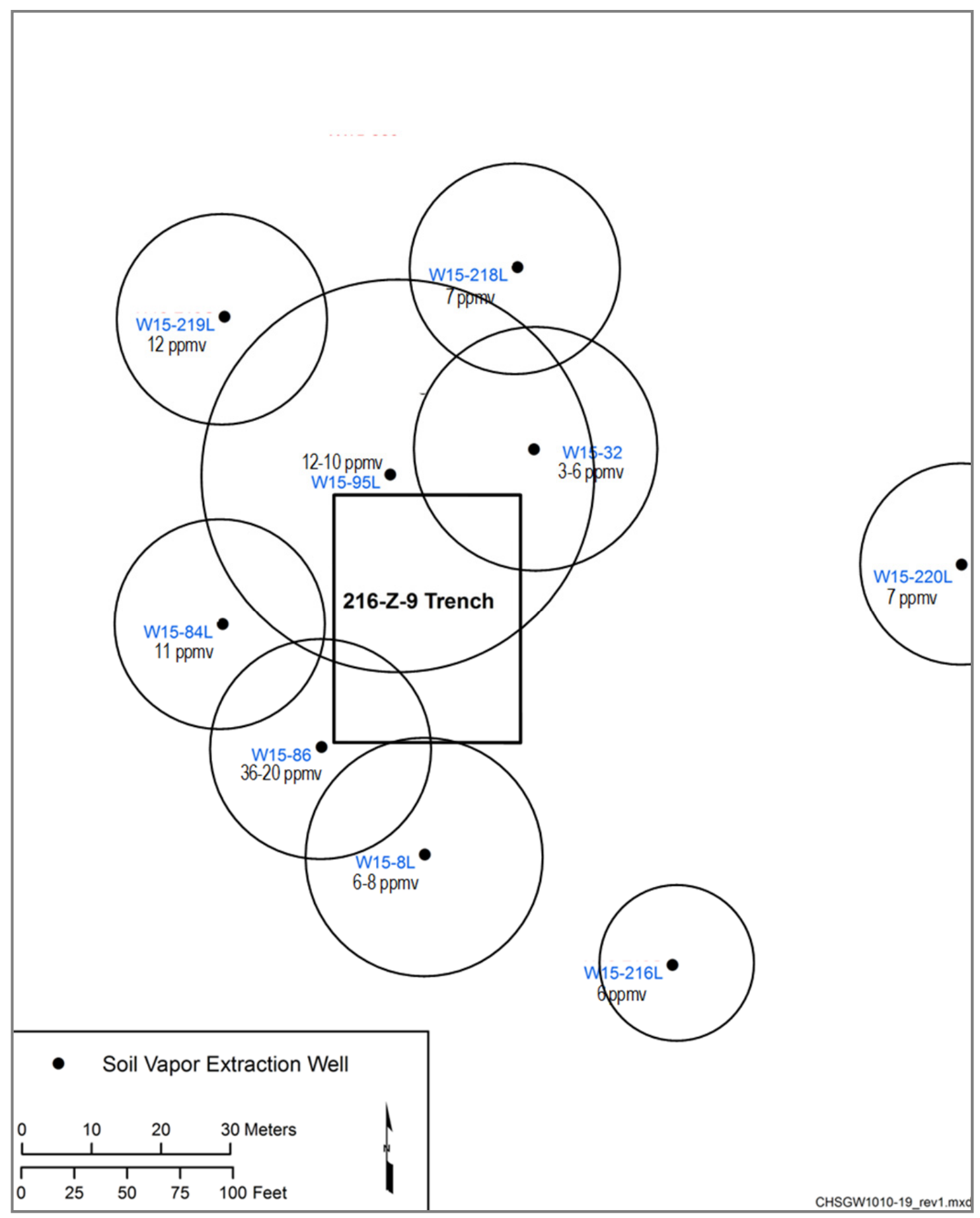

Figure 4.33. Summary of Single-Well Test Data for Below the CCU and at Well 86 (across the CCU). Note that well open intervals are not all at the same elevation. Circles around each well show the radius from which soil gas was withdrawn based on assumption of an ideal spherical zone of influence from the center of the well screen. Where a single concentration is shown, concentration remained essentially constant for the duration of the soil gas extraction period of the test. Ranges indicate when concentration conditions changed during extraction. The 299- prefix has been omitted from all well names. 


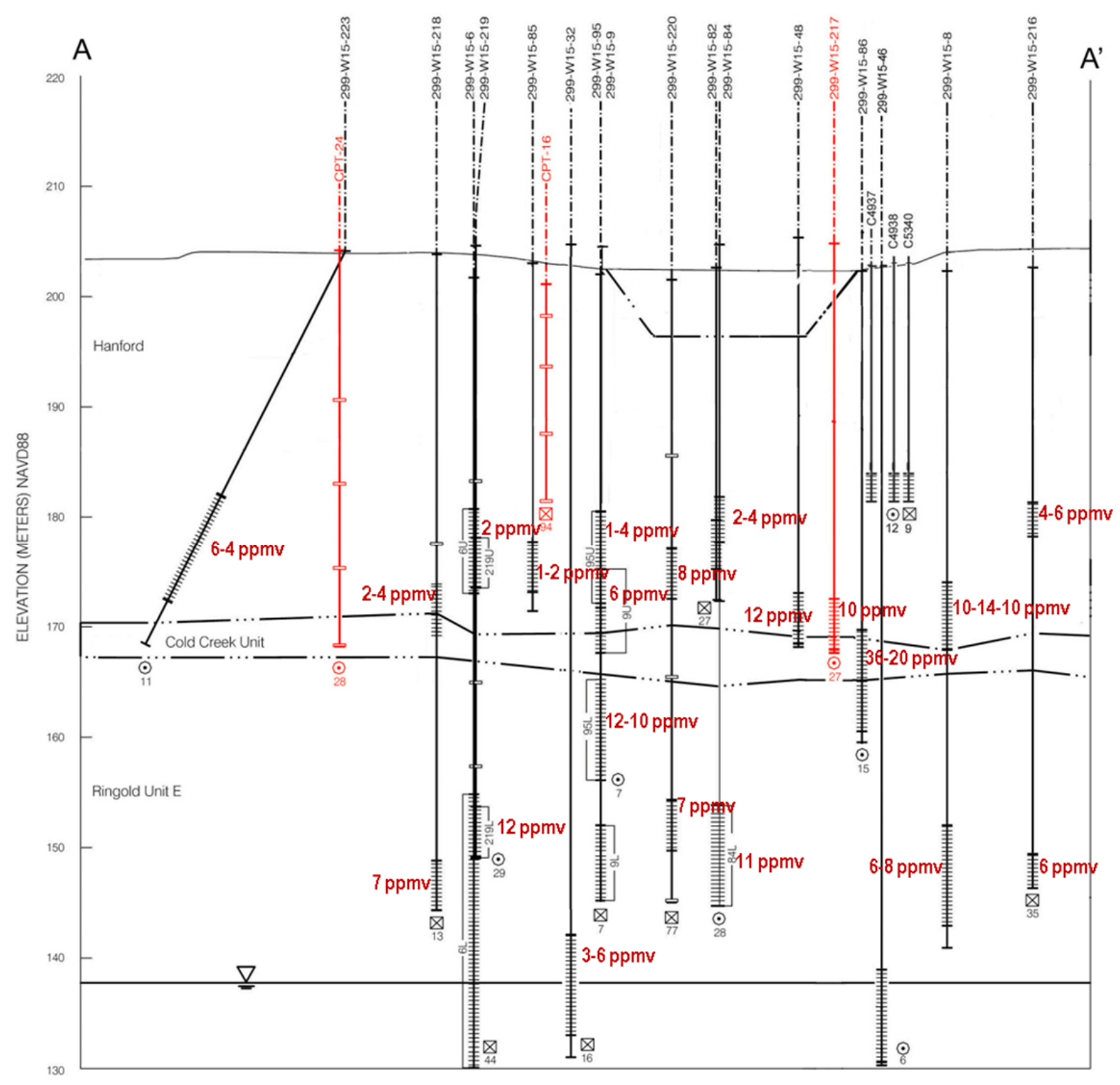

Figure 4.34. Summary of Single-Well Test Data on a North-South Cross Sectional View of Test Wells (A is north and A' is south). Where a single concentration is shown, concentration remained essentially constant for the duration of the soil gas extraction period of the test. Ranges indicate when concentration conditions changed during extraction (after DOE-RL 2010).

In addition to having higher concentrations than wells farther from the $\mathrm{CCU}$, many wells near the $\mathrm{CCU}$ also had a relatively constant concentration profile during the single-well test. Examining the distribution of these well locations and their associated zone of influence during the single-well test (Figures 4.32 through 4.34) can be used to infer the lateral extent of the source zone in the CCU. For instance, there will be vapor-phase concentration gradients progressing with distance from a source area that are related to the physical configuration and size of the source. Figure 4.35 shows the simulated difference in relative $\left(\mathrm{C} / \mathrm{C}_{\text {source }}\right)$ soil gas concentration contours after a 6-month rebound for small $(20 \mathrm{~m}$ 
wide) and large (150 m wide) sources. The small source has concentration contours that are generally curved and decrease laterally beyond the source zone above and below the source. Thus, if the source were smaller compared to the zone of influence as depicted in the figure, changes in concentration would be expected over time during extraction (Figure 4.35a). The large source also has concentration contours that decrease laterally beyond the source zone above and below the source, but the contours are relatively flat within the lateral extent of the source zone. As shown in Figure 4.35b, wells that collect soil gas vertically near the source zone (i.e., the $\mathrm{CCU}$ ) and where the zone of influence remains over the source zone for the entire extraction period would show generally constant concentration profiles over time (especially for more lateral soil gas flow). Thus, assessing the size of the zone where relatively constant concentrations were observed in the single-well tests can be used to infer the lateral extent of a CCU source.

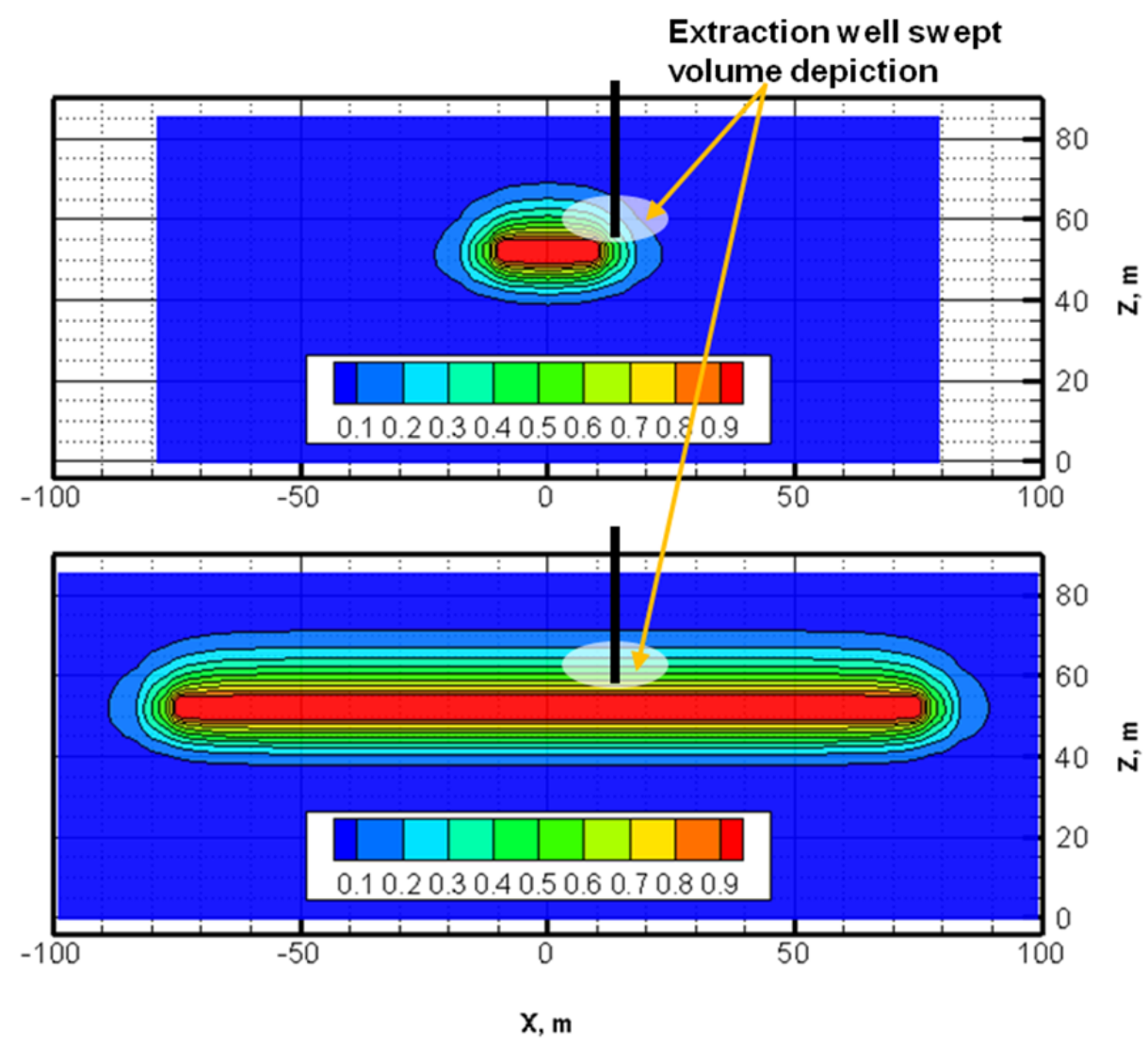

Figure 4.35. Simulated Soil Gas Concentration Contours after 6 Months of Rebound for a Small (a) and Large (b) Source. Relative concentrations are shown $\left(\mathrm{C} / \mathrm{C}_{\text {source }}\right)$.

Above the CCU, the concentrations decrease to the north and east of the trench. The central part of the trench, to the south, and to the southwest have elevated concentrations. The background at the exterior of the site is approximately 4-6 ppmv. The zone of consistent CT concentration on Figure 4.32 suggests that the CCU source zone footprint is approximately 60 by $60 \mathrm{~m}$ above the CCU.

Above the CCU, well C4937 (east of well 86) has been a persistent hot spot in CT vapor concentration since a small silt lens containing high CT concentrations was discovered (2003) and the 
vapor well installed (2005). However, the vapor-phase mass discharge from this well is small as evidenced by 1) consistent low concentrations in two nearby wells (C4938 and C5340) during standard SVE operations, and 2) no signature of high concentration in either well $8 \mathrm{U}$ or well 48 during the single-well test (although it is possible that the zone of influence did not reach this location because well C4937 is screened higher than these wells). With respect to future groundwater impacts, the small contamination zone around well C4937 would be expected to have a negligible effect because of 1) low mass discharge; 2) its position is much closer to the surface than to the groundwater; and 3) the presence of the intervening CCU where higher moisture content minimizes vapor diffusion from Hanford formation sources down to the groundwater.

Below the CCU, the concentrations are generally slightly higher and more uniform across the site at approximately 10 ppmv. This suggests that there are no significant hotspots except for well 86 , which is within the CCU source zone. However, the CT concentrations decrease to the north, east, and south with distance from the trench. The background at the site exterior is approximately 6-7 ppmv. The distribution of relatively constant concentration distribution shown in Figure 4.33 (below the CCU) suggest a relatively constant source zone over a distance of about $90 \mathrm{~m}$ north-south. There are fewer wells to establish the distance of constant concentrations east-west. Based on the available data, the eastwest distance was assumed to also be $90 \mathrm{~m}$. The source size for below the CCU was selected because it would be most pertinent in terms of groundwater impact. Contaminants moving upward from the CCU will mostly impact ground surface — not the groundwater.

The CT vapor concentration data suggests that, especially below the CCU, the vapor concentrations do not decline to near zero at the end of a cycle or away from the source area. Thus, there is a continued background boundary effect. As discussed in Section 4.2.1, the background vapor concentration needs to be considered in computing the overall source strength.

Figure 4.34 depicts the vertical distribution of CT vapor concentration during the single-well tests. Figure 4.36 provides additional assessment of the vertical concentration and mass discharge trends. The wells screened above the CCU (in red) and below the CCU (in blue) are each plotted with concentration (a) and mass discharge (b) as a function of distance between the CCU and the center of the well screen. Linear regression analyses of these data are also presented. The data from wells below the CCU have a strong correlation with distance from the CCU. This result supports the conceptualization of the CCU as the source and the conceptualization that the CCU source has a large areal extent across the well locations.

A weaker correlation with distance is indicated in Figure 4.36 for the data associated with wells above the CCU. The data from wells above the CCU are grouped in circles by spatial location to interpret outliers in the correlation. The scatter in the data from above the CCU indicates that the areal extent of the source is smaller than for below the CCU. Some of the northern wells have lower concentrations than expected for a large uniform source. In addition, some exterior wells have higher concentrations than expected, potentially attributed to the background CT concentrations discussed above.

Individual well characterization data collected in the 2010 SVE operational cycle (e.g., during operations extracting from multiple wells, but with measurement of CT vapor concentration at a single well) also show relatively low concentrations with no significant "hot spots." These concentrations are generally consistent with those measured during the 2011 single-well test (Table 4.8). In both years, the distribution of higher and lower concentration wells is similar and suggests a similar location of the 
source zone, though with less certainty in the 2010 data than the 2011 single-well test data because the 2010 characterization results cannot be attributed to a specific zone of influence for soil gas extraction.
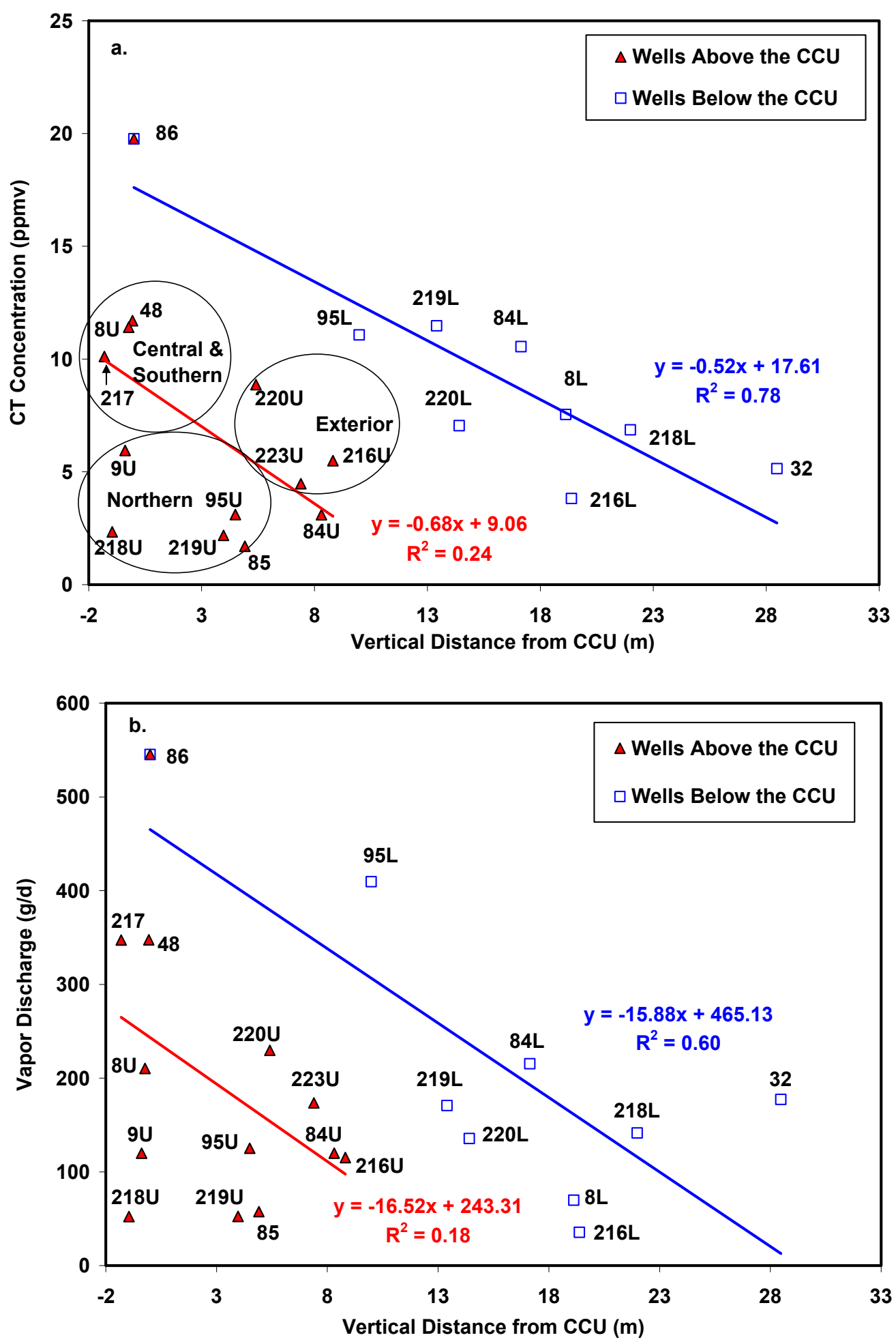

Figure 4.36. Concentration (a) and Vapor Mass Discharge (b) as a Function of Distance from the CCU. The 299-W15 prefix has been omitted from all well names. 
Table 4.8. Comparison of Maximum CT Concentrations Measured during the 2011 Single-Well Testing and the 2010 SVE Operations Individual Well Characterization Sampling. The 299-W15 prefix has been omitted from all well names.

\begin{tabular}{cccc}
\hline $\begin{array}{c}\text { Above/Below } \\
\text { CCU }\end{array}$ & Stressed Well & $\begin{array}{c}\text { 2011 Single-Well } \\
\text { Concentration (ppmv) }\end{array}$ & $\begin{array}{c}\text { 2010 Characterization } \\
\text { Concentration (ppmv) }\end{array}$ \\
\hline Above & 48 & 11.7 & 7.6 \\
Above & 85 & 1.7 & 0.8 \\
Above & 217 & 10.1 & 6.9 \\
Above & 223 & 4.5 & 7.6 \\
Above & $216 \mathrm{U}$ & 5.5 & No data \\
Above & $218 \mathrm{U}$ & 2.3 & 0.1 \\
Above & $219 \mathrm{U}$ & 2.2 & 2 \\
Above & $220 \mathrm{U}$ & 8.9 & 6.5 \\
Above & $84 \mathrm{U}$ & 3.1 & 0.2 \\
Above & $8 \mathrm{U}$ & 11.4 & 4.8 \\
Above & $95 \mathrm{U}$ & 3.1 & 0.6 \\
Above & $9 \mathrm{U}$ & 5.9 & 4.8 \\
Across & 86 & 19.8 & 13.2 \\
Below & 32 & 5.1 & 4.4 \\
Below & $216 \mathrm{~L}$ & 3.8 & No data \\
Below & $218 \mathrm{~L}$ & 6.9 & 6.6 \\
Below & $219 \mathrm{~L}$ & 11.5 & 6.3 \\
Below & $220 \mathrm{~L}$ & 7.0 & 7.2 \\
Below & $84 \mathrm{~L}$ & 10.6 & 7.9 \\
Below & $8 \mathrm{~L}$ & 7.5 & 7.1 \\
Below & $95 \mathrm{~L}$ & 11.1 & 10.8 \\
\hline
\end{tabular}

\subsubsection{Implications for Impact to Groundwater}

The results of this project have provided data needed to develop an improved understanding of the remaining and persistent CT contamination sources at the Z-9 Trench site. Carroll et al. (2012) recently published a methodology for using field measurements of source mass discharge (MFr, after Brusseau et al. 2010) with predictive transport modeling to determine the groundwater contaminant concentrations that result from persistence of the vadose zone source. Figure 4.37 summarizes how this analysis correlates source mass discharge (MFr) and groundwater contaminant concentration, and some of the site characteristics that can impact this correlation.

The predictive modeling analysis of Carroll et al. (2012) was applied using the 90 by $90 \mathrm{~m} \mathrm{CCU}$ source identified in the treatability test effort. This analysis provides as an output the relation between the measured source mass discharge (e.g., as measured in this report) and the resultant groundwater CT concentration. While the source mass discharge from the vadose zone source was measured in this test, through the modeling analysis the source mass discharge can also be related to a corresponding CT source vapor concentration (e.g., at the interface between the Ringold Formation and the CCU). Figure 4.38 shows simulated CT concentrations through the centerline of the vadose zone source along the axis of groundwater flow direction as a function of the vadose zone source strength expressed as a source mass discharge and as a corresponding CT source vapor concentration. The simulations used the input parameters listed in Table 4.9. 


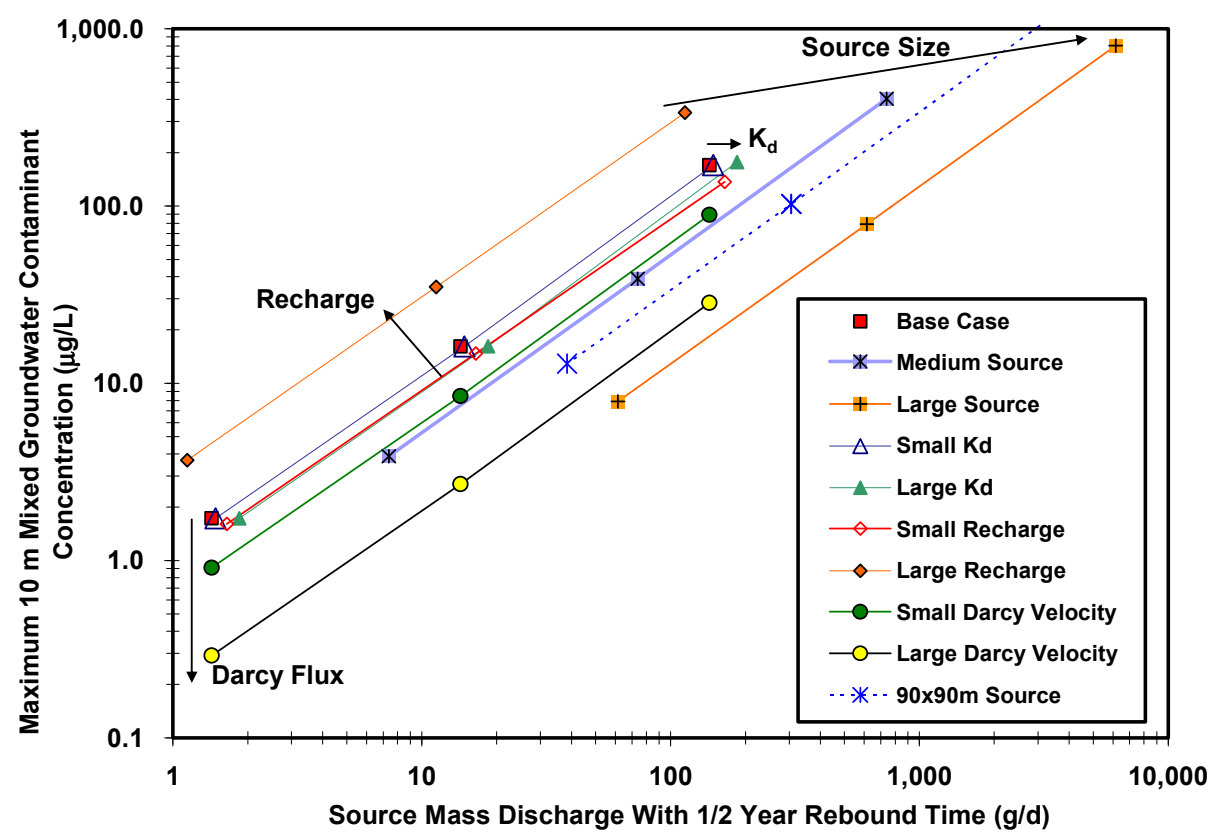

Figure 4.37. Framework for Relating Source Mass Discharge (MFr) to Resultant Groundwater Contaminant Concentration Showing Variability Associated with Commonly Uncertain Input Parameters Including Source Size (after Carroll et al. 2012). Simulation results for the 90 by $90 \mathrm{~m}$ source from this report are added for comparison.

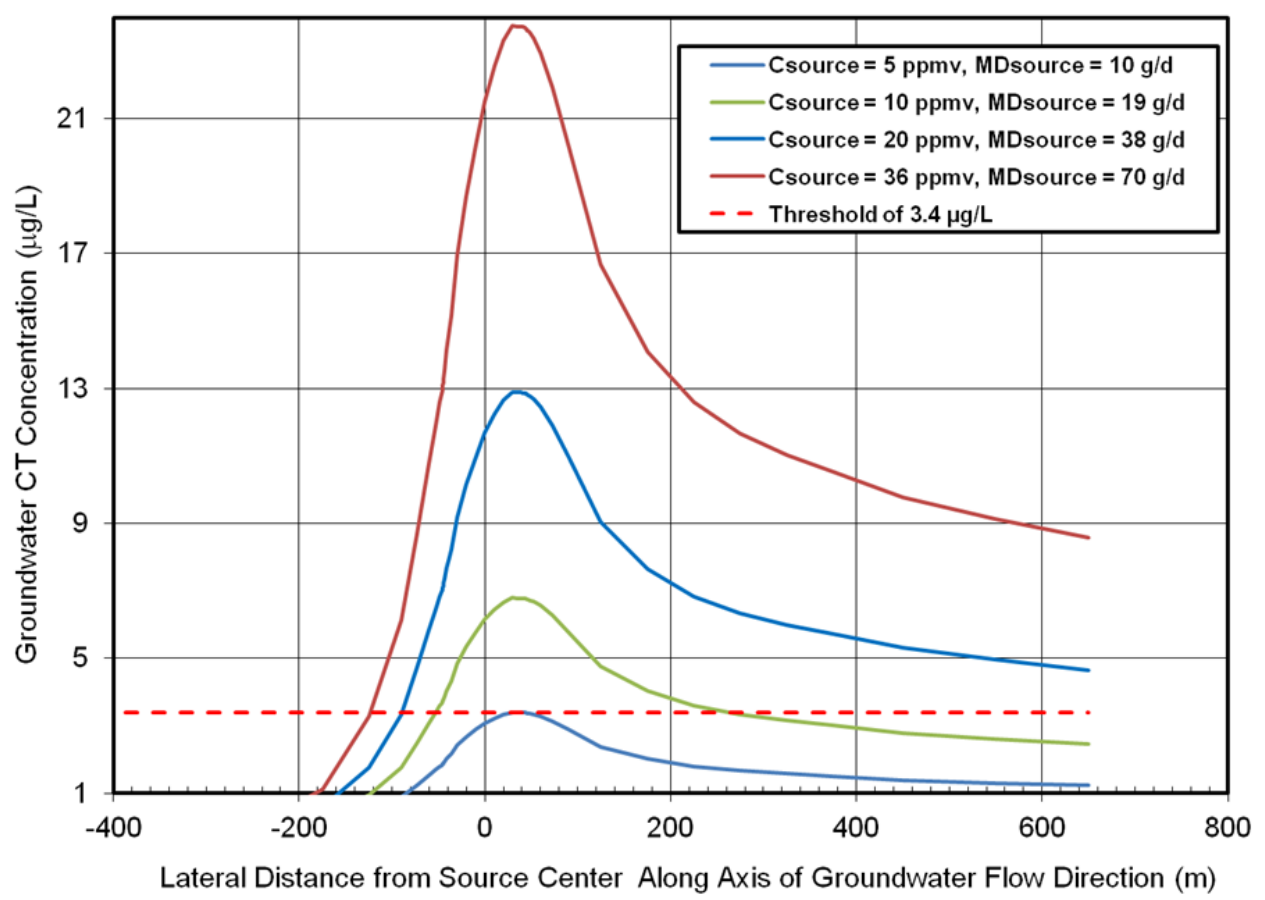

Figure 4.38. Simulated Groundwater CT Concentration in a 10-m Well Screen Resulting from the Specified Vadose Zone Source. The vadose zone source strength is shown as Csource, the CT source vapor concentration at the interface between the Ringold Formation and the $\mathrm{CCU}$, and the MDsource, the source mass discharge as determined using the methods described in this treatability test. 
Table 4.9. Parameter Values for Simulations

\begin{tabular}{|c|c|}
\hline Parameter & Value \\
\hline CT Diffusion Coefficient in Water ${ }^{(\mathrm{a})}\left(\mathrm{m}^{2} /\right.$ day $)$ & $8.25 \times 10^{-5}$ \\
\hline CT Diffusion Coefficient in Air ${ }^{(a)}\left(\mathrm{m}^{2} /\right.$ day $)$ & 0.715 \\
\hline Henry's Law Coefficient for $\mathrm{CT}^{(\mathrm{a})}(-)$ & 0.813 \\
\hline CT Aqueous Solubility ${ }^{(\mathrm{a})}(\mathrm{mg} / \mathrm{L})$ & 800 \\
\hline Darcy velocity of groundwater $(\mathrm{m} / \mathrm{d})$ & 0.00545 \\
\hline $\mathrm{Kd}(\mathrm{L} / \mathrm{kg})$ & Zero \\
\hline Recharge rate $^{(\mathrm{a})}(\mathrm{cm} / \mathrm{yr})$ & 0.4 \\
\hline Source dimension $(\mathrm{m} \times \mathrm{m})$ & $90 \times 90$ \\
\hline \multicolumn{2}{|c|}{ High-Permeability Sediment (Hanford and Ringold Formations) } \\
\hline Hydraulic Conductivity $^{(\mathrm{b})}(\mathrm{cm} / \mathrm{s})$ & $5.73 \times 10^{-3}$ \\
\hline Van Genuchten $\alpha^{(\mathrm{a})}(1 / \mathrm{cm})$ & 1 \\
\hline Van Genuchten $\mathrm{n}^{(\mathrm{a})}(-)$ & 2.5 \\
\hline Irreducible Water Saturation $^{\mathrm{a}}(-)$ & 0.0583 \\
\hline Porosity $^{(a)}(-)$ & 0.3 \\
\hline \multicolumn{2}{|c|}{ Low-Permeability Sediment (CCU) } \\
\hline Hydraulic Conductivity $^{(\mathrm{b})}(\mathrm{cm} / \mathrm{s})$ & $1.38 \times 10^{-4}$ \\
\hline Van Genuchten $\alpha^{(\mathrm{a})}(1 / \mathrm{cm})$ & 0.1 \\
\hline Van Genuchten $\mathrm{n}^{(\mathrm{a})}(-)$ & 2.5 \\
\hline Irreducible Water Saturation $^{(\text {a) }}(-)$ & 0.0583 \\
\hline Porosity $^{(a)}(-)$ & 0.3 \\
\hline
\end{tabular}

(a) Truex et al. (2009); Oostrom et al. (2010).

(b) Khaleel et al. (2001).

Note the Carroll et al. (2012) analysis applies an approach that maximizes mass transfer across the water table to provide a conservative estimate of groundwater contaminant concentration. In addition, other mitigating factors need to be considered for interpreting the estimated impact to groundwater. The Carroll et al. (2012) estimate is based on an assumption that the source mass discharge remains constant over time. However, continued mass discharge from the source will, over time, reduce the source mass discharge. Potentially, this process can be evaluated over time based on the observed vapor-phase concentrations and comparison to the maximum estimated in the Carroll et al. (2012) analysis. Wells 299-W15-95L, 299-W15-9L, and 299-W15-84L may be appropriate for this type of monitoring. Well 95L is screened closest to the CCU; however, because concentration profiles in the absence of SVE will become fairly uniform with depth directly beneath the source area, all three wells may be suitable for monitoring in the long term. The Carroll et al. (2012) analysis demonstrates that, in the long term, sorption has negligible effects on the groundwater impact. However, in the short term, sorption can mitigate impact in conjunction with decay in the source mass discharge. The impact of abiotic CT degradation is also not included and would also act to reduce concentrations over time.

The estimate is also a function of the input parameters and subject to uncertainty in these parameters. For instance, a moderately higher groundwater velocity will result in lower groundwater contaminant concentrations from the same vadose zone source (Truex et al. 2009; Carroll et al. 2012). Source size, the subject of this treatability test investigation, also impacts the resultant groundwater contaminant 
concentration, and is a part of the Carroll et al. (2012) analysis that is not accounted for in the analytical solution used by Truex et al. (2009). Recharge rate can also be an important factor at some sites, but at the Hanford Site, recharge rates are expected to remain low enough that the vapor-phase component of the impact to groundwater dominates and small variations in recharge will not have a significant impact.

The estimated CT source vapor concentration at the interface between the Ringold Formation and the $\mathrm{CCU}$ is lower than the estimate based on the one-dimensional analytical technique presented in Truex et al. (2009) for the same resultant groundwater CT concentration. Limitations of the analytical technique are discussed in Truex et al. (2009). Most notably for the Hanford Site application, vapor transport in the vadose zone and the coupled processes for contaminant mass transfer into the groundwater are by nature multidimensional. The analytical technique cannot account for the impact of combined lateral and vertical vapor transport. In addition, the impact of a large source size (in terms of cumulative mass transfer to the groundwater along the flow path and spatial extent of the vapor plume) is not included in the analytical technique. Oostrom et al. (2010) provides additional analysis of the difference between one-dimensional analyses and three-dimensional analysis for vapor-transport and resultant impacts to groundwater. 


\subsection{Quality Assurance Results}

Quality assurance samples were collected along with other gas samples during the single-well portion of the test (Summa canisters) per the treatability test plan (DOE-RL 2010). Duplicate samples showed high variability in several cases, primarily associated with actual variability over time in the extracted vapor concentrations (as indicated by the on-line GC results from the SVE system). None of the quality assurance evaluations impacted the ability to conduct the data analysis for the test. 


\subsection{References}

Brusseau ML, V Rohay, and MJ Truex. 2010. "Analysis of Soil Vapor Extraction Data to Evaluate Mass-Transfer Constraints and Estimate Source-Zone Mass Flux." Ground Water Monitoring and Remediation 30(3):57-64.

Carroll KC, M Oostrom, MJ Truex, VJ Rohay, and ML Brusseau. 2012. "Assessing Performance and Closure for Soil Vapor Extraction: Integrating Vapor Discharge and Impact to Groundwater Quality." Journal of Contaminant Hydrology 128:71-82.

DOE-RL. 2010. Treatability Test Plan for Characterization of Vadose Zone Carbon Tetrachloride Source Strength Using Tomographic Methods at the 216-Z-9 Site. DOE/RL-2010-79, Rev. 0, U.S. Department of Energy, Richland Operations Office, Richland, Washington.

EPA. 1992. Guidance for Conducting Treatability Studies under CERCLA. EPA/540/R-92/071a, U.S. Environmental Protection Agency, Washington, D.C.

EPA. 1999. Compendium of Methods for Determination of Toxic Organic Compounds in Ambient Air, Second Edition, Compendium Method TO-15, Determination of VOCs in Air Collected in Specially Prepared Canisters and Analyzed by Gas Chromatography/Mass Spectrometry (GC/MS).

EPA/625/R-96/010b, U.S. Environmental Protection Agency, Washington, D.C.

EPA. 2001. Development of Recommendations and Methods to Support Assessment of Soil Venting Performance and Closure. EPA/600/R-01/070, U.S. Environmental Protection Agency, Washington, D.C.

EPA, Ecology, and DOE-RL. 2008. Record of Decision, Hanford 200 Area 200-ZP-1 Superfund Site Benton County, Washington. U.S. Environmental Protection Agency, Region 10, Lacey, Washington; Washington State Department of Ecology, Olympia, Washington; U.S. Department of Energy, Richland Operations Office, Richland, Washington.

EPA, Ecology, and DOE-RL. 2011. Record of Decision, Hanford 200 Area Superfund Site 200-CW-5 and 200-PW-1, 200-PW-3, and 200-PW-6 Operable Units. U.S. Environmental Protection Agency, Region 10, Lacey, Washington; Washington State Department of Ecology, Olympia, Washington; U.S. Department of Energy, Richland Operations Office, Richland, Washington. Accessed April 27, 2012, at http://www.epa.gov/region10/pdf/sites/hanford/200/hanford_200_rod.pdf.

Falta RW. 1996. "A Program for Analyzing Transient and Steady-State Gas Pump Tests.” Ground Water 34(4):750-755.

FHI. 2003. Performance Evaluation Report for Soil Vapor Extraction Operations at the 200-PW-1 Carbon Tetrachloride Site, Fiscal Year 2002. WMP-17869, Rev. 0, Fluor Hanford, Inc., Richland, Washington.

Furbish DJ. 1991. "The Response of Water Level in a Well to a Time Series of Atmospheric Loading under Confined Conditions. Water Resources Research 27(4):557-568. 
Khaleel R, TE Jones, AJ Knepp, FM Mann, DA Myers, PM Rogers, RJ Serne, and MI Wood. 2001. Modeling Data Package for S-SX Field Investigation Report. RPP-8296, Rev. 0, CH2M HILL, Hanford Group, Inc., Richland, Washington.

Last GV, RD Mackley, and DC Lanigan. 2006. Borehole Geologic Data for the 216-Z Crib Facilities, A Status of Data Assembled through the Hanford Borehole Geologic Information System (HBGIS).

PNNL-16103, Rev. 0, Pacific Northwest National Laboratory, Richland, Washington.

Mackley RD, FA Spane, TC Pulsipher, and CH Allwardt. 2010. Guide to using Multiple Regression in Excel (MRCX v.1.1) for Removal of River Stage Effects from Well Water Levels. PNNL-19775, Rev. 1, Pacific Northwest National Laboratory, Richland, Washington.

Oostrom M, PD Thorne, F Zhang, GV Last, and MJ Truex. 2007. Modeling of Carbon Tetrachloride Flow and Transport in the Subsurface of the 200 West Disposal Sites: Large Scale Model Configuration and Local-Scale Prediction of Future Carbon Tetrachloride Distribution Beneath the 216-Z-9 Disposal Site. PNNL-17181, Pacific Northwest National Laboratory, Richland, Washington.

Oostrom M, MJ Truex, GD Tartakovsky, and TW Wietsma. 2010. "Three-Dimensional Simulation of Volatile Organic Compound Mass Flux from the Vadose Zone to Groundwater." Ground Water Monitoring and Remediation 30(3):45-56.

Rasmussen TC and LA Crawford. 1997. "Identifying and Removing Barometric Pressure Effects in Confined and Unconfined Aquifers.” Ground Water 35(3):502-511.

Rohay VJ. 2007. Performance Evaluation Report for Soil Vapor Extraction Operations at the 200-PW-1 Operable Unit Carbon Tetrachloride Site, Fiscal Year 2006. SGW-33746, Fluor Hanford, Inc., Richland, Washington.

Spane FA. 1999. Effects of Barometric Fluctuations on Well Water-Level Measurements and Aquifer Test Data. PNNL-13078, Pacific Northwest National Laboratory, Richland, Washington.

Spane FA. 2002. "Considering Barometric Pressure in Groundwater Flow Investigations." Water Resources Research 38(6):14.1-14.18.

Truex MJ, M Oostrom, and ML Brusseau. 2009. "Estimating Persistent Mass Flux of Volatile Contaminants from the Vadose Zone to Ground Water." Ground Water Monitoring and Remediation 29(2):63-72.

USACE. 2002. Engineering Design: Soil Vapor Extraction and Bioventing. USACE EM 1110-1-4001, U.S. Army Corps of Engineers, Washington, D.C. 


\section{Distribution}

No. of

Copies

2 Electronic Distribution

U.S. Department of Energy, Office of Environmental Management

Kurt Gerdes

Skip Chamberlain
No. of

$\underline{\text { Copies }}$

4 DOE, Richland Operations Office

BL Charboneau

A6-33

JG Morse

A5-11

Administrative Record

H6-08

DOE Public Reading Room

$\mathrm{H} 2-53$

3 CH2M HILL Plateau Remediation

Company

ME Byrnes

R3-60

SA Simmons

R3-60

VJ Rohay

H8-15

2 Pacific Northwest National Laboratory

KC Carroll

K6-96

MJ Truex

K6-96 


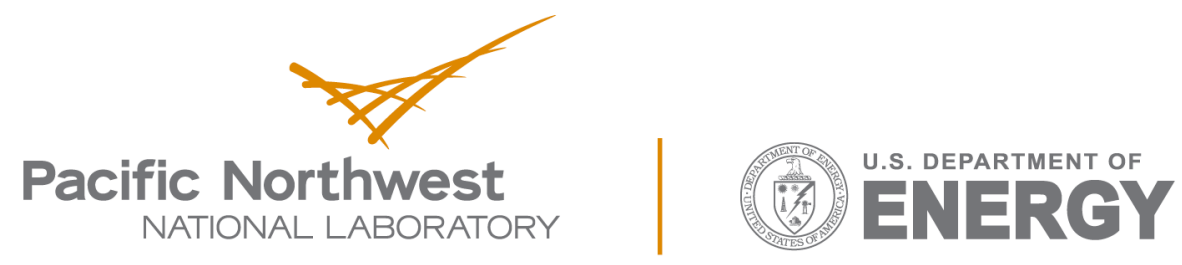

Proudly Operated by Battelle Since 1965

902 Battelle Boulevard

P.O. Box 999

Richland, WA 99352

1-888-375-PNNL (7665)

www.pnnl.gov 